\title{
Effects of the West Virginia K-12 RuralNet project on elementary school teachers' instructional practices
}

\author{
Marcia L. Marcolini Hoover \\ West Virginia University
}

Follow this and additional works at: https://researchrepository.wvu.edu/etd

\section{Recommended Citation}

Marcolini Hoover, Marcia L., "Effects of the West Virginia K--12 RuralNet project on elementary school teachers' instructional practices" (2003). Graduate Theses, Dissertations, and Problem Reports. 2492. https://researchrepository.wvu.edu/etd/2492

This Dissertation is protected by copyright and/or related rights. It has been brought to you by the The Research Repository @ WVU with permission from the rights-holder(s). You are free to use this Dissertation in any way that is permitted by the copyright and related rights legislation that applies to your use. For other uses you must obtain permission from the rights-holder(s) directly, unless additional rights are indicated by a Creative Commons license in the record and/ or on the work itself. This Dissertation has been accepted for inclusion in WVU Graduate Theses, Dissertations, and Problem Reports collection by an authorized administrator of The Research Repository @ WVU. For more information, please contact researchrepository@mail.wvu.edu. 


\title{
Effects of the West Virginia K-12 RuralNet Project on Elementary School Teachers' Instructional Practices
}

\author{
Marcia L. Marcolini Hoover \\ Dissertation submitted to the \\ College of Human Resources and Education \\ at West Virginia University \\ in partial fulfillment of the requirements \\ for the degree of \\ Doctor of Education \\ in \\ Technology Education \\ David L. McCrory, Chair \\ John G. Wells \\ Anne H. Nardi \\ Stacy A. Gartin \\ Jaci Webb Dempsey \\ Department of Advanced Educational Studies
}

Morgantown, West Virginia 2003

Keywords: Internet, Professional Development, Teacher Training Copyright 2003 Marcia L. Marcolini Hoover 


\section{Abstract \\ The Effect of the West Virginia K-12 RuralNet Project on Elementary School Teachers' Instructional Practices}

Marcia L. Marcolini

The Internet is being heralded as a technology capable of transforming education through its vast resources and communication channels. Government agencies, funding organizations, and institutions of higher education are working together to provide resources, training, and incentives for teachers at every level to incorporate the Internet into their teaching. One of the major barriers in the attempt to transform education through technology appears to be adequate teacher training. One project designed to address the need for teacher training, was the West Virginia K-12 RuralNet project. This \$3.1 million National Science Foundation funded initiative was designed to provide a year-long professional development program to West Virginia public school teachers in the use of Internet resources, consistent with the National Science Education Standards (NSES). Using a mixed-methods approach, this study investigated the effects of the West Virginia K-12 RuralNet project on elementary school teachers' instructional practices. The study sought to answer the research question: What effect has the West Virginia K-12 RuralNet Project had on elementary school teachers' instructional practices? Analysis of self-reporting surveys, interviews and classroom observations indicted that: 1) Participants viewed the RuralNet project as a foundation for learning, however they reported that there is still a great need for basic skills training in a variety of computer hardware and software programs; 2) Teachers still face technical barriers to effectively utilizing technology in classroom instruction such as outdated and non-functioning computers; 3) Participants perceived that the RuralNet Project had an impact on their instructional practices; however, this perception varied from the actual observed classroom practices indicating a discrepancy between self-reported and observed data. While the nature of the study does not allow for broad generalizations, it does provide insight into a number of issues that one should consider when developing technology related professional development programs, or when conducting research related to the instructional impact of such programs. 


\section{Dedication}

This document is dedicated to my family. To my mother, Mildred I. Marcolini, thank you for the many hours of babysitting and prayer, and for tolerating me during times of frustration. You have always been a source of strength and encouragement for me. I love you. To my father, Samuel F. Marcolini, although you are no longer on this earth, you still remain an important part of my life. By example, you taught me to be strong in times of difficulty, to persevere against all odds, and to do what had to be done. Mom and Dad, You gave me the courage to embark on this endeavor, and the skills needed to see it to fruition. I am forever indebted to you.

To my husband, Douglas A. Hoover, thanks for your loving support and gentle encouragement. We embarked on a short journey that took many turns and became a long and ever-changing adventure. Thanks for having faith in me, gently nudging me forward, and providing me with a strong shoulder on which to lean. To my little angel, Jonathan, thanks for always making momma smile and reminding me of what truly matters in this world. To my other Douglas thanks for putting up with all the times I couldn't be there for you. We've learned many lessons together. I love my three fellows and appreciate the love and support you've shown me throughout this endeavor. I look forward to future times together with fewer distractions.

To my many siblings and their families, thanks for the many hours of babysitting, for making me laugh, for frequent distractions, and for just being. I am a better person for having known all of you.

To my God, who has never left me alone, who carries me when I am weak, and who has blessed me with this opportunity, thank you. 


\section{Acknowledgements}

The completion of this dissertation would not have been possible without the guidance and encouragement from my committee chair, Dr. David L. McCrory, who has patiently guided me through my studies at West Virginia University. I greatly appreciate your countless hours of guidance as you nudged me through this process and helped me develop the skills necessary to reach my goals.

I am also grateful to my committee members, Dr. John G. Wells, Dr. Anne H. Nardi, Dr. Stacy A. Gartin, and Dr. Jaci Webb Dempsey, who pushed me to excellence in my studies, taught me to question myself even when I thought I knew the answer, and shared their expertise with me along the way. Thank you for your time, encouragement, and countless suggestions.

I have been blessed with many opportunities throughout my doctoral studies, much of which can be credited to Dr. Randall Wiesenmayer, who had faith in my ability and gave me a chance to prove myself. Thank you for the opportunity to be a part of the West Virginia K-12 RuralNet Project, for always listening, understanding, and encouraging me to follow through with this challenge. You have been a great mentor and friend.

A special thank you to Dr. Lee Ann Miller, whose friendship, encouragement, and kind words sustained me throughout this journey. 


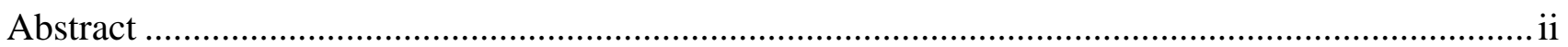

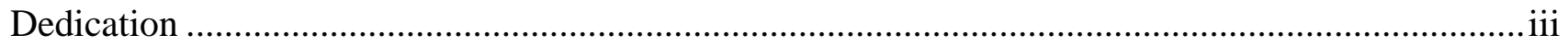

Acknowledgements .............................................................................................................. iv

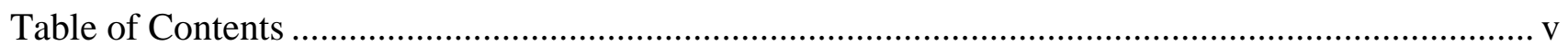

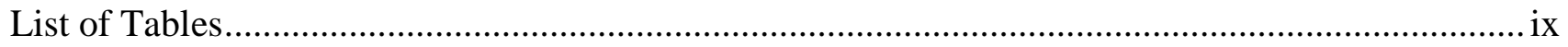

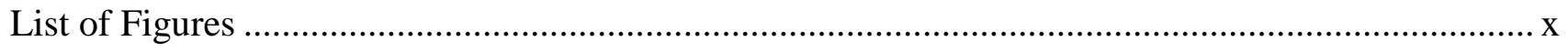

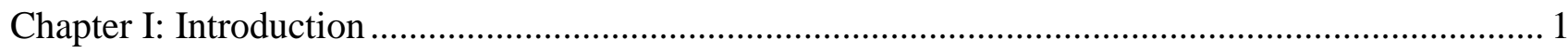

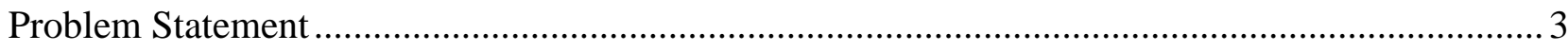

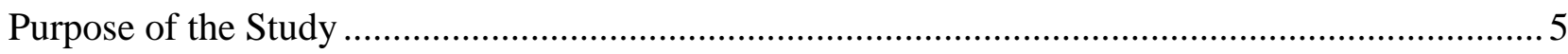

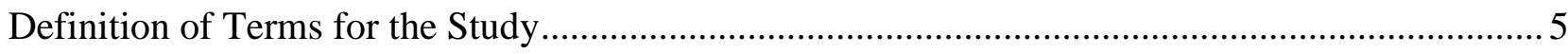

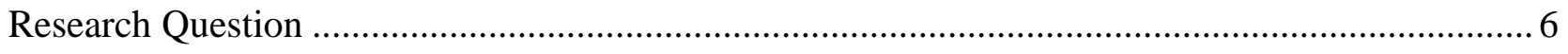

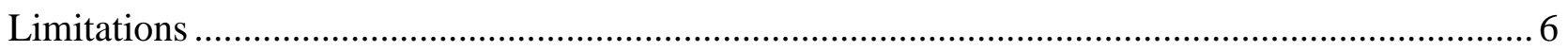

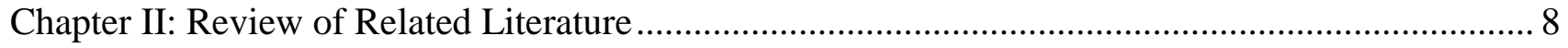

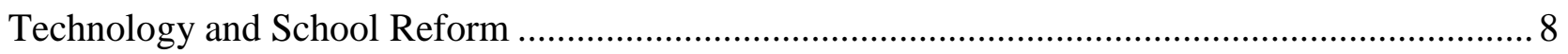

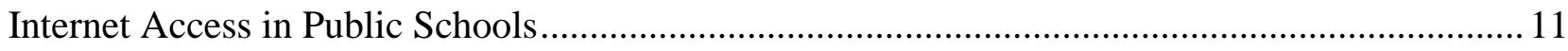

Professional Development and Technology Implementation ........................................................ 14

Technology Integration and Instructional Practice …….............................................................. 22

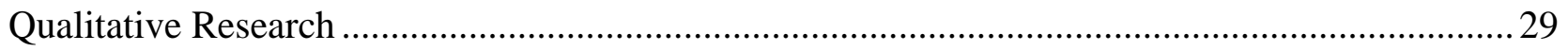


Comparing Research Paradigms: Qualitative versus Quantitative.

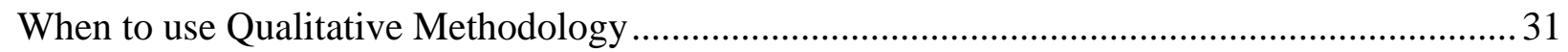

Characteristics of Qualitative Inquiry......................................................................... 32

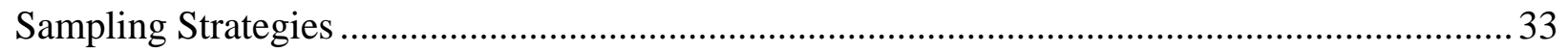

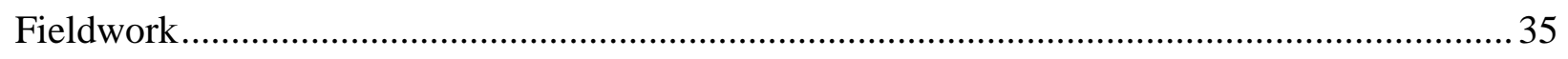

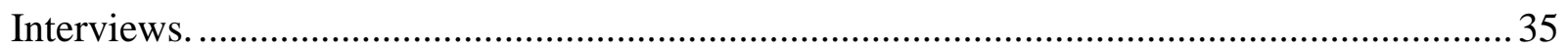

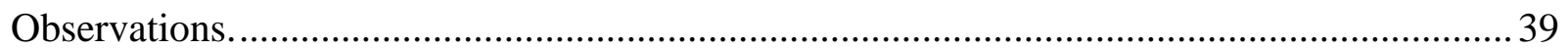

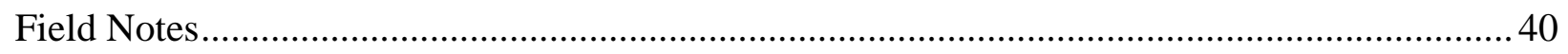

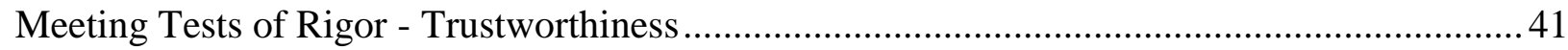

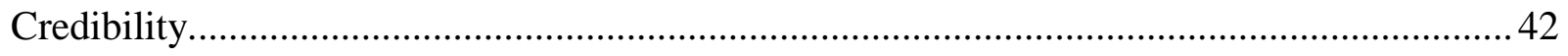

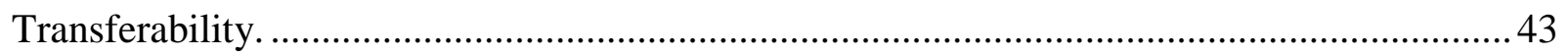

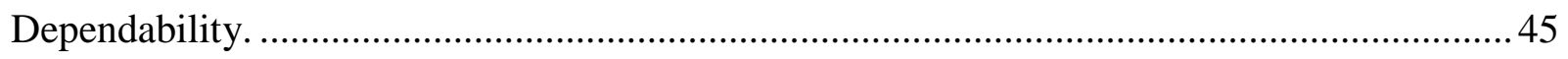

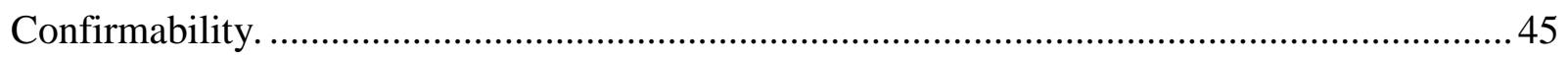

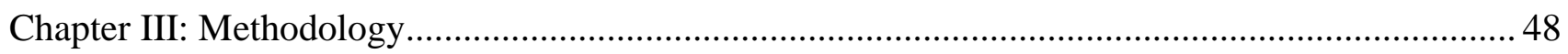

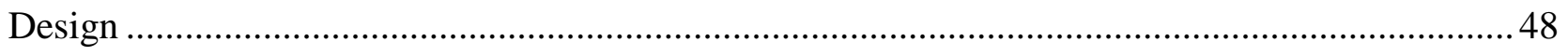

The West Virginia K-12 RuralNet Project................................................................... 48

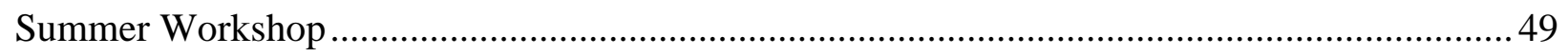

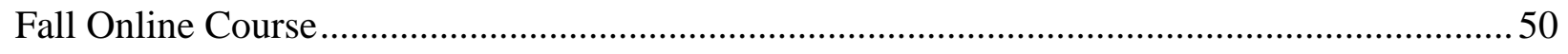

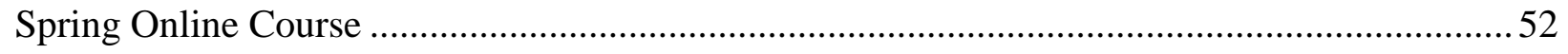

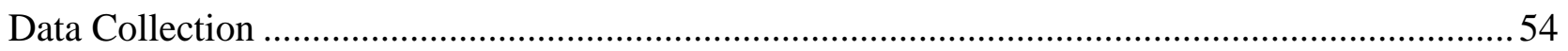

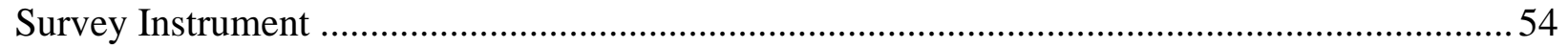

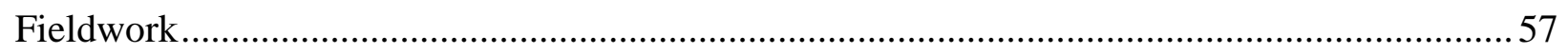

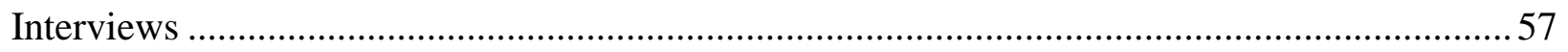




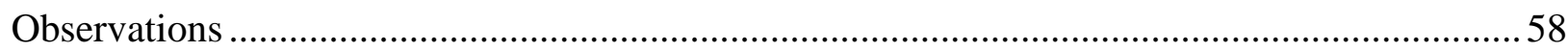

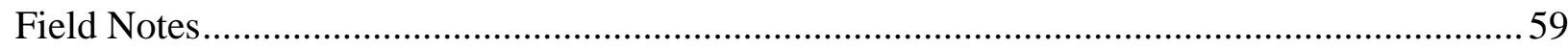

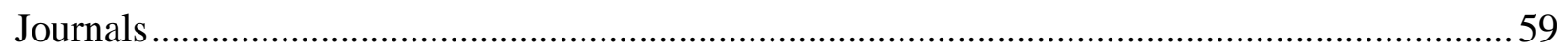

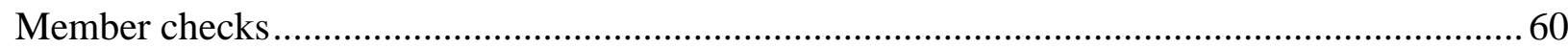

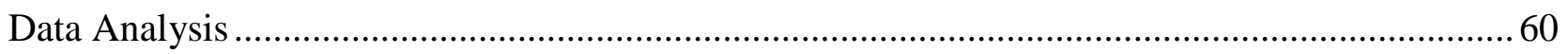

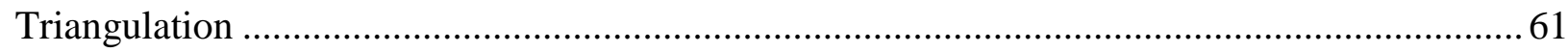

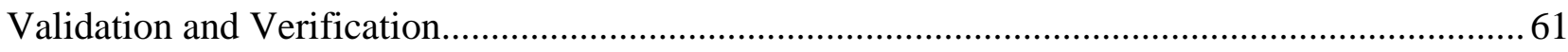

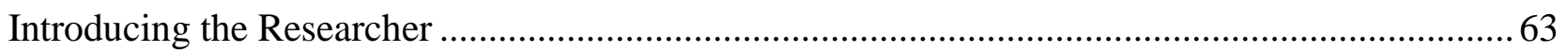

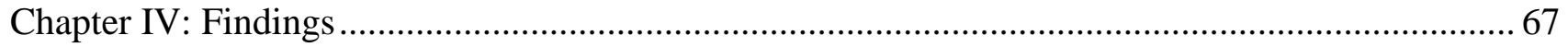

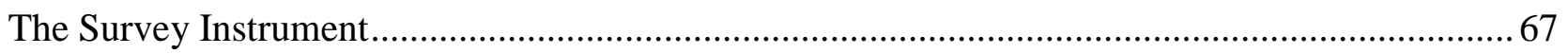

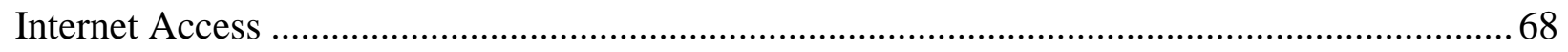

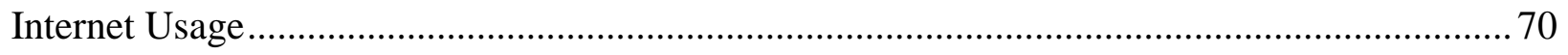

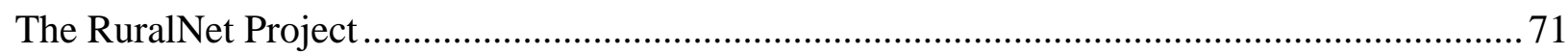

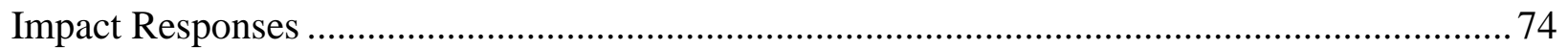

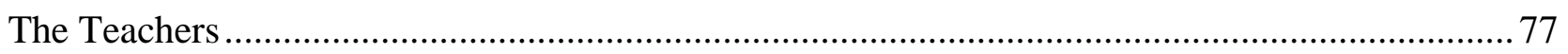

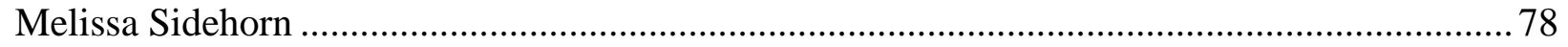

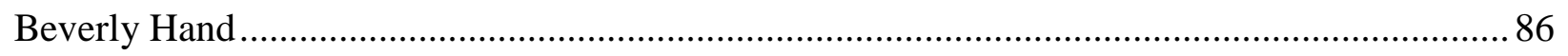

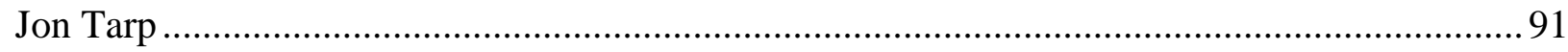

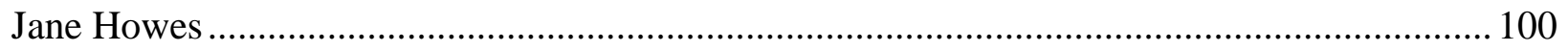

Aubrey Temo

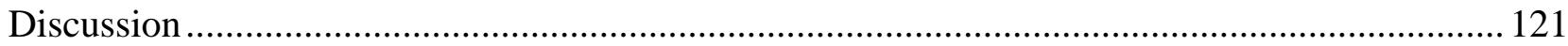

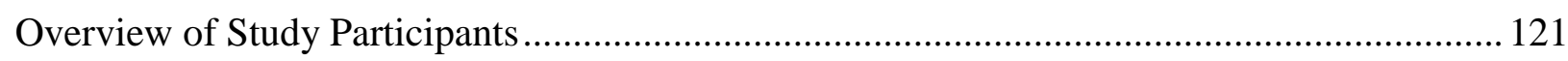

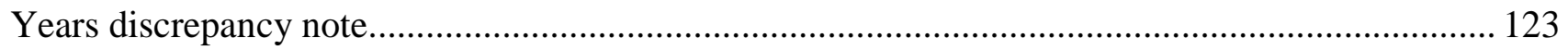




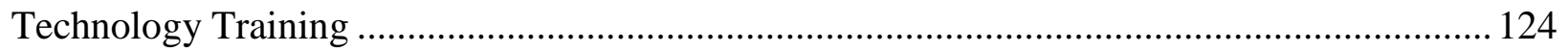

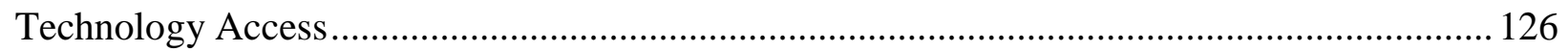

Perceptions of the RuralNet Experience .................................................................... 131

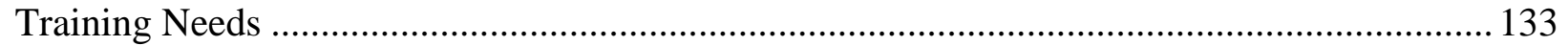

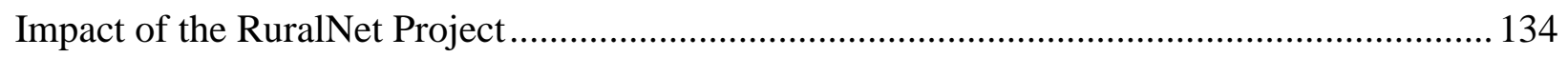

Chapter V: Conclusions, Implications, and Recommendations ................................................. 153

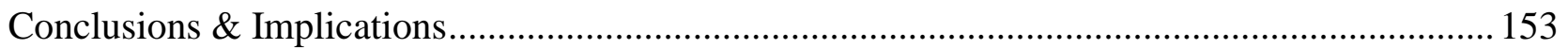

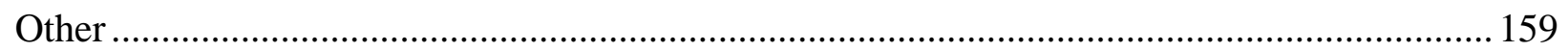

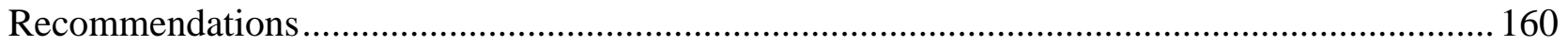

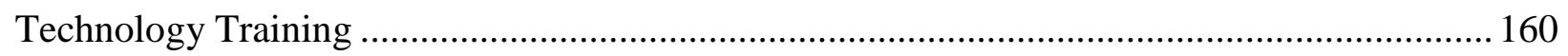

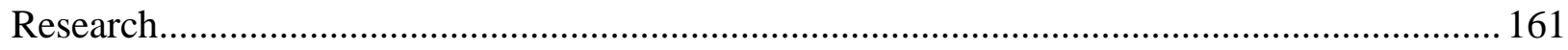

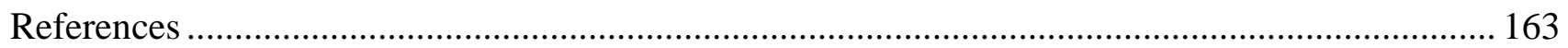

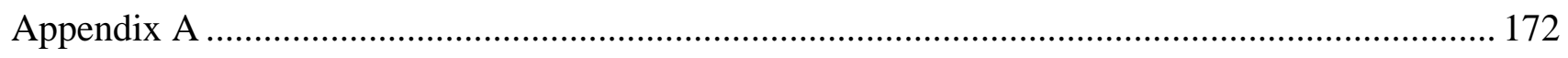

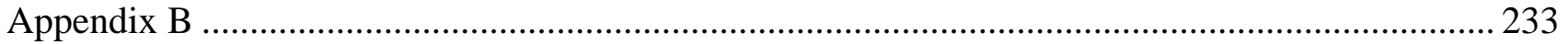

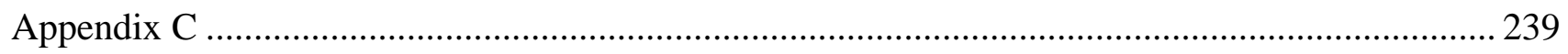

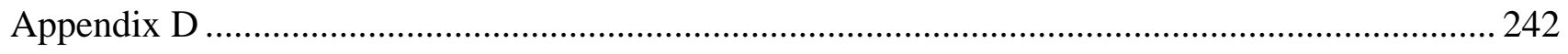

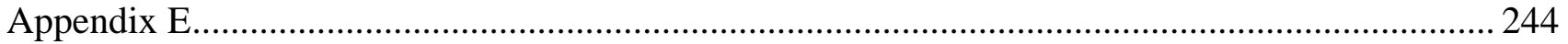




\section{List of Tables}

Table 1: RuralNet Project Question Responses ........................................................... 73

Table 2: Teaching Preparation Statement Responses ..................................................... 75

Table 3: Teaching Practice Statement Responses ........................................................... 76

Table 4: Overview of Study Participants Demographic Information ................................... 122

Table 5: Participants' Years of Teaching Service ............................................................ 123

Table 6: Summary of Technology Training Participation ............................................... 125

Table 7: Classroom Technology Access by Participant....................................................... 127

Table 8: Summary of Survey Responses Regarding RuralNet Project Impact....................... 136

Table 9: Summary of Cross-case Comparison for RuralNet Project Interview Data ............... 141

Table 10: Summary of Cross-case Comparison of Classroom Structure Observation Data....... 145

Table 11: Summary of Cross-case Comparison of Internet Specific Observation Data............ 148 


\section{List of Figures}

Figure 1. Survey respondents by range of teaching experience .......................................... 68

Figure 2. The number of survey respondents with Internet access by location. ......................69

Figure 3. The number of Internet accessible computers available to each respondent...............70 


\section{Chapter I: Introduction}

The Internet is being heralded as a technology capable of transforming education through its vast resources and communication channels. Government agencies, funding organizations, and institutions of higher education are working together to provide resources, training, and incentives for teachers at every level to incorporate the Internet into their teaching. One of the major barriers in the attempt to transform education through technology appears to be adequate teacher training. One project designed to address the need for teacher training was the West Virginia K-12 RuralNet project. This \$3.1 million National Science Foundation funded initiative was designed to provide a year-long professional development program to West Virginia public school teachers in the use of Internet resources, consistent with the National Science Education Standards (NSES).

Using a mixed-methods approach, this study investigated the effects of the West Virginia K-12 RuralNet project on elementary school teachers' instructional practices, including, but not limited to: lesson development, classroom preparation, classroom management techniques, instructional delivery methods, and student assessment. The study sought to answer the research question: What effect has the West Virginia K-12 RuralNet Project had on elementary school teachers' instructional practices?

Analysis of self-reporting surveys, interviews and classroom observations indicted that:

- Participants viewed the RuralNet project as a foundation for learning, however they reported that there is still a great need for basic skills training in a variety of computer hardware and software programs.

- Teachers still face technical barriers to effectively utilizing technology in classroom instruction such as outdated and non-functioning computers. 
- Participants perceived that the RuralNet Project had an impact on their instructional practices; however, this perception varied from the actual observed classroom practices indicating a discrepancy between self-reported and observed data. While the nature of the study does not allow for broad generalizations, it does provide insight into a number of issues that one should consider when developing technology related professional development programs, or when conducting research related to the instructional impact of such programs. First, Internet training must extend the teachers' view beyond one of the Internet as a source of information. Training must also go beyond basic skills and model best classroom practices, eliminating the misconception that one must be a technology expert before one can integrate technology into your classroom. Second, research related to the impact of training programs on teachers' instructional practices must also investigate the issue of technology access. Such studies should include a variety of methodologies, including classroom observations in order to provide a clearer view of actual technology access and classroom practices. Finally, researchers investigating a project with which they are associated and to which participants feel an attachment may obtain self-reporting data that reflects such feelings rather than the actual situation. To avoid unreliable data, the researcher should consider implementing one or more of the following techniques: 1) have an individual not related to the project administer the survey, 2) use qualitative data to confirm or verify self-reported information, and 3) use a population of individuals other than those with whom the researcher has a close affiliation. Implementing one or more of these steps may help provide data that is reliable. 


\section{Problem Statement}

For more than a decade, there have been claims about how technology will revolutionize education. Means (1994), for example, said, "Electronic technology has been hailed as a powerful change agent for transforming schools since the heyday of the radio. Television in the 1960's, computer -assisted instruction in the 1970's, and the microcomputer, videodisc, and artificial intelligence in the 1980's were all supposed to create a new kind of classroom" (p. xi). Today, the Internet is being heralded as the most important technology for transforming teaching and learning because of its potential to provide unlimited resources, overcome geographical boundaries, and increase collaboration between schools, teacher, students, and research institutions. Lockard, Abrams, \& Many, (1997) stated that "the Internet holds the potential of being the most significant influence on early twenty-first century education, if schools and teachers are able to gain access to it and learn to use it effectively."

While the body of research on Internet technology in the classroom is limited, one can learn many lessons from the current status of computers in the classroom. Over the past decade there has been a significant increase in the number of computers being purchased by schools (O’Donnell, 1996; Quality Education Data, 1992 \& 1991; Thompson, 1983; VanProoyen \& Clouse, 1994). Likewise, Internet access is rapidly increasing as technology becomes more affordable through national initiatives such as the Federal Communication Commission's Schools and Libraries Universal Service Fund often referred to as the E-Rate. We are reminded however, that the purchase of technology does not necessarily correlate with actual computer usage or significant impact on teaching and learning (Cuban, 2001; O’Donnell, 1996; Zappone, 1991). 
Experts agree that one of the biggest obstacles to the use of technology in education is a lack of adequate teacher training (Beaver, 1990; Drazdowski, 1990; Dupagne \& Krendl, 1992; Fawson \& Van Uitert, 1990). The Office of Technology Assessment asserted that teacher training is "the most important ingredient affecting implementation of new technology "(1988). One prerequisite to the effective use of technology is professional development that consists of more than 'how to' workshops, but rather provides "authentic tasks in collaborative settings and the time to do the tasks well" (David, 1994, p. 179-185).

Knowledge of basic skills alone is not enough to foster classroom Internet integration; teachers need systematic, research-based guidance in the development of better ways to integrate technology into instruction (Chrisholm \& Wetzel, 1997; Office of Technology Assessment [OTA], 1995; Panel on Educational Technology, 1997). Some researchers suggest that technology can be used to change educational practices by creating student-centered environments in which knowledge is constructed through meaningful, real-life experiences (e.g. Means, 1994) however, a lack of understanding about its educational applications has led to the non-comprehensive use of technology (OTA, 1995).

The West Virginia K-12 RuralNet Project was a four-year, \$3.1 million National Science Foundation awarded to West Virginia University in 1995. The project's intent was to provide training to West Virginia public school teachers in the use of Internet resources, consistent with the National Science Education Standards, or NSES, (National Research Council, 1996). Over 1000 kindergarten through $12^{\text {th }}$ grade teachers throughout the state of West Virginia participated in the West Virginia K-12 RuralNet Project initiative. This year-long professional development program went beyond basic skills training by providing teachers with the skills needed to develop, refine, utilize and evaluate Internet enhanced curriculum frameworks. Teachers not only 
learned about the instructional uses of technology, but they experienced using the Internet from a student's perspective. Thus, the West Virginia K-12 RuralNet project provided an opportunity to explore the effects of training on teachers' instructional practices. (A more detailed description of the RuralNet project is presented in Chapter 3 of this document)

Technology integration mandates and the Internet's potential for enhancing teaching and learning highlighted the need for research about the effect of training on teacher's instructional practices. Such research could provide a basis for developing and guiding effective teacher training models.

\section{Purpose of the Study}

This study examined the effects of the West Virginia K-12 RuralNet Project on elementary school teachers' instructional practices, including, but not limited to: lesson development, classroom preparation, classroom management techniques, instructional delivery methods, and student assessment. By providing insight into how Internet training effected the instructional practices of elementary school teachers, this study's results can benefit current and future elementary school professionals, as well as those committed to implementing pre-service teacher training and teacher professional development programs.

\section{Definition of Terms for the Study}

The following terms and appropriate definitions are used for this study:

E-mail. Short for electronic mail, the transmission of messages over communications networks (Webopedia, 2000).

Internet. An electronic communications network that connects computer networks and organizational computer facilities around the world (Merriam-Webster Online, 2000). 
Listserv. An automatic mailing list server developed by Eric Thomas for BITNET in 1986. When e-mail is addressed to a LISTSERV mailing list, it is automatically broadcast to everyone on the list. The result is similar to a newsgroup or forum, except that the messages are transmitted as email and are therefore available only to individuals on the list (Webopedia, 2000).

Netiquette. Etiquette governing communication on the Internet (Merriam-Webster Online, 2000).

Online Course

Uniform Resource Locator (URL). The global address of documents and other resources on the World Wide Web (Webopedia, 2000).

WebBoard. A popular web conferencing software package used for web-based discussions and chats. Created by O'Reilly Software.

Web browser. A software application used to locate and display Web pages. The two most popular browsers are Netscape Navigator and Microsoft Internet Explorer (Webopedia, 2000).

World Wide Web (Web). A part of the Internet designed to allow easier navigation of the network through the use of graphical user interfaces and hypertext links between different addresses (Merriam-Webster Online, 2000).

\section{Research Question}

The following research question will be addressed through this study:

What effect has the West Virginia K-12 RuralNet Project had on Elementary school teachers' instructional practices?

\section{Limitations}

The primary limitations of this study are: 
1. The generalizability of the findings is limited to the particular participants and settings of this study.

2. The questionnaire is limited by the reliability of self-reported data.

3. This study is limited to elementary school teachers and is not intended to represent teaching at all grade levels.

4. Only elementary teachers who completed the 1998-1999 West Virginia K-12 RuralNet project training are included in this study. 


\section{Chapter II: Review of Related Literature \\ Technology and School Reform}

Experts have been claiming that technology holds the potential for revolutionizing education since the introduction of microcomputers in the 1980's (Cuban 2001; David, 1994; Means, 1994). In September of 1993, the U.S. Department of Education noted, in the report Using Technology to Support Education Reform, that "support for the use of technology to promote fundamental school reform appears to be reaching a new high" (p. 1). Today, educators, researchers, policy makers and reformers alike still agree that technology is an essential part of school reform.

The Chairman's Initiative Brief of the task force on technology, entitled "Education Technology: Changing the Way America Learns", was released in August of 1999 by the Education Policy Studies Division of the National Governors' Association Center for Best Practices. In addressing initiatives to reform education systems the report states that: Technology complements the goals of school reformers by helping educators and students create new ways of teaching and learning in and out of the classroom. When used effectively, technology can improve student performance and help prepare students for the digital economy they will enter as adults. Because technology and school reform are so closely intertwined, it is important that legislators include technology as an integral part of their state's reform initiatives; technology initiatives should not be proposed independent of other reform initiatives. (p. 3)

In a research project sponsored by the U.S. Department of Education, Office of Educational Research and Improvement (1993), a team of researchers led by Barbara Means 
conducted case studies of nine school sites where staff were active participants in incorporating technology in ways that support education reform. It was found that technology served the goals of education reform at the nine case sites by contributing to:

- Student learning through involvement in authentic, challenging tasks,

- New roles for students and teachers,

- Professionalization of teachers, and

- Creation of a culture that supports learning both in the classroom and beyond the school walls.

Means' study provides examples of how technology and school reform can be successful companions. "The key to the partnership lies in educators' developing reformed sets of curricular and instructional goals and then using technology as a tool to support these goals" (Means, 1994).

The Clinton Administration encouraged the use of technology in U.S. schools through legislation such as the Goals 2000: Educate America Act, a governmental framework for systematic educational reform. Through the establishment of a set of national education goals and the development of a partnership between federal, state and local agencies, this legislation hopes to facilitate broad change across the many levels of the educational system. Title II, Part $\mathrm{C}$, of the legislation is entitled Leadership in Educational Technology. The purpose of this part of the legislation, in addition to promoting achievement of the National Education Goals, includes:

- Promoting awareness of the potential of technology for improving teaching and learning,

- Supporting state and local efforts to increase the effective use of technology in education,

- Demonstrating ways in which technology can be used to improve teaching and learning, and 
- Promoting high-quality professional development opportunities for teachers and administrators regarding the integration of technology into instruction and administration. In a report to the President on the use of technology to strengthen K-12 education in the United States, the Panel on Educational Technology noted that the extensive and effective use of computers, networking, and other technologies seems to be a common element in approaches to support systematic and curricular reform (President's Advisors on Science and Technology, 1997). After a review of research literature, solicited written submissions, and private briefings, President Clinton's Panel on Educational Technology made a number of recommendations related to the use of technology within America's schools, including:

- Focus on learning with technology not about technology,

- Emphasize content and pedagogy, and not just hardware, and

- Give special attention to professional development.

These recommendations have implications for classroom instructional practices as well as the professional development of teachers.

A major motivation for the utilization of networked technologies in education is the belief that they are highly compatible with the project-based, constructivist approach to student learning goals that drives the reform movement (Carvin, 2000; Herman, 1994; Means, 1994; U.S. Department of Education, 1993). Herman (1994), when discussing the various types of computing power now available in desktop form to students, stated: "These options seem to provide a means for achieving the dramatic transformations in curricula and in instructional processes that reformers and cognitive researchers advocate" (p. 133).

In December of 2000 the bipartisan, congressional Web-based Education Commission submitted a report to the President entitled The Power of the Internet for Learning: Moving from 
Promise to Practice. In the report, the commission urged the new Administration and 107th Congress to make E-learning a centerpiece of the nation's education policy in order to fulfill the Internet's promise to help transform education and improve student achievement. This report was the result of interviews and testimonies of hundreds of educators, policymakers, researchers and others who shared their experiences and visions of the Internet.

Based on the evidence presented, the commission found that the promise of the Internet includes: centering learning around the student instead of the classroom, focusing on the strengths and needs of individual learners, and making lifelong learning a practical reality. The commission went on to issue a seven-point call to action for government, industry, and the education community, including:

- Making new Internet resources widely and equitably available and affordable to all learners,

- Providing relevant and continuous training and support for educators and administrators,

- Development of high-quality online educational content,

- Protecting online learners and ensuring their privacy, and

- Creating a new research framework of how people learn via the Internet.

This report indicates that the Internet is being viewed as holding the promise to transform teaching and learning and reinforces the tie between technology and school reform.

\section{Internet Access in Public Schools}

Internet access in the nation's schools continues to rise. Each fall since 1994, the U. S. Education Department's National Center for Education Statistics (NCES) has surveyed a nationally representative sample of approximately 1,000 public schools to monitor progress made in providing students and teachers with access to information technology. Reports 
released by the NCES reveal a reported increase in Internet connectivity over the years. The percentage of public schools connected to the Internet increased from 35\% in 1994 to $95 \%$ in 1999 (U.S. Department of Education, 2000) and by the fall of 2001, an estimated 99\% of all U.S. public schools had access to the Internet (U.S. Department of Education, 2002). Additionally, schools have made continual progress in increasing the number of instructional rooms with Internet connections from 3\% in 1994 to $77 \%$ in 2000, and $87 \%$ in 2001. Differences in Internet access in instructional rooms by school characteristics were apparent in 2000 and continued to persist in 2001. For example, schools with higher poverty levels (measured by the percentage of students eligible for free or reduced price lunch) or larger minority enrollments had a smaller percentage of instructional rooms with Internet connectivity. Although the percentage of instructional rooms with Internet access was lower for these schools the NCES report released in September of 2002 showed a continued increase in classroom access between 2000 and 2001. Schools with the highest concentration of poverty increased instructional room access from $60 \%$ to $79 \%$ and schools with the highest minority enrollment increased access from $64 \%$ to $81 \%$ (U.S. Department of Education, 2002).

The September 2002 NCES survey also showed changes in the types and speed of Internet connections in public schools. Approximately $74 \%$ of public schools having Internet access in 1996 used dial-up connections to access the Internet, in 2001, only 5\% of the schools reported using dial-up connections and 55\% reported accessing the Internet via a T1/DS1 line. One factor attributed for the increase in Internet access in public schools is the Federal Communications Commission's (FCC) Schools and Libraries Universal Service Program, often referred to as the Education Rate (E-Rate) program, which was established in 1996 to provide 
schools and libraries with discounted rates for Internet related access and services (U.S.

Department of Education, 2001).

The West Virginia Department of Education's web site provides data on Internet connectivity in West Virginia Public schools. According to the web site, 100\% of public K-12 schools in West Virginia are connected to the Internet via direct frame relay technology. Over $89 \%$ of the classrooms are networked and more than 70, 000 computers are connected to the Internet. This connectivity is in part due to the 1994 Bell-Atlantic World School Program that provided Internet connections to nearly 700 schools in West Virginia. In 1996, Citizens Communications offered connections comparable to those in place through Bell-Atlantic to approximately 140 schools in their service area. According to Market Data Retrieval (MDR), a Connecticut based Market Research Firm, as of 2001only 84\% of West Virginia's Classrooms had Internet access. MDR also reported that there were approximately 5.6 students per Internetconnected computer in the state of West Virginia and 7.0 students per Internet-connected computer in West Virginia Schools classified as high-poverty. These numbers were lower than the reported 2001 U.S. Average of 6.8 students per Internet-connected computer and 8.1 students per Internet-connected computer in high-poverty schools (Skinner, 2002).

The NCES 2001 and 2002 reports show that the nation has made great strides connecting every classroom in every school in the United States to the Internet. However, school access does not necessarily correlate to instructional usage. Using data from the 1999 survey of public school Internet access and the 1999 survey of public school teachers' use of computers and the Internet, NCES released an Issue Brief in April 2002 entitled "Beyond School-Level Internet Access: Support for Instructional Use of Technology". Although 95\% of schools reported Internet access in 1999, instructional use of computers or the Internet during class time varied in 
correlation with classroom access, training and assistance. Only $68 \%$ of teachers reporting classroom level access and the availability of training and support also reported using the Internet and computers for instruction during class time compared to $52 \%$ of teachers who reported classroom level access, but no training and assistance. Thus the report concludes that "Classroom-level access to the Internet and support in the form of training and assistance appear to be important factors in instructional use of the Internet during class time" (U.S. Department of Education; April 2002, p. 2).

Having classrooms connected to the Internet is just one piece of the educational improvement puzzle. Experts on school reform consider technology as one means for transforming education but teachers must be prepared to utilize the technology in meaningful ways. "Technology in and of itself will not change education; what matters is how it is used" (Sandholtz, Ringstaff, \& Dwyer; 1997, p. 10).

\section{Professional Development and Technology Implementation}

The professional preparation of teachers has been identified as an essential element to improving elementary and secondary education (National Commission on Teaching and America's Future, 1996). While dealing with the everyday challenges of the classroom, teachers are being asked to rethink the way they teach while at the same time developing technological skills. As of 1997 , only about $15 \%$ of the typical educational technology budget was spent on teacher professional development (President's Advisors on Science and Technology, 1997). Skinner (2002) reported that technology spending on professional development activities has dropped from $17 \%$ in 2000 , to a mere $14 \%$ in 2001 . Noting that hardware accounted for twothirds of the spending, and software spending remained at 20 percent. Without increased teacher training in the integration of information technologies into their teaching, the financial 
investments in hardware, software and infrastructure will be largely wasted (President's Advisors on Science and Technology, 1997, p. 7).

Recognizing the importance of teacher training on student achievement, President George W. Bush initiated the Improving Teacher Quality State Grants program as part of the No Child Left Behind Act of 2001. The Executive Summary of the Act, states that this program "focuses on using practices grounded in scientifically based research to prepare, train, and recruit highquality teachers". Combining previous initiatives such as the Eisenhower Professional Development and the Class Size Reduction programs provided funds for the new Improving Teacher Quality State Grants. Under this new program, states have the flexibility to select strategies that best meet their particular needs for improved teaching that will help raise student achievement in core academic subjects, but they must demonstrate annual progress in ensuring highly qualified core subject teachers in their state. The No Child Left Behind Legislation also reauthorizes the Elementary and Secondary Education Act of 1965 (ESEA). The reauthorized ESEA consolidates the current Technology Literacy Challenge Fund and the Technology Innovative Challenge grant programs to establish the Enhancing Education Through Technology (Ed Tech) Program. Under the Ed Tech program, the U.S. Department of Education provides grant funds to State Educational Agencies for use by elementary and secondary schools in the implementation and support of effective technology use to improve student academic achievement. Ed Tech guidelines require that fund recipients use at least $25 \%$ of the grant to provide "ongoing, sustained, and intensive, high-quality professional development" in the integration of advanced technologies into curricula and instruction (US Department of Education, March 2002). 
Skinner (2002) used data collected by Market Data Retrieval to report on a variety of school technology issues. He reported that in 2001, West Virginia ranked the second highest state in the percentage of schools where at least half the teachers are "beginners" when it comes to using technology. West Virginia reported 38\% of schools compared to the national average of 24 percent.

The U.S. Department of Education released a report in September of 2000 entitled Teachers' Tools for the 21st Century: A Report on Teachers' Use of Technology. Drawing on data from the 1999 "Public School teachers use of Computers and the Internet Survey" with supplemental data from the National Assessment of Educational Progress, and the Current Population Survey, this report focuses on teachers' use of computers and the Internet for instructional purposes and examines the relationship between teachers' use of technology and various contextual factors. The survey sample for this empirical study consisted of 2019 full-time teachers in regular public elementary, middle, and high schools in the 50 states and the District of Columbia. Findings presented in this report indicate that about half of the teachers with computers available in their schools used them for classroom instruction and that teachers' use of technology was related to their training, preparation, and work environments. Teachers reported a greater likelihood to use educational technologies when the technologies were available in their classrooms as opposed to computer labs, and available in greater numbers. Additionally, teachers who spent more time in professional development reported feeling better prepared and more likely to use computer and Internet technologies than their colleagues. Finally, teachers who perceived that lacking computers and time for student computer use as great barriers were less likely to assign students to use computers or the Internet for instructional activities. 
Using a nationally representative sample of 4, 049 full-time U.S. public school teachers in grades 1-12, the National Center for Education Statistics conducted a study focusing on teacher quality. The report released in January 1999 indicated that only $20 \%$ of the teachers surveyed reported feeling "very well prepared" to integrate educational technology into classroom instruction (US Department of Education, 1999). The report also suggests a relationship between teachers' participation in professional development activities and their classroom practices. Teachers who had spent more than 8 hours in professional development on new methods of teaching in the classroom were more likely than those who spent 1 to 8 hours in professional development to report that participation in the program improved their teaching "a lot". Thus, increased time in professional development seems related to the perception of improvements in one's teaching.

While teacher development may be a main criterion for improving teaching and learning, experts agree that there must be a move away from the traditional models of professional development that often fail to produce any changes (Burns, 2002; Darling-Hammond \& McLaughlin, 1996; Fullan, 1991; Lieberman, 1996). "Nothing has promised so much and has been so frustratingly wasteful as the thousands of workshops and conferences that led to no significant change in practice when the teachers returned to their classrooms" (Fullan, 1991, p. 315). Some reasons for failure of traditional development opportunities is that they are typically short-term with no follow-up or support mechanisms, they rarely address the teacher's individual concerns, classroom context and challenges, and they fail to incorporate the characteristics of effective change processes (Fullan, 1991; Lieberman 1996).

Part of the federal government's efforts to support standards-based educational reform was the Eisenhower Professional Development Program, established in 1988 and reauthorized in 
1994 as Title II of the Elementary and Secondary Act (ESEA). This program was the government's largest investment that is focused solely on developing the skills and knowledge of classroom teachers. (U.S. Department of Education, 2000b). The goal of the program was to "support professional development experiences for teachers that enhance classroom teaching and, ultimately, improve student learning" (p. 1). The National Evaluation of the Eisenhower Professional Development Program resulted in the publication of three reports between the years of 1996 and 2000.

The first report was based on six exploratory case studies of school districts and was conducted during the first months of the evaluation. The purpose of the initial report was to obtain an initial description of the program and the issues it faced in different local contexts.

The second Eisenhower report: Designing Effective Professional Development: Lessons from the Eisenhower Program, was based upon data from national probability samples of districts and teachers as well as 10 in-depth case studies and focuses on the program operations and the quality of Eisenhower activities across the country. It also provided data on the selfreported effects of teachers' experiences in Eisenhower assisted activities on change in teaching practice. This report concluded that six key features of professional development are effective in improving teaching practice: reform type, duration, collective participation, active learning, coherence, and content focus (U.S. Department of Education 1999a, p. 59)

The third Eisenhower report was based on longitudinal study of purposefully selected teachers in 30 schools, in 10 districts, in 5 states and is entitled, Does Professional Development Change Teaching Practice? Results from a Three-Year Study. In this study researchers examined the quality of teachers' professional development in Eisenhower-assisted and other professional development activities and its effects on changing teaching practice in mathematics 
and science from 1996-1999. The focus of the study was on relationships between features of professional development and teaching practice making the findings applicable to teachers' professional development in mathematics and science in general, regardless of the funding source. This report found that:

- Professional development focused on specific, higher-order teaching strategies increases teachers' use of those strategies in the classroom.

- On average, teachers do not experience high quality professional development on a consistent basis. Furthermore, professional development experiences of teachers vary significantly, even within the same school.

- Little overall change in teaching practice occurred in the longitudinal teacher sample from 1996-1999. However, individual teachers in the sample did alter their classroom practices, and moderate change does occur in the classroom practice of specific teachers from year to year.

In summary, the Eisenhower reports indicated that the most effective professional development is focused on specific higher-order teaching strategies and has the six features of high quality identified in the analysis of the national teacher sample. Furthermore, the findings imply that to positively impact instructional practice, teachers need to be provided with consistent, high-quality training that provides both the depth of effective professional development experiences and the breadth of coverage of specific content and teaching strategies that teachers should learn over time.

A study was conducted by Berkowitz (2000) to determine the effect of in-service technology training on physical education teachers' attitudes toward technology and use of technology in their planning and delivery of instruction. Post in-service training attitudes did not 
change significantly. Teachers primarily used technology for communication with colleagues, administration, and parents, followed by management tasks, student learning experiences, and teaching. Technology was utilized for planning and assessment of students the least. Three factors arose as having influenced teachers' use of technology: time, access to equipment and support. The study also indicted that teachers need continued opportunities to further their skills so they can begin to apply them and impact student learning.

Davenport (2000) developed and administered a survey to a random sample of 325 Tennessee K-12 educators who had completed Internet training in attempts to determine what factors influence educators to use the Internet in classroom activities or professional development. Findings from the study conclude that educators who have attended Internet training are utilizing the Internet. However, Tennessee K-12 educators indicate that there is little Internet staff development available to them and they would like to receive more training on how to use the Internet. Data analysis also indicates a relationship between Internet usage and beliefs about Internet training and school support.

Catchings (2000) conducted a phenomenological study of factors contributing to the implementation of technology in elementary schools. Multiple case studies were conducted and data was collected via descriptive observations, open-ended interviews, a teacher questionnaire and examination of documents and artifacts. The study revealed several factors as contributing to school-wide technology implementation: in-school professional development programs, a community of leadership, a comprehensive school-based technology plan, and positive teacher attitudes toward the appropriate use of technology.

Burns (2002) reported on professional development findings from the Southwest Educational Development Laboratory's (SEDL) two-year project entitled “Applying Technology 
to Restructuring and Learning" (ARTL). The ARTL project involved six schools in six different states and was intended to help teachers create learner-centered, technology rich learning environments. Burns reported that most of the teachers in the project had undergone district technology training, yet their instruction was traditional and technology use was almost nonexistent. ARTL provided 25 teachers in each school with 72 hours of professional development over a two-year period, supplemented by monthly follow-up classroom visits. Burns reported that teachers' instruction had changed dramatically with an increase in learnercentered approaches and student computer usage on a regular basis, following the two-year training program. Through interviews and discussions, ARTL project staff revealed three weaknesses with traditional skills-based technology training: presenting a curriculum-related activity as an adjunct, focusing on technology manipulation which resulted in a belief that teachers needed to be technology experts, and excessively long training sessions which relayed the belief that teachers would need to devote significant amounts of curriculum time to training students in the use of the technology. In contrast the SEDL's professional development model focused on comfort in technology over proficiency; classroom management techniques; and modeling of instruction and technology use advocated in the classroom. Using these three areas to focus the professional development instruction, teachers in ARTL training became students, and learned how to integrate technology in their classrooms in ways that promoted learnercentered instruction.

If technology is to be successfully integrated into the curriculum, it appears that professional development programs must be thoughtfully designed and provide continuity between training, classrooms and schools. Mergondoller (1997) outlined the successful components of technology related professional development programs. According to him, such 
programs include opportunities for teachers to learn, practice and integrate what is learned, and take advantage of informal coaching and structured presentations. Additionally, he states that successful technology training programs must emphasize pedagogy. "Technology must be seen as a means to an end, rather than an end unto itself" (p. 15).

\section{Technology Integration and Instructional Practice}

Some experts in the area of technology and school reform believe that when used properly, the integration of technologies into classroom instruction can lead toward a more constructivist model of teaching and learning. (Means, 1994; President's Advisors on Science and Technology, 1997; Sandholtz, Ringstaff, \& Dwyer, 1997). The following studies investigated the relationship between technology integration and instructional practice.

In the article, The Internet's Impact on Teacher Practice and Classroom Culture, Green and O'Brien (2002) reported on their study investigating the relationship between Internet usage, teacher practices and classroom culture. The study focused on two main research questions: Does Internet use result in an increase in constructivist teacher practices? What other features of classroom life are impacted when the Internet is used as a source of information for student research projects? The study took place in an upstate New York school district that has been considered at the leading edge of technology since 1983, and involved five fifth grade classrooms, in two different schools. Data included interviews, direct observations and assessment of students work. Study implications related to professional development included the idea that in order to increase constructivist-teaching practices, staff development programs must show teachers how to create situations where students are engaged in higher-order thinking rather than focus on how to use computer applications and the Internet. Simply integrating Internet technology did not result in changes toward constructivist practices. 
Lane-Kelso (2000) conducted a case study of three teachers involved in a training program. She examined their approaches to teaching, and if and how their approaches changed when incorporating telecommunications and the Internet into their instructional delivery. Data collection techniques included interviews, classroom observations, and journals. Results from the study show that participants who reported using computers as an integral part of teaching: 1) shifted from text-only resources in the classroom to using the Internet for the most current information sources, 2) increased student interest in learning, and 3) enhanced their professional role among peers.

Hoffman (1996) conducted a study to determine the relationship between the use of instructional technology and changes in teachers' methods. Using a quantitative survey of 441 teachers and interviews with 23 of the survey participants, Hoffman's study indicated that teachers perceived a reciprocal relationship between classroom computer use and changes in teaching methods. The quantitative portion of the study indicated that teachers perceived computer use as a predictor of teachers' adoption of innovative methods while the qualitative case studies indicated that teachers perceived the use of computers as a means of facilitating the adoption of new teaching and learning methods.

The Apple Classrooms of Tomorrow (ACOT) program began in 1985 as a research collaboration between universities, public schools, and Apple Computer, designed to investigate how routine use of technology by teachers and students would affect teaching and learning. Qualitative data from 32 elementary and secondary teachers in ACOT classrooms and 600 teachers participating in the professional development centers indicate that the staff development program had a meaningful influence on teachers. Sandholtz, Ringstaff, and Dwyer, (1997) stated, “At the classroom level, changes occurred in teachers' and students' level of technology use, in 
teachers' instructional practices, and in their philosophical beliefs and attitudes toward teaching" (p. 157). The authors noted that during the first few years of the project, adding technology did not revolutionize classroom instruction. However as the project progressed, the changes in classrooms became more noticeable. Some of these instructional changes reported include: teachers working across disciplines, encouraging increased student collaboration, project oriented tasks, providing greater opportunity for students to mix learning and communication tools, and changes in evaluation methodology.

Falvo (1999) conducted a qualitative study of five West Virginia teachers merging the Internet into their instruction. This study provided narratives about the teachers, how they utilized Internet technology and the effect Internet training has had on them as professionals. It also presented evidence that Internet training has impacted the teachers as professionals by providing them with additional opportunities to receive training, conduct training, and communicate with peers. Additionally, the stories highlighted successes and failures in the teachers' attempts to utilize the Internet to bring about more student-centered learning activities. Falvo concluded that teachers are still using the Internet mainly as a resource and are not capitalizing on its strengths as a means of communication and collaboration. He discussed the lack of teacher preparation time and poor professional development models as two factors contributing to the misuse of Internet technologies.

Becker and Ravitz (1999) explored the influence of computer and Internet use on teachers' pedagogical practices and perceptions. Self-reporting survey data from $441 \mathrm{~K}-12$ teachers who are part of the National School Network (NSN) indicated that teachers who utilized computer and Internet technologies reported changes in instructional practice toward more constructivist oriented activities. Substantial use of computer technology appeared to have the 
greatest impact on high school social studies, science, and non-academic core teachers' pedagogy. The data also suggested that frequent Internet and computer use is most consistently related to a move toward practices that encourage increased student control of learning. The authors concluded that the relationship between pedagogical change and technology use is causal.

Milman, (2000) used interviews and observations to examine the conditions influencing technology use in the classroom, how technology was defined and employed, motivation for the use of technology, and the consequences of technology use by three elementary school teachers. The context of the study was framed in the theories of symbolic interactionism and constructivism. Results of the study indicate that technology use is a complex process influenced by the teachers' beliefs about teaching and learning, and conditions within the state, district and school. The study also indicated that even when a teacher holds a constructivist view of learning, they do no always use technology to transform their teaching practices.

Dias (2000) investigated teachers identified as technology integrators to find out how and why they are integrating technology, and their beliefs about technology integration. The researcher employed qualitative methods to gather and analyze the data, presenting detailed descriptions of the four teachers under study. The study identified eight emergent themes from the data; 1) technology integrators use effective teaching practices, 2) technology integrators make use of multiple technologies, 3) instructional use of technology impacts students, 4) technology is a tool, 5) technology fluency is an important basic skill, 6) barriers exist that impact technology integration, 7) reasons for technology selections are based on efficiency and currency, and 8) factors outside the classroom influence practice. The researcher concludes that best teaching practices and best technology integration practices go hand-in-hand. 
The review of literature on professional development and technology integration indicates that there is a perceived relationship between the use of technology and instructional practices. Regardless of which is seen the catalyst, some changes occur in teaching and learning when technology is utilized, but the amount of change is dependent upon various factors (Becker \& Ravitz, 1999; Berkowitz, 2000; Davenport; 2000; Dias, 2000; Hoffman, 1996; Lane-Kelso, 2000; Sandholtz et al., 1997; U.S. Department of Education, 1999a, 2000). Government officials and researchers alike agree that professional development of teachers is a crucial factor to successful technology implementation (Becker and Ravitz, 1999; Berkowitz, 2000; Burns, 2002; Catchings, 2000; Falvo, 1999; Green and O’Brien, 2002; U.S. Department of Education, 1999 \& 2000). Teachers who participate in professional development, report perceiving themselves as better prepared and more likely to use computer and Internet technologies than their colleagues (US Department of Education, 1999 \& 2000). However, participation in professional development programs will produce little change if the programs are ill structured (Falvo, 1999; Fullan, 1991; Lieberman 1996).

The studies presented in this chapter identified various factors contributing to the success or failure of training programs in producing changes in teacher practice. Factors identified as leading to the failure of professional development programs include: length of training session, lack of follow-up or support mechanisms, focusing on technology manipulation without addressing classroom context or teacher's individual concerns, and presenting a curriculum related activity as an adjunct to technology training (Burns, 2002; Fullan, 1991; Lieberman 1996). These factors often lead to teachers' misconceptions about what is needed in order to effectively integrate technology into the curriculum. For example, Burns (2002) suggested that training sessions that are too long result in the belief that teachers would need to devote 
significant amounts of curriculum time to training students in the use of the technology.

However, Fullan (1991) and Lieberman (1996) pointed out that short training sessions with no follow-up are ineffective. Additionally, training sessions which focus on manipulation of technology with curriculum related activities presented separately often produced the belief that teachers must be technology experts to successfully integrate computers into their instruction (Burns, 2002).

In contrast, training programs that are effective at improving teaching practice appear to focus on comfort in technology over proficiency, stress higher order teaching strategies rather than specific software applications, present classroom management techniques, and model instruction and technology use advocated in the classroom (Green \& O'Brien, 2002; U.S. Department of Education, 1999a). The 1999 Eisenhower reports also presented key features professional development models that are effective in improving teaching practice, including reform type, duration, collective participation, active learning, coherence, and content focus. Furthermore, the reports noted that teachers need consistent, high-quality training that provides both the depth of effective professional development experiences and the breadth of coverage of specific content and teaching strategies that teacher should learn over time (U.S. Department of Education, 1999a). In addition to impacting classroom teaching and learning, it has also been suggested that participation in professional development programs enhances the professional role of teachers' among their peers (Falvo, 1999; Berkowitz, 2000; Davenport, 2000; Lane-Kelso, 2000). However, teachers need access on-going training opportunities in order to further their skills and apply them in the classroom (Berkowitz, 2000; U.S. Department of Education 2002). In addition to training, the review of literature identified other factors that impact the use of classroom technology including; preparation time, teachers' beliefs about teaching and 
learning, teachers' attitudes toward the appropriate use of technology, and work environment. Research shows that simply holding a constructivist view of learning does not always lead to the appropriate use of technology to transform teaching practices (Milman, 2000). Various studies indicated that teachers do not experience high quality professional development programs on a consistent basis and suggest that teachers need on-going technology training opportunities to further their skills and apply them to classroom learning (Berkowitz, 2000; Davenport, 2000; Falvo, 1999; U.S. Department of Education, 1999a). What teachers are able to achieve in the classroom is also greatly impacted by conditions within the school, district, or state including; access to equipment, preparation time, and ongoing administrative and technical support. The U.S. Department of Education (2000), noted that teachers' likelihood to use educational technologies is dependent upon the quantity and location of the computers. Teachers reported being more likely to utilize computers when the technologies were available in their classrooms and available in greater numbers.

The review of literature also provided information on if and how teachers are currently utilizing computer and Internet technology in their classrooms as well as what changes have occurred as a result of participation in specific training programs. Studies indicated that about half of the teachers with computers available in their schools are using them for instruction (U.S. Department of Education, 2000), and educators who have attended training are utilizing the Internet (Davenport, 2000). However, much of the technology usage is primarily for communication with peers (Berkowitz, 2000; Falvo, 1999). In addition to peer communication, the literature indicates a shift from text-only resources in the classroom to using the Internet as a resource (Falvo, 1999; Lane-Kelso, 2000). Becker and Ravitz (1999) indicated that teachers who frequently utilized computer and Internet technologies reported changes in instructional 
practice toward more constructivist-oriented activities and encourage increased student control of learning. Sandholtz, Ringstaff, and Dwyer, (1997) noted that during the first few years of the ACOT project, adding technology did not revolutionize classroom instruction. However as the project progressed, the changes in classrooms became more noticeable. Some of these instructional changes reported included: teachers working across disciplines, encouraging increased student collaboration, project oriented tasks, providing greater opportunity for students to mix learning and communication tools, and changes in evaluation methodology. Little overall change in the teaching practice of Eisenhower participants occurred in the longitudinal teacher sample from 1996-1999. However, individual teachers in the sample did alter their classroom practices, and moderate change does occur in the classroom practice of specific teachers from year to year (U.S. Department of Education 1999a). The above shows that teachers with computers do attempt to utilize them for classroom instruction, but major professional development initiatives have initially produced little or moderate change in teaching practices. Nevertheless, instructional changes did become more apparent over time with continued training opportunities and support.

\section{Qualitative Research}

There has been a long-standing debate between researchers regarding the relative value of qualitative and quantitative research methodology (Patton, 1990). This researcher does not intend to engage in the argument, but rather to provide the reader with an understanding of the rationale used in selecting the methodology for this study.

\section{Comparing Research Paradigms: Qualitative versus Quantitative}

Qualitative research, or phenomenological inquiry, attempts to understand occurrences within context-specific settings through the use of naturalistic approaches. Quantitative research, 
or logical positivism, tests hypothetical generalizations through the use of quantitative measures and experimental procedures (Patton, 1990). Both of these paradigms are based on underlying philosophical and epistemological principles that influence the researcher's actions.

Quantitative researchers take a structured, focused, singular stance in an attempt to verify or disconfirm a hypothesis. Design for the quantitative study is determined beforehand and any alteration would confound the variables making meaningful interpretation of findings impossible. Theory is developed and hypotheses derived from the theory; the theory takes its validity from the number of hypotheses that are "proved" not disconfirmed during testing. In contrast, naturalistic inquirers take an open, exploratory and complex stance in an attempt to understand the world through the perceptions of study participants (emic perspective). The naturalistic design emerges as the researcher gathers information and gains insights. Theory for the naturalistic inquirer is discovered from the data and thus grounded in the real world (Guba \& Lincoln, 1981).

While the paradigms of qualitative and quantitative methodology appear to be in opposition, researchers need not adhere to a single paradigm. Recognizing that different methods are appropriate for different situations, Patton (1990) promotes a "paradigm of choices" encouraging researchers to use "methodological appropriateness as the primary criterion for judging methodological quality" (p. 39). Although Guba and Lincoln (1981) clearly favor qualitative methodology for all inquiry into human behavior, they also recommend choosing research paradigms "on the basis of best fit between the assumptions and postures of a paradigm and the phenomenon being studied or evaluated" (p. 56). Other researchers advocate the collection of both qualitative and quantitative data within the same study (Patton, 1988). 
Combining these competing paradigms allows researchers to strengthen their study by merging the detail of qualitative inquiry with the generalizability of quantitative inquiry.

\section{When to use Qualitative Methodology}

There are different reasons for undertaking qualitative research. Guba and Lincoln, (1981) state that the purpose of naturalistic inquiry is to "focus on the discovery of elements or insights not yet included in existing theories" (p. 71). Merriam (1998) also notes that qualitative studies are often undertaken when there is a "lack of theory, or existing theory fails to adequately describe a phenomenon" (p. 7). She notes that this is a particularly useful application of qualitative methods because they primarily employ an inductive research strategy, building theory from observations and intuitive understanding gained in the field.

Patton (1987) states that qualitative researchers "focus on capturing processes, documenting variations, and exploring important individual differences between various participants' experiences and outcomes" (p. 14). Patton (1987; 1990) also presents a thorough review of "appropriate qualitative applications" for undertaking qualitative research as viewed from a pragmatic standpoint. Included in his more than twenty practical applications of qualitative research are:

- Exploratory research where little is known about the nature of the phenomenon.

- Research where no acceptable, valid, and reliable quantitative measure exists for particular outcomes.

- Elucidating and confirmatory research conducted to add depth, detail and meaning to quantitative studies.

While the reasons one has for selecting qualitative methodology may vary, the ability of qualitative data to thoroughly depict a phenomenon through thick, rich description is an 
important factor. Guba and Lincoln (1985) point out "If you want people to understand better than they otherwise might, provide them information in the form in which they usually experience it" (p. 120). In other words, the product of qualitative research is typically presented in the familiar narrative format thus allowing the reader to relate to the data more easily than if it were provided in a numerical format.

\section{Characteristics of Qualitative Inquiry}

Qualitative research is a blanket term used to cover various forms of inquiry including naturalistic inquiry, field study, participant observation, ethnography and case study. While these forms of inquiry differ in procedure they all hold common essential characteristics. Various writers have defined what they consider to be the primary characteristics of qualitative inquiry (see, for example: Guba \& Lincoln, 1981,1985; Merriam, 1998; Patton, 1990). The following list represents a synthesis of these authors' descriptions of qualitative research characteristics.

1. Through fieldwork, the qualitative researcher uses the natural setting as a primary source of data.

2. The researcher serves as the "human instrument" for data collection and analysis.

3. Qualitative research encourages the utilization of tacit knowledge (intuitions, apprehensions, and feelings).

4. Qualitative inquiry relies on purposeful sampling or selecting a small number of information rich cases for in-depth study.

5. Qualitative research primarily employs an open research strategy oriented toward extrapolation, discovery and inductive analysis. 
6. Qualitative research findings are grounded in specific contexts thus resulting in theory that is grounded in real-world patterns.

7. Qualitative researchers utilize an emergent design. The research design is not predetermined, but emerges as fieldwork unfolds. The researcher must report on the emerging design decisions in addition to research outcomes.

8. The end product of qualitative research is in the form of rich descriptions and narratives.

9. Qualitative research is judged on the basis of trustworthiness: credibility, transferability, dependability, and confirmability.

Patton (1990) reminds us that "these are not absolute characteristics of qualitative inquiry, but rather strategic ideals that provide direction and framework for developing specific designs and concrete data-collection tactics" (p. 59).

\section{Sampling Strategies}

Quantitative research typically relies upon probability sampling or selecting large random and statistically representative samples for the purpose of generalization to the population. In contrast, qualitative inquiry relies on purposeful sampling or selecting a small number of information-rich cases for in-depth study. The aim of purposeful sampling is to select cases that will provide insight about the issues under study and thus illuminate the research questions (Patton, 1990).

Various writers have differentiated among the types of sampling strategies for purposefully selecting information-rich cases (Miles and Huberman, 1994; Patton, 1990). Patton outlines 16 such purposeful sampling strategies including the more common methods of: extreme or deviant case sampling, intensity sampling, maximum variation sampling, typical case sampling, critical case sampling, criterion sampling, random purposeful sampling, convenience 
sampling, and others (1990, pp. 169-183). According to Guba and Lincoln (1988) maximum variation sampling provides the broadest scope of information and is thus the most advantageous strategy for naturalistic inquiry. Maximum variation sampling

aims at capturing and describing the central themes or principal outcomes that cut across a great deal of participant or program variation. For small samples a great deal of heterogeneity can be a problem because individual cases are so different from each other. The maximum variation sampling strategy turns that apparent weakness into a strength by applying the following logic: Any common patterns that emerge from great variation are of particular interest and value in capturing the core experiences and central, shared aspects or impacts of a program (Patton, 1990, p. 172).

The data obtained through utilization of maximum variation sampling will yield detailed descriptions of each unique case as well as shared patterns that cut across cases.

Sample size in qualitative inquiry is dependent upon the purpose of the study, research questions, how the study results will be used, and the resources at hand (Merriam, 1998; Miles \& Huberman, 1994; Patton, 1990). If the researcher is seeking breadth, a specific set of experiences for large number of people could be studied. If the researcher is seeking depth, an open range of experiences of small number of people may be more valuable. Patton (1990) states:

There are no rules for sample size in qualitative inquiry. Sample size is dependent upon the purpose of the inquiry, what you want to know, what will be useful, what will have credibility, and what can be done with available time and resources (p. 184, emphasis in original). 
Guba and Lincoln (1985) recommend that sampling continues until a point of redundancy or saturation is reached. "In purposeful sampling, the sample is determined by informational considerations. If the purpose is to maximize information, the sampling is terminated when no new information is forthcoming from the new sampled units; thus redundancy is the primary criterion" (p. 202, emphasis in original).

While qualitative inquiry should remain emergent and flexible, it is beneficial for planning purposes to specify an approximate sample size. Patton (1990) recommends specifying a minimum sample size "based on expected reasonable coverage of the phenomenon given the purpose of the study" (p. 186). As the inquiry progresses, the sample size may be adjusted. The researcher is however obligated to describe sampling procedures and decisions so that the reader has an appropriate context for judging the sample.

\section{Fieldwork}

The data collection process associated with qualitative analysis is called fieldwork. During fieldwork the researcher has "direct and personal contact with the people under study in their own environments" (Patton, 1990, p. 46). The purpose of fieldwork is to collect data in the form of description and quotations. During analysis and interpretation, this data will become the judgment-free descriptions used to take the reader into the research setting. There are two basic data collection techniques conducted during fieldwork, interviews and observations. These techniques may be used alone or in combination with document analysis.

\section{Interviews.}

Interviewing is probably the most common form of data collection in qualitative studies (Merriam, 1998). Patton (1990) states that the purpose of interviewing is to "allow us to enter into the other person's perspective" and "find out those things we cannot directly observe." (p. 
278). Guba \& Lincoln (1981), Merriam (1998), and Patton (1990) all write about various types of interviews that seem to vary along a continuum in the amount of planned structure and the extent to which the interview questions are predetermined.

The unstructured/informal interview is the most open-ended approach to interviewing. This type of interviewing is characterized by its free-flowing, conversational format with questions being generated spontaneously. Often used in conjunction with participant observation, the unstructured/informal interview can provide insight about a program and help focus questions for subsequent interviews. The strength of unstructured/informal interviewing is that it is flexible enough to be responsive to varying individuals and situations thus increasing the correctness of interview questions and responses (Patton 1990). Drawbacks of this type of interviewing include increased time requirements to collect standardized data, dependence upon the interviewers conversational skills, and difficulty in pulling together and analyzing the data.

The highly structured/standardized interview is desirable when it is necessary to obtain the same information from each interview respondent. This type of interview is sometimes considered an oral survey because of its rigid adherence to predetermined questions and sequencing (Guba and Lincoln, 1981; Merriam, 1998). An advantage of the highly structured/standardized interview is that it reduces interviewer effects by asking the same questions of each respondent. Additionally, it facilitates effective use of time and supports the data analysis process by aiding in locating respondents' answers to specific questions (Patton, 1990). The weakness of this approach is that it prohibits the researcher from pursuing unanticipated topics and issues, thus reducing the extent to which individual differences and circumstances can be taken into account. Instead of participant perspectives and understandings of the world, you often get reactions to the researcher's preconceived notions (Merriam, 1998). 
One common use of this highly structured format in qualitative research is the collection of sociodemographic information from respondents.

A third approach to interviewing is the semi-structured interview. This approach utilizes a mix of both highly structured and unstructured approaches in an attempt to obtain basically the same information from each respondent while allowing the researcher the freedom to establish a conversational style. Typically, an interview guide or list of questions and topics that the researcher wants to investigate during an interview is utilized. An interview guide provides the topical framework within which the researcher can develop and sequence questions, and pursue issues in greater depth. While the focus of the interview has been predetermined, the researcher is free to develop and sequence questions, and pursue issues in greater depth. Interview guides insure that basically the same information is obtained from each respondent; make good use of limited interview time; keep interactions focused; and make interviewing of multiple subjects more systematic and comprehensive (Hopeful, 1997; Patton, 1990).

While all three types of interviewing vary in the amount of planned structure and the extent to which the interview questions are predetermined, they all hold common the principle that responses should be open-ended (Patton, 1990). Guba and Lincoln (1981) assert that openended questions are:

designed to permit a free response from the subject rather than one limited by stated alternatives and implied boundaries. The distinguishing characteristic on open-ended questions is that they raise issue but do not provide or suggest any structure for the respondent's reply; the respondent is given the opportunity to answer in his own terms and to respond from or create his own frame of reference. (p. 177) 
Rather than forcing respondents to fit their knowledge, experiences and feelings into the researcher's categories, qualitative interviewing provides a "framework within which respondents can express their own understandings in their own terms" (Patton, 1990 p. 290, emphasis in original).

There are three basic ways to record interview data; audiotape, written notes, or videotape. The most common method of capturing interview data is audiotape (Merriam 1998). Recording the interview on audiotape ensures that everything said is preserved and provides the best database for analysis (p. 87). Patton (1990) states that the audio tape recorder is "indispensable" and suggests that it allows the researcher to be more attentive to the interviewee and maintain the interactive nature of in-depth interviewing (p. 348). Drawbacks to using audiotape include technical failure and respondent's apprehension about being recorded. Written notes may also be utilized as a means of capturing interview data. While the researcher need not worry about mechanical failure, it is difficult to keep up with the pace of spoken language and capture verbatim everything that is said. Videotape has the advantage of capturing respondents' nonverbal behavior, however, it is more cumbersome and more intrusive than tape recording the interview. Some researchers advocate taking written notes in addition to tape recording the session (see, for example: Merriam 1998; Patton 1990). The interviewer can note nonverbal behavior, important comments, or researcher insights while relying on the tape recorder to capture the interview text. Additionally, note taking provides a form of nonverbal feedback to the respondent that something they said is important enough to be written down (Merriam, 1998; Patton, 1990). While all three methods are acceptable, the researcher should consider the advantages and drawbacks of each method before making data recording decisions. 


\section{Observations.}

Observations are a primary source of data in qualitative inquiry. Various terms are used to label this process of going into the program context to obtain descriptive data, including participant observation, field observation, qualitative observation, direct observation or field research. "All these terms refer to the circumstance of being in or around an on-going social setting for the purpose of making a qualitative analysis of that setting" (Lofland 1971, p. 93).

This classic form of naturalistic inquiry requires the researcher to go into the context of a program and observe participants for the purpose of systematically describing the setting, activities, participants, and the meanings of what was observed from the perspective the participants. Through observations the researcher has the opportunity to discover nuances that may escape participant awareness and learn about things participants may be unwilling to talk about in an interview thus providing a deeper understanding of the program under study. (Patton, 1990). “Observations can range from highly structured, detailed notation of behavior guided by checklists to a more holistic description of events and behavior" (Marshall \& Rossman, 1995, p. 79). Fetterman (1988) notes that fieldwork in the form of participant observation may or may not be continuous; however, it is "usually conducted over a period of time to identify patterns of behavior" (p. 45).

There are a variety of observational approaches available to the qualitative researcher. The researcher must decide upon the extent of participation, duration of observations, extent of which the researcher identity and observation purpose will be revealed, and the focus of the observations. These approaches vary in dimensions along a continuum and observational decisions should be based upon the purpose of the study, the available resources, and the questions being asked (Guba and Lincoln, 1981; Patton, 1990). The researcher must also be 
aware that observer presence may disrupt or create changes in the natural setting being studied and observational approaches should be selected to help minimize any distortions. Merriam (1998) states that subjectivity and interaction are assumed in qualitative research since the researcher is the primary instrument of data collection. "The question, then, is not whether the process of observing affects what is being observed, but how the researcher can identify those effects and account for them in interpreting the data" (p. 103). Reflection and introspection are considered important element of fieldwork, and observations permit the researcher to access personal knowledge and direct experience as resources to assist in understanding and interpreting the program being studied (Patton 1990).

Observational data are typically recorded in the form of running notes which include detailed descriptions of surroundings, people, activities, interactions, and sounds (Guba and Lincoln, 1981; Hoepfl, 1997). Observational notes should also contain direct quotations and observer comments and should be completed as soon after the observation as possible (Merriam, 1998; Patton 1990). In addition to running notes, researchers may also utilize diagrams, videotapes, audio tapes and photographs as a means of accurately recording observational data.

\section{Field Notes}

Field notes are the products of interviews and observations. They contain information about the study participants, the program context, and researcher reactions. Through direct quotations derived from observations and interviews, field notes provide us with an "emic perspective" (an insider's perspective) of the program under study (Fetterman, 1989, p. 30). Lofland (1971) states that field notes are "the most important determinant of later bringing off a qualitative analysis. Field notes provide the observer's raison d'être. If he is not doing them, he might as well not be in the setting" (p. 102). 
Fieldnotes must be descriptive and should contain such information as the date, location of observation/interview, individuals present, description of the physical setting, social interactions that occurred, and activities (Patton, 1990). "Field notes contain the descriptive information that will permit the observer to return to the observation later during analysis and eventually permit the reader of the study findings to experience the activity observed through the research report" (p. 239).

Since the researcher's own experience is a crucial part of the data in naturalistic inquiry, field notes also contain the researcher's feelings, reactions to the experience, and reflections about the personal meaning and significance of what has occurred (Merriam, 1998; Patton, 1990). Additionally, insights, initial interpretations, hunches, and working hypotheses should also be recorded as part of the researcher's commentary since they are the beginnings of data analysis (Merriam, 1998; Patton, 1990). Field notes, then, contain the voluminous raw data in the form of descriptions, quotations, feelings and interpretations that are analyzed in order to generate findings, understandings and insights that later become the product of qualitative inquiry.

\section{Meeting Tests of Rigor - Trustworthiness}

Meeting tests of rigor is a prerequisite for establishing trust in the outcomes of any study. "In determining what constitutes "good" inquiry, the scientific inquirer relies almost exclusively on criteria of rigor, that is internal and external validity, reliability, and objectivity" (Guba and Lincoln, 1981, p. 66). Strauss and Corbin (1990) point out that these "usual canons of 'good science' ...require redefinition in order to fit the realities of qualitative research" (p. 250). Guba and Lincoln (1985) have developed "naturalistic analogues" to the four criteria of rigor commonly used by qualitative researchers. In place of the terms internal validity, external 
validity (ability to generalize), reliability, and objectivity they suggest using credibility, transferability, and dependability and confirmability (p. 300).

\section{Credibility.}

The first criterion put forth by Guba and Lincoln is credibility, which replaces the concept of internal validity. In quantitative-experimental studies, internal validity depends upon the degree to which research findings depict reality (Hopeful, 1997; Merriam, 1998; Guba \& Lincoln, 1981). This perspective views reality as a singular entity and information is internally valid only if it "describes that reality and facilitates its control and manipulation" (Guba and Lincoln, 1981, p. 105). The quantitative researcher must assert hypotheses and then test them to determine if they are true or false. The naturalistic researcher, however, adopts a stance that reality is multidimensional, holistic, and ever changing (Merriam, 1998). Since qualitative researchers assume multiple realities, relationships cannot be tested for truthfulness; rather, data should adequately represent research participants' perspectives. Guba and Lincoln (1981) explain that to the naturalistic researcher truth-value is established by testing the credibility of findings and interpretations with the various sources of data.

Numerous techniques can be employed to enhance the credibility of the research findings including; triangulation, member checks, and researcher disclosure. Patton (1990) describes triangulation as "a process by which the researcher can guard against the accusation that a study's findings are simply an artifact of a single method, single source, or a single investigator's biases" (p. 470). He identifies four types of triangulation: 1) methods triangulation, checking the consistency of findings generated by different data-collection methods; 2) triangulation of data sources, consistency of different data sources within the same method; 3) analyst triangulation, 
using multiple analysts to review findings; and 4) theory triangulation, using multiple perspectives to interpret the data (p. 464).

Member checks are another technique that can be employed to help establish credibility and control for researcher bias. This process consists of establishing corroboration by presenting data and interpretations to the individuals from whom they were taken and asking them if they find the results to be plausible (Guba and Lincoln, 1981; Merriam, 1998). Patton (1990) also advocates member checks in the form of feedback provided to research participants throughout the fieldwork process. He states that "feedback is a major part of the verification process in fieldwork" and recommends providing participants with descriptions and analysis and including their reactions as part of the data (p. 267).

Since the researcher is the primary instrument of data collection in qualitative inquiry, the qualitative report must include information about the researcher. Patton (1990) points out that there is no precise list of questions that must be addressed to establish researcher credibility. He goes on to state that "The principle is to report any personal and professional information that may have affected data collection, analysis, and interpretation - either negatively or positively in the minds of users of the findings" (p. 472, emphasis in original).

\section{Transferability.}

The concept Guba and Lincoln suggest naturalistic inquirers use in place of external validity is transferability. In scientific-experimental research external validity refers to the ability to generalize study findings across settings to the larger population. Thus to establish the transfer across time and space, findings are stripped of their context (Patton, 1990). Cronbach (1975) comments on the issue of generalizations by stating "Generalizations decay. At one time a conclusion describes the existing situation well, at a later time it accounts for rather little 
variance, and ultimately is valid only as history" (p. 122). He goes on to say, "When we give proper weight to local conditions, any generalization is a working hypothesis, not a conclusion" (p. 125).

Rather than searching for findings to generalize, qualitative researchers "tend to focus on providing useful information that is fairly specific to one or a few programs" (Patton, 1990, p. 486). Since the data of qualitative research are context specific, emphasis is placed on the transferability of working hypotheses rather than generalizability of findings. This transfer of insights cannot be made without thorough knowledge of the study context (Guba \& Lincoln, 1981; Merriam, 1998). It is therefore the researcher's obligation to provide enough detailed information in the form of "thick descriptions" for the reader to determine if there is a "fit" between the study and their situation. Guba and Lincoln (1981) comment on the need for "thick descriptions" by stating:

The collectivity of descriptors and inferred values provides the best basis for making judgement about the similarity between two settings. The obligation of the evaluator is thus not to establish the external validity of his findings and interpretations but rather to provide the descriptive and value data base that will make it possible for someone else in another setting to make the judgement by collecting comparable data there. (p. 327) Merriam (1998) outlined three strategies for enhancing the probability of qualitative studies being transferred: 1) rich, thick description; 2) typicality or modal category; 3) multi-site designs. Rich, thick description refers to the researcher providing enough detail for the reader to draw independent conclusions about the study and decide whether it is appropriate to transfer the findings. Typicality involves describing how typical the setting is compared with others in the 
same class. Multi site design is the process of using random or purposeful sampling to select study sites that maximize diversity in the phenomenon under investigation. This variation will allow readers to transfer results to a greater range of settings (p. 211-212).

\section{Dependability.}

The third construct put forth by Guba and Lincoln is dependability, which is used as the "naturalistic analogue" for reliability. Reliability is concerned with replication of study findings. Dependability, however, represents a very different set of assumptions than reliability. The qualitative inquirer assumes that the world is constantly changing and thus can not be replicated. The qualitative researcher therefore "attempts to account for changing conditions in the phenomenon chosen for study as well as changes in the design created by increasingly refined understanding of the setting" (Marshall \& Rossman, 1995, p. 145). Guba and Lincoln (1981) refer to the process of documenting research design changes as maintaining an "audit trail". This "audit trail" provides examiners of the study with the means to verify that the study was carried out in a competent manner and to attest to its consistency.

\section{Confirmability.}

Guba and Lincoln's concept of confirmability replaces the conventional idea of objectivity. Traditionally, quantitative research is viewed as value-free and thus objective while qualitative research, which relies upon interpretations, is considered subjective. Subjectivity leads to a breakdown in the trustworthiness of a study by producing results that are biased and unreliable. Guba \& Lincoln's concept of confirmability "shifts the burden of proof from the investigator to the information itself" by simply asking that the researcher "report his data in such a way that it can be confirmed from other sources if necessary" (1981, p. 126). 
Patton (1990) concludes that the terms objectivity and subjectivity have become “ideological ammunition in the paradigms debate." He notes that to be useful, any research strategy must be credible and recommends that researchers strive for "empathetic neutrality" (p. 55). While noting that the term empathetic neutrality may appear to be combining contradictory terms, Patton points out that empathy refers to "a stance toward the people one encounters, while neutrality is a stance toward the findings" (p. 58). The researcher who employs empathy and neutrality is committed to understanding the world from others' perspectives, communicates interest and caring about participants and builds rapport by taking a stance that is nonjudgmental, and is committed to reporting what is found in a balanced manner.

When speaking of confirmability, Marshall and Rossman (1995) state that the appropriate qualitative criterion is "Do the data help confirm the general findings and lead to the implications?" (p. 145). They go on to outline strategies that the researcher can utilize to balance bias in interpretation including:

- A constant search for negative cases

- Checking the data for possible rival hypotheses

- Practicing value-free note taking

- Asking questions of the data, and

- Conducting an audit of the data collection and analysis (pp. 145-146).

Qualitative research intentionally avoids controlling the research conditions and focuses on capturing the complexity of varying perspectives and contexts. The use of an emerging and flexible research design, however, prohibits the replication of qualitative studies (Marshall \& Rossman, 1995). The goal of the qualitative inquirer is, therefore, to maintain accurate and wellorganized records. Such records should consist of thorough notes and a journal of design 
decisions including the rationale behind each decision, thus allowing others to inspect procedures, protocols, and decisions. Additionally, collected data should be well organized and easily retrievable making them available for reanalysis by another researcher. 


\section{Chapter III: Methodology}

\section{Design}

This mixed-methods study was designed to examine the effects of the West Virginia K-12 RuralNet project on elementary school teachers' instructional practices, including, but not limited to: lesson development, classroom preparation, classroom management techniques, instructional delivery methods, and student assessment. Given the current trend toward using technology to transform teaching and learning, and the research that indicates that successful technology related professional development programs encourage teachers to transform their traditional beliefs and educational practices, the information gathered from this study will benefit both education practitioners and those who develop teacher-training programs. The study addressed the following research question: What effect has the West Virginia K-12 RuralNet Project had on elementary school teachers' instructional practices?

\section{The West Virginia K-12 RuralNet Project}

This section provides background information about the West Virginia K-12 RuralNet project and the training presented to the teacher participants. The West Virginia K-12 RuralNet project (RuralNet) was a \$3.1 million NSF-funded initiative awarded to West Virginia University in 1995. The project's intent was to provide West Virginia public school teachers with training that would enhance science and math instruction through the use of Internet integration. This training was consistent with the National Science Education Standards, or NSES. From 1995 -1999 over one thousand K-12 teachers throughout the state of West Virginia participated in the RuralNet project. The yearlong RuralNet training program is a three phase instructional model consisting of a five-day summer workshop and two online courses offered 
through West Virginia University and Marshall University. (A full description of the courses appears in Appendix A).

\section{Summer Workshop}

During this five-day, intensive, hands-on course, participants were introduced to the numerous science resources available via the Internet and provided with training in the basic telecommunications skills needed to participate in the fall and spring online courses. Structured workshop activities lasted Monday through Friday from 9 a.m. to 5 p.m. each day with open lab hours preceding and following the structured activities.

The first day of the workshop provided teachers with an orientation of the computer's operating system and file management techniques, e-mail basics, and netiquette. Day two of the workshop focused on the World Wide Web. Web browser software, "surfing" techniques, search engines, and bookmarks were presented. Teachers were also introduced to the RuralNet listserv and advanced e-mail techniques. Curriculum Integration strategies were the subject of day three. Teachers explored concepts, models and examples of Internet integration including environmental education using the Internet, online science collaboration activities, and classroom resources. Participants also conducted a hands-on weather collection collaborative activity in which they exchanged weather data from their workshop site with other workshop participants via an interactive web based data entry form. Discussions of related classroom activities, data analysis techniques, classroom management and state curriculum requirements were conducted face-to-face and electronically via electronic mail and a listserv. On the fourth day, considerations for implementing web-based instruction were addressed. Teachers explored issues surrounding classroom management, computer access, time management, technical support and acceptable use policies. In the afternoon, instruction on downloading Internet 
resources and software as well as browser plug-ins was presented. Participants formed small groups and began creating a mini Internet integration project. This project consisted of selecting a topic, locating and retrieving web resources, and generating Internet enhanced classroom activities. On the final day of the workshop, teachers completed their Internet integration projects and presented them to workshop peers.

In addition to presentation of basic skills, the summer workshops also included participation in meaningful activities that teachers can utilize in their classrooms, such as Internet scavenger hunts, URL review activities, and collaborative group work via e-mail. Each day participants were provided with review and structured independent practice time during which they could review skills presented the previous day and receive individual coaching from a workshop trainer.

\section{Fall Online Course}

The fall online course focused on the fundamental mechanics of locating and retrieving online science and math resources from the Internet and integrating them into a curriculum framework. Participants began by selecting a science topic (or science topic with a math component) that served as a platform for discussion and focused Internet searches. Throughout the course, teachers were involved in three connected, yet distinct sets of activities: Internet lessons, Internet collaborative activity, and curriculum framework development.

All course assignments and lessons were posted on the RuralNet website allowing teachers to access course information at any time. Teachers were encouraged to work at an individual pace, however benchmark completion dates were provided. All assignments related to lessons 1 through 4 were submitted to a course mentor via e-mail with selected information 
posted to the project listserv. Additionally, weekly journal entries and the draft curriculum frameworks were submitted via e-mail to the course coordinator.

The four Internet lessons were centered on improving Internet skills in the use of selected tools and compilation of an electronic resource library. Lesson 1 reinforced basic Internet communication skills (e-mail and the RuralNet listserv) thus enabling teachers to remain connected throughout the course. During lesson 2 skills related to the use of web browser software (Netscape Navigator) were developed. Lesson 3 focused on refining Internet search strategies, thus enabling teachers to more readily find resources. Lesson 4 presented techniques for retrieval and storage of Internet resources.

During the Internet collaborative activity, teachers became aware of different ways that the Internet can be used for effective learning in the classroom via examination of collaborative models and participation in an online collaborative activity with their peers. First, teachers were presented with examples, benefits, and types of collaborative activities. Next, teachers joined a collaborative activity being sure to keep an annotated record of their participation. This collaborative activity was either a RuralNet sponsored project or one found while searching the Internet. Finally, teachers evaluated their collaborative activity including a brief description of: the project, satisfied teaching objectives, student motivation, required management and Internet skills, recommendations for improving the activity, and problems with using collaborative projects in their classroom. The curriculum framework module was a set of activities that focused on the development and construction of a draft curriculum framework for instructional use. This framework served as the starting point for the spring online course.

At the conclusion of the Fall online course, participants were expected to be able to do the following: communicate via electronic mail, and the RuralNet listserv; locate and retrieve 
science/math resources (text documents, images, graphics, movie clips, sounds) from the Internet; and electronically collaborate with peers in the sharing, reviewing, and collection of Internet resources.

\section{Spring Online Course}

The spring semester online course was designed to enhance the electronic community and provide teachers with the skills needed to evaluate and revise Internet enhanced curriculum frameworks through online discussions. Participants in this course used small discussion groups and WebBoard technologies to review, discuss, evaluate and refine the frameworks created during the fall online course. Focus questions, and evaluation criteria were provided to guide the discussions and peer-critiques.

To assist in course management and individual pace of completion, most of the assignments and discussions took place asynchronously via web-based forms and WebBoard (threaded mail) discussion forums. E-mail and the RuralNet listserv were used extensively throughout the course. All course assignments were posted to the Web-based forms or submitted to the listserv, and three assignment reports were submitted to a course monitor via e-mail.

At the beginning of the course, teachers were assigned to small groups consisting of six to eight participants and two group mentors. The group mentors were responsible for assisting in discussion facilitation, collection of assignments, and answering course related questions as they arose. Each group had its own webpage, consisting of the draft curriculum frameworks submitted during the fall course and a series of interactive database forms. Participants began by entering personal introductions. The Personal Introductions Page consisted of three sections that were designed to help group members develop a better understanding of the challenges faced in implementing Internet technology into teaching. Section 1 - Personal Introduction consisted of 
an introduction to group peers including instructional subject area, experience with the Internet, special classroom projects, and course expectations. Section 2 - Internet Resources included a brief overview of the Internet resources available at home and in school (i.e. reliable home connection, e-mail addresses for students, Internet connectivity in the classroom, type and number of computers, Internet labs in the school, projection system for showing Internet resources). In Section 3 - Special Circumstances, teachers discussed special circumstances with the administration or students that may place unusual limitations or increase ability to integrate Internet resources. Discussions included circumstances such as: parents do not want children accessing the World Wide Web, teachers can not get reliable technical support, most students have computers at home, the principal is a big supporter of Internet use, or the school has its own web server. Once these introductions were completed, participants began the framework peer review process.

Teachers began by posting and reviewing comments to group members' frameworks. The purpose of evaluating the frameworks was not to criticize, but rather to help others improve their drafts by providing additional ideas and resources. Before commenting, participants were to have read the provided draft framework and background information so that they were familiar with the grade, resources, and circumstances that influenced development of the framework. Points for consideration were provided to help focus the framework comments. After completing the group review process, participants submitted assignment reports, discussing the value of the framework comments provided by group members, to the course monitor.

The second step of the process required course participants to find, review, and post comments on two frameworks designed for the same instructional level as the participant's classroom. Course participants posted comments to each of the two frameworks and submitted 
assignment reports, discussing the two reviewed grade level frameworks, the value of the review process, and common barriers to integration that appeared across the various frameworks. Some common barriers that emerged included: time, access, technical problems, classroom management issues, and lack of school support for the integration of technology. These barriers became the basis of the large group discussions.

For the final lesson all group participants were brought together on the RuralNet WebBoard to discuss ideas and concerns, answer questions, or make general comments about the class thus far. Five main discussion forums were created on the WebBoard; Classroom Management, New Technologies, Working the System, Information Literacy, and Merging the Internet and the Curriculum. In addition, a Technical Help Desk was established. The final assignment report for this task discussed participants' experiences with the WebBoard and assessed the ability of the WebBoard as a medium for large group discussions. All course participants were expected to use the information obtained during the review and discussion process, to revise their draft curriculum frameworks. An outline of required framework components was provided. Teachers participating in this course for graduate level credit were also required to implement their curriculum framework and evaluate its impact. Portfolios of this implementation including copies of relevant online discussions, lesson plans, units, completed student assignments or specific projects, and photographs were produced as evidence of attempts to integrate Internet tools and resources into the classroom.

\section{Data Collection}

\section{Survey Instrument}

The self-reporting survey instrument was mailed via U.S. Postal Service to the population of elementary school teachers completing the yearlong RuralNet training during the 1998-1999 
year $(\mathrm{N}=20)$. These individuals were located throughout the state of West Virginia and were teaching within grades K-6 at the time of their participation in RuralNet project. Seven of the twenty teachers responded to the instrument for a response rate of $35 \%$. One additional followup mailing was conducted and individuals were emailed prior to and following both mailings in attempts to increase the response rate. Two teachers notified the researcher that they were no longer teaching and thus unable to participate in the study. One additional survey was returned to sender due to the participant no longer living at the address on file with the RuralNet Project. Results of the survey instrument were analyzed using descriptive statistics.

The self-reporting survey instrument was a modified version of the RuralNet Fall 1998 online course survey. A pilot study of the instrument was conducted in November of 1999. A follow-up focus group meeting indicated to what degree: (a) the instructions were clear, (b) the directions were clear, and (c) whether teachers had difficulty understanding the questions. The survey instrument was modified based on the focus group's recommendations.

The five survey sections included: Internet Access, Internet Usage, The RuralNet Project, Impact Responses and Demographic Information. The Internet Access portion of the survey consisted of three checkbox response questions requesting information regarding; (a) Internet access from home, (b) location and quantity of school Internet access, and (c) amount of Internet access time while at school.

The Internet Usage portion of the survey consisted of eight questions designed to help the researcher develop an understanding of each participant's Internet usage at his/her school. Questions focused on the (a) length of time the participant has been using the Internet for teaching preparation and with students, (b) availability of Internet training and technical support, and (c) Internet training the participant has attended. 
In the RuralNet Project section of the survey, participants were asked to rate ten statements regarding the effect of the RuralNet project on Internet knowledge, skills, and usage. These ten statements focused on: (a) locating and retrieving Internet resources, (b) Internet integration, (c) classroom management and organization, and (d) collaboration with teachers and other professionals. This section of the survey utilized a five-point Likert type scale anchored on one end of the scale by "strongly agree" and on the other end by "strongly disagree."

Impact Responses requested that participants check off items that apply to changes in class preparation, and teaching practice as a result of participation in the RuralNet project. A total of seventeen check-box statements were provided. Some items allowed participants to indicate Internet usage prior to RuralNet or no change because of RuralNet participation

The demographic portion of the survey requested information about the teachers (a) grade level, (b) years teaching, (c) gender, (d) age, and (e) willingness to participate in interviews and classroom observations. Survey participants who were willing to participate in interviews and observations, provided their name, school, school district, e-mail address, telephone number, and the most convenient days and times to be reached by telephone.

Results of the survey instrument were analyzed using descriptive statistics to:

- Provide a profile of the teachers participating in the study

- Inform selection of subjects for classroom observations and interviews

- To guide the emerging data collection process

- Results of the survey are included in the triangulation process 


\section{Fieldwork}

A sample of five questionnaire respondents was self-nominated via the survey instrument to participate in interviews. Of these five, three were purposefully selected to participate in classroom observations based upon the following criterion:

- Available Internet resources at the school where the teacher is employed

- Willingness of the teacher to have the researcher regularly visit his/her classroom

- Willingness of the school administration to have the researcher regularly visit the school

- Information rich cases

- Each teacher had to be currently teaching at the elementary school level.

\section{Interviews}

Each of the five interview participants was interviewed using a semi-structured interview protocol. The interview questions were open-ended in order to allow respondents to share their perceptions and perspectives. The purpose of the interview was to assess from the teachers' perspective, how their classroom instructional practices have changed since participating in the RuralNet project. The interviews were audio taped and lasted approximately 30-45 minutes. To enhance reliability of the study a semi-structured interview protocol (see Appendix C) was utilized. Each teacher was asked the same questions and responses were recorded both on audiotape and in researcher field notes. Additionally, nonverbal behaviors were entered as a part of the researcher's field notes. Follow-up interviews were conducted as issues emerged.

Following interviews, researcher interview notes were reviewed to verify the clarity of responses. Respondents were contacted via e-mail or telephone to provide clarification to vague or ambiguous responses. This feedback became a part of the data. 


\section{Observations}

Classroom observations of three of the interview/observation participants were conducted so that accurate descriptions of the classroom settings, instructional practices, and teacher participants could be presented as part of the data. The fourth teacher who volunteered to participate in classroom observations is currently teaching at the $8^{\text {th }}$ grade level and thus did not meet criteria for participation. The fifth teacher, who was self-nominated to participate in the interview portion of the study, did not volunteer for observations. Upon further inquiry, via a telephone call, this teacher noted that she would be more than happy to participate in classroom observations, but with the current technology situation at he0r school there wouldn't be much to observe. Following the initial interview and observation, the researcher concurred and dropped her as an observation participant.

As a participant observer the researcher attempted to develop an "insider's eye view" of life in each specific teacher's classroom. Through detailed observational notes a description of the classroom-learning environment was constructed thus enabling the reader to visualize the classrooms under study. The researcher's feelings and perceptions became part of the data by providing insights. However, the researcher did not set out to prove a specific perspective and the data were not manipulated to prove any pre-determined results.

Overt observations in which the participants have full knowledge of the observations being made, the observer, and the purpose of the study were conducted. According to Patton, the length of time during which observations take place depends on the purpose of the study and the questions being asked (1990, p. 214). Observations for this study centered on the effect of the RuralNet project on teachers' instructional practices. Six observations of varying lengths were conducted in each interview/observation participant's classroom at dates and times agreed upon 
by the participating teachers. The first observation served to provide a description of the school and classroom settings. The five additional observations included examining formal and informal interactions and activities including, morning preparatory time, classroom instructional lessons, and planning periods. These five observations began at the beginning of the day before students arrived and lasted throughout the day until student dismissal. An observation guide (see Appendix D) was used to help provide consistency and reliability among observations. This guide provided a list of data sources to be addressed at each observation site and did not guide all aspects of fieldwork.

\section{Field Notes}

During the interview and observation process, descriptive, concrete and detailed field notes were recorded. These field notes contained descriptions of the school and classroom settings, social interactions, verbal and nonverbal communications (including direct quotations of what people said), and activities that took place.

Since, the "observer's own experience is a crucial part of the data" (Patton, p. 241), the researcher recorded her own feelings, reactions, insights and interpretations about what was happening while conducting the interviews and observations. This does not however, imply that the researcher set out to make judgments or perform analysis while in the field. Rather, the researcher recorded reactions, and field-generated insights as they naturally occurred and labeled them as such. The "raw" field notes were filed according to school and participant and revised after each school visit to fill in the details, providing a source of detailed narratives.

\section{Journals}

Two journals were maintained throughout the study: a research journal and a personal journal. The research journal consisted of a log of day-to-day activities and any methodological 
decisions. The personal or reflective journal served as a diary of the researcher's personal thoughts or reflections about all aspects of the research with entries made after leaving the research site.

\section{Member checks}

Throughout the research process, participants were provided with formal and informal feedback. Participants were given the opportunity to respond verbally or in writing to descriptive information from observations and analysis of the interviews. Reactions to my descriptions are included as part of the data. Participants were given the opportunity throughout the research process to review, edit, and verify the accuracy of all interview transcriptions.

\section{Data Analysis}

The data analysis process utilized standard qualitative procedures based upon Miles and Huberman's (1994) model of data reduction and display. Content was logically analyzed to identify, code, and categorize the data using codes derived from the survey instrument and interview protocol. Next, inductive analysis was conducted to look for common or recurring themes, patterns and categories emerging from the data. This process established a data index or classification scheme.

Next, individual cases were developed for each participant utilizing data from the various collection methods. Each case was written as a narrative, eliminating redundancies, organizing the topics and summarizing the relevant issues. Once individual cases were established, grade level comparisons were made via cross case analysis of the relevant issues or topics.

Data in this study are presented in the form of thick descriptions that include narratives, quotes, and field-documented observations, thus giving the reader access to the data while 
providing insight into study participants' professional lives and perspectives. Tables, matrices, or diagrams were used as forms of data displays when the data lent itself to such.

\section{Triangulation}

Triangulation of methods and data sources was conducted in an attempt to reduce systematic bias that can result from utilizing a single method or single data source. Methods of triangulation were achieved by verifying the consistency of findings generated through the various data collection methods, including a self-reporting survey instrument, interviews, and observations. Triangulation of data sources was achieved by checking for consistency of information derived from multiple participants within each method of data collection.

\section{Validation and Verification}

The various aspects of rigor or trustworthiness of this study were classified using the naturalistic terms set forth by Guba and Lincoln (1985). The terms internal validity, external validity (ability to generalize), reliability, and objectivity have been replaced with credibility, transferability, dependability and confirmability.

Various techniques were employed to enhance the credibility of the research including triangulation of data sources, a pilot study, and member checks. Triangulation of data and methods were achieved by validating the consistency of information generated across a variety of data sources and the five participants. Data was obtained through multiple observations of the participants' classroom instruction, audio taped teacher interviews, and self-reported survey instruments. Information collected in one manner was compared with the same type of information generated in another mode. Additionally, information gathered from each participant was analyzed independently and then cross case analyzed. 
A pilot study was conducted in November 1999 to assist in the refinement of data collection tools and procedures. Three West Virginia elementary school teachers who completed the initial RuralNet training participated in the pilot test. Revisions to the survey instrument, observation protocol, and interview protocol were based upon the study findings and recommendations of the participants.

Member checks was another technique employed to establish credibility and control for researcher bias. Interview participants were presented with my understanding of their individual perspectives and given opportunity throughout the research process to review, edit and verify the accuracy of the transcribed and interpreted data. Descriptive data from observations was also presented to participants for review and response. All written and verbal responses were recorded and included in the data.

Since the data of qualitative research are context specific, emphasis is placed on transferability of insights rather than generalizability of findings. Care was taken to provide thick descriptions or a balance between data analysis and data representation. Information in the form of thick descriptions, representative data, and data collection protocols is provided so that the reader can draw independent conclusions about the study and decide whether it is appropriate to transfer the findings.

Dependability and confirmability issues were addressed in a variety of ways. First, at least three subjects were used in this study, analyzing each case separately and then looking for replication of findings across each respondent. Second, observation and interview protocols provided consistency in the collection of data for each case. Throughout the study, the researcher maintained a research journal of all day-to-day activities and research methods decisions, thus accounting for design changes and establishing dependability. Finally, 
confirmability was established when the data, findings, and recommendations were verified as supporting the process of the study.

\section{Introducing the Researcher}

The researcher is the instrument of ethnographic research and thus it is important to understand the experience, beliefs and perspective one brings to the study. Qualitative researchers call this the disclosure of the researcher's lens. The following is an attempt to provide the reader with an understanding of the "lens" through which I view the world, myself, and the topic under study. First I will discuss my personal and educational philosophies, and my view of technology's role in education, then I will discuss the experiences I bring to this study.

My personal philosophy is based upon the ideals I learned as a child: live life to the fullest, respect humankind and the environment, and contribute more to society than you take. Growing up in a household with ten children, these ideals became a part of everyday life. I learned to respect varying personalities and opinions, raise fruits and vegetables from the land, and find pleasure in the simple things of life.

My parents were the greatest influence in my life, teaching me how to live by their example. One of the most important things I have learned is the value of education. Education is a life changing experience. It helps one to appreciate the diversity of the world and to learn to see life through others' eyes. Education is also a lifelong process, for the world is continually changing. It is my personal goal to be a lifelong learner. I hope to continue to learn all I can about the world around me, while still enjoying the marvels and simple pleasures it provides. I believe it is my responsibility to leave the world a little better through respect, appreciation, and contribution to society. Only by trying to learn and understand can one truly appreciate, respect, and contribute to the world in which we live. 
Education is an endeavor pursued by people of all ages and races. I believe that it is through education that one gains a better understanding of self, society, and the world. Whether viewed as an accumulation of specific subject matter or the pursuit of truth, education is the basis for new creativity, scientific and technological advancement, and the transfer of cultural heritage. Education is the source of understanding, knowledge, freedom, self-awareness, and change.

Although often described as what takes place within the classroom walls, education extends far beyond this formal setting into everyday life. Education is a lifelong process that begins when one is born and ends when one perishes. Through the formal education system one can learn to apply the knowledge gained toward making more informed decisions, generating new ideas, and changing the world in which we live.

I believe that technology, like education, is a part of everyday life. Technology is an interwoven part of our society and transcends everything we do to the point of transparency. While I do not view computer technology as a solution to all of the problems in the world or the educational systems, I do believe it provides an alternate, efficient and effective tool for teachers to add to their repertoire of techniques. Computer technologies, particularly the Internet, can provide increased opportunities for research, communication and collaboration thus helping to expand the classroom walls into the world.

I obtained a bachelor's degree in Elementary Education from California University of Pennsylvania in 1989. During the summer following graduation, I worked for the Job Training Pennsylvania (JTPA), a politically funded job training program for economically disadvantaged youth in Washington and Greene counties in Pennsylvania. I then spent one year as a substitute teacher. In the fall I accepted a graduate assistant position working for the Vice President of Administration and Finance at California University of Pennsylvania. I had also worked for this 
Vice President as an undergraduate and saw it as an opportunity to obtain a master's degree while learning more about Higher Education Administration and developing my technical skills. During this time I also retained a position as a nursery school teacher for the local YMCA. Coming from a family of teachers, I had every intention of earning my Master's degree and returning to the elementary classroom. A twist of fate led me into a full-time position as a data systems analyst at California University of Pennsylvania. While based in the Purchasing office, I worked extensively with the accounting, budgeting, and other offices that fell under the domain of the Vice President for Administration and Finance. I continued to work in this capacity and develop my technical skills for five years. I also completed my Master's degree in Education with emphasis in the Reading Specialist curriculum. I was still interested in teaching and took advantage of every opportunity to teach others and even developed and conducted a universitywide training program on the purchasing and budgeting systems. It was this experience that made me realize I had a place in educating adults. So in 1995 , I resigned my position at California University of Pennsylvania and enrolled in the Doctoral program in Technology Education at West Virginia University.

During my first two terms at West Virginia University I worked as a Graduate Teaching Assistant, developing curriculum and conducting workshops on computer technology for the Health Sciences Center. In the summer of 1996, I accepted a Graduate Research Position with the West Virginia K-12 RuralNet Project. In 1997, this position led to a full-time Clinical Associate position developing training curriculum and online courses, and conducting workshops, for participants of the RuralNet project. As of the fall of 2002, I am still involved in developing and instructing technology training and online courses at West Virginia University. 
The emphasis of my doctoral studies is on communication and information systems and their place in K-12 education.

My beliefs, experiences, and perspectives influence the way I view the schools and classrooms in this study. Thus, I have presented the above information in an attempt to assist the reader in understanding my voice in this study and to disclose any perceived biases. The names of the schools and teachers in this study have been changed to maintain confidentiality. 


\section{Chapter IV: Findings}

The purpose of this mixed-methods study was to examine the effects of the West Virginia K-12 RuralNet project on elementary school teachers' instructional practices, including, but not limited to: lesson development, classroom preparation, classroom management techniques, instructional delivery methods, and student assessment. The study sought to answer the following research question: What effect has the West Virginia K-12 RuralNet Project had on elementary school teachers' instructional practices?

Three methods of data collection were utilized; a survey instrument, interviews, and classroom observations. This chapter will present the data as collected via the survey instrument, interviews and observations with interview and observation participants presented as individual cases, followed by a discussion of data.

\section{The Survey Instrument}

The self-reporting survey instrument was mailed via U.S. Postal Service to the population of elementary school teachers completing the yearlong RuralNet training during the 1998-1999 year $(\mathrm{N}=20)$. These individuals were located throughout the state of West Virginia and were teaching within grades K-6 at the time of their participation in RuralNet project. Seven of the twenty teachers responded to the instrument for a response rate of $35 \%$. One additional followup mailing was conducted and individuals were emailed prior to and following both mailings in attempts to increase the response rate. Two teachers notified the researcher that they were no longer teaching and thus unable to participate in the study. One additional survey was returned to sender due to the participant no longer living at the address on file with the RuralNet Project. Results of the survey instrument were analyzed using descriptive statistics.

Demographic Information 
The Demographic portion of the survey indicated that respondents ranged from six to twenty-nine years of teaching experience with five teachers having twenty-two or more years in the classroom (see Figure 1). Both genders were represented with one male and six female teachers responding. Respondents' instructional grade levels included kindergarten, second, third, sixth, gifted K-5 and gifted 8. Respondents were between 40 and 55 years old. Of the seven respondents, five indicated willingness to participate in interviews and four indicated willingness to participate in observations.

\section{Respondents by Years of Experience}

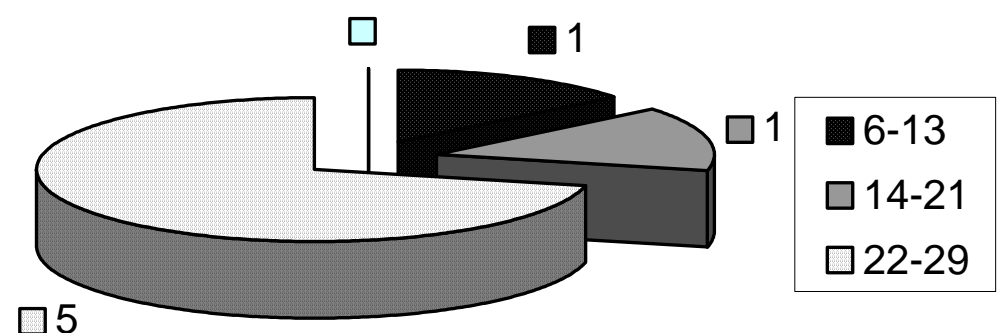

Figure 1. Survey respondents $(n=7)$ by range of teaching experience.

\section{Internet Access}

The Internet access portion of the survey was used to assess participants' access to the Internet from home and school. All seven respondents indicated that they have access to the Internet in their home and at school (see Figure 2). However, school access varied significantly. Figure 3 below, shows a breakdown of school Internet access for each participant. Two of the respondents ( $\mathrm{B}$ and $\mathrm{F}$ ) only had Internet accessible computers in their classroom. Four of the respondents have only one Internet accessible computer in their classroom while the other three respondents have two, four or six Internet accessible computers in their classroom. Five of the 
respondents indicated access to between one and five Internet-ready computers in their library with three teachers only having access to one library computer. Only one respondent (E) had access to a computer lab. This lab contains approximately thirty computers. Four participants $(\mathrm{C}, \mathrm{D}, \mathrm{E}, \mathrm{\&} \mathrm{F})$ also indicated that they had Internet access through the school office.

All seven respondents indicated that they had unlimited access time to the Internet while at school. However, access to a computer does not necessarily correlate to usage. As one teacher noted on her survey, "The computer in my classroom is available to me all day long - 24 hours however, I don't have the time to do a lot of Internet searches."

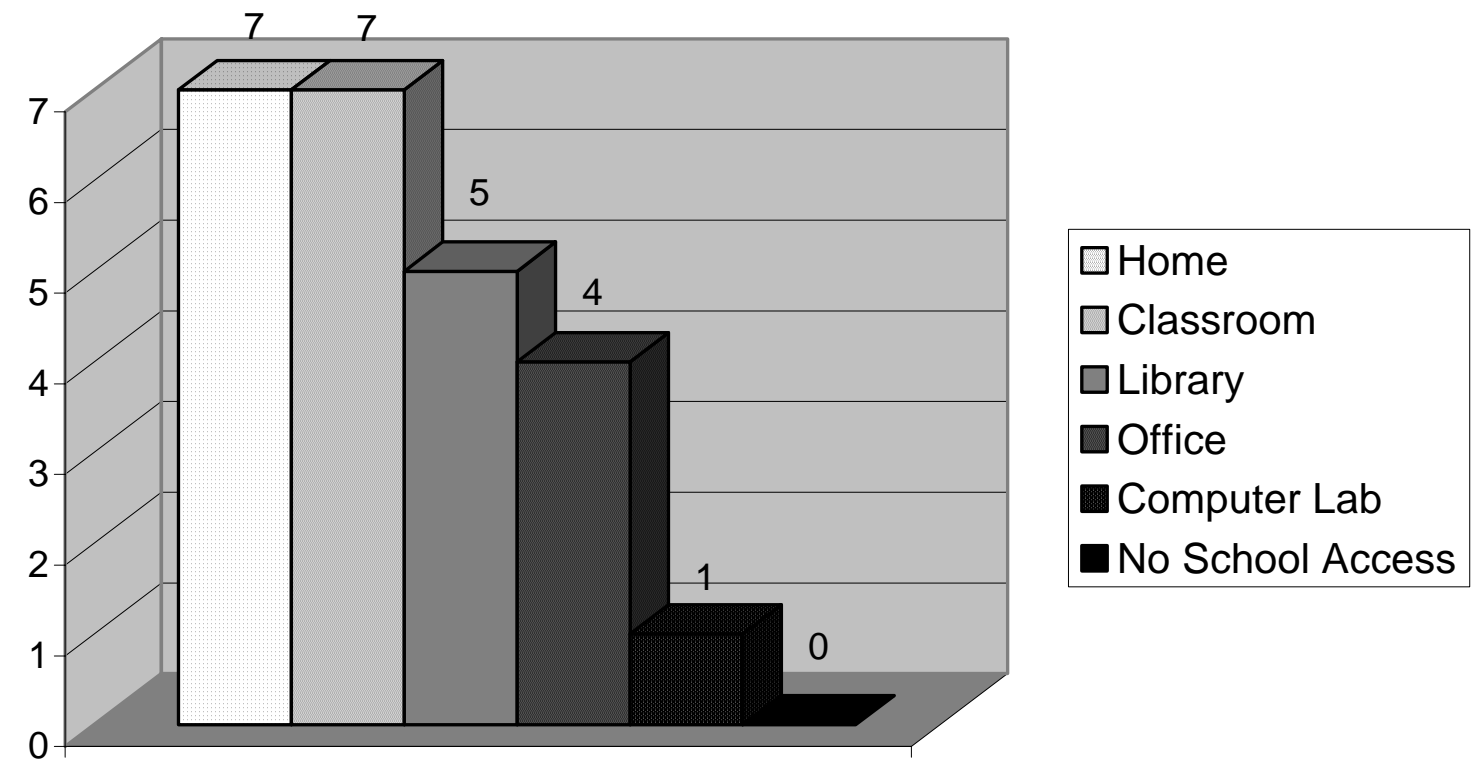

Figure 2. The number of survey respondents with Internet access by computer location. 


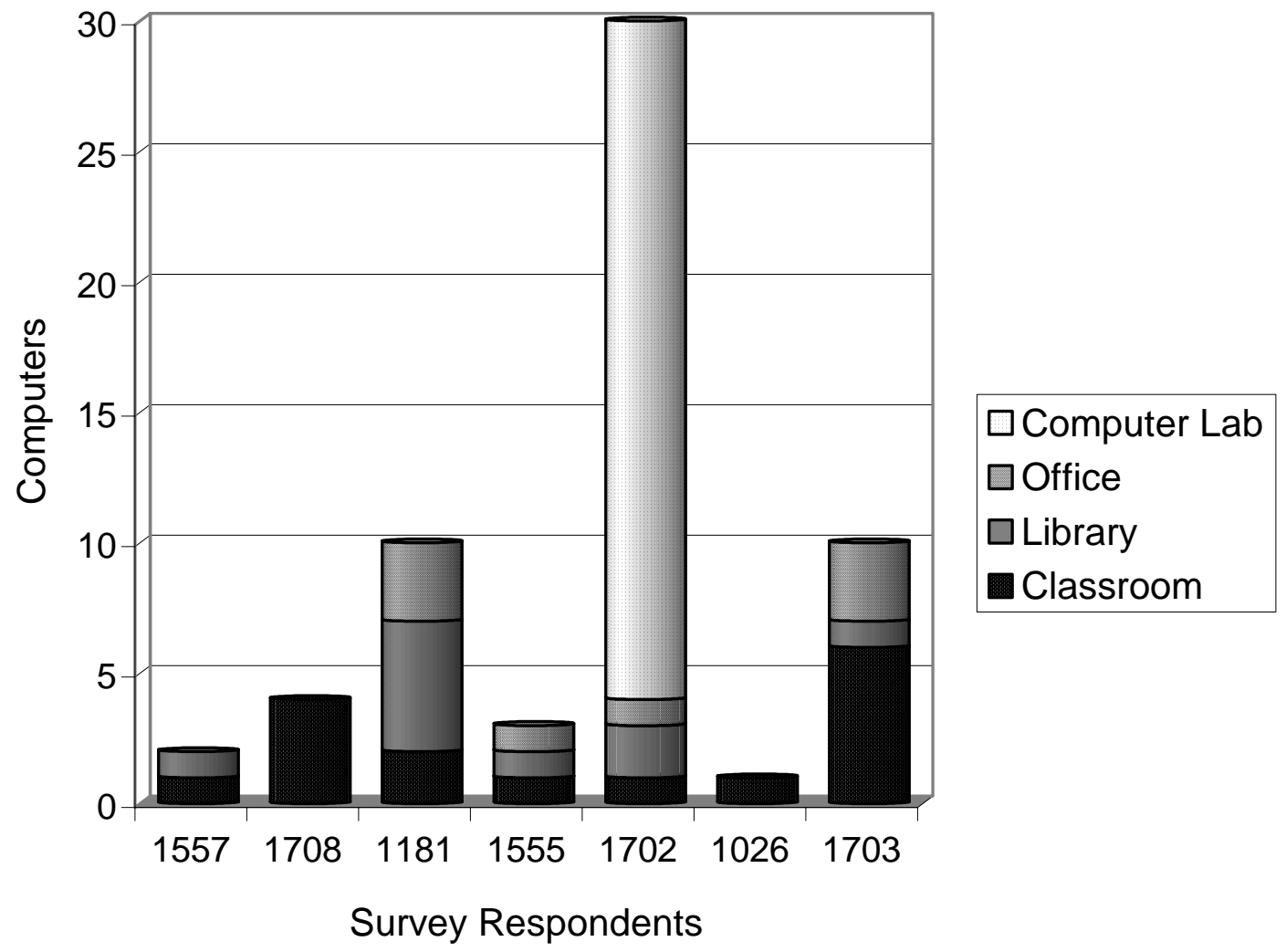

Figure 3. The number of Internet accessible computers available to each respondent by location.

\section{Internet Usage}

Only six individuals responded to the Internet usage portion of the survey. All six respondents reported that they use the Internet with their students for teaching purposes. Respondents' total experience using the Internet ranged from three to seven years, with four of the teachers reporting five years of Internet experience for a mean of five years experience with a standard deviation of 1.264. Experience using the Internet for teaching preparation/resources ranged from two and a half to seven years for an average of 4.417 years and a standard deviation of 1.625. When asked to indicate total experience using the Internet with students, responses ranged from two to five years producing a mean of 4.08 years with a standard deviation of 1.908 . 
It should be noted that for each of the questions on Internet experience, the mode or most frequent response was five years.

In this section of the survey teachers were also asked to indicate if ongoing Internet training and technical support were available to them. Four of the six respondents indicated the availability of ongoing Internet training. Four of the respondents also indicated that ongoing technical support was available to them, however, one noted that the support was self-provided by her sons who are computer engineers. Additionally, four of the respondents indicated that they served as a resource person for other Internet users in their school.

Participants also listed the training they attended and the dates that such training took place. Five of the six respondents to this section listed RuralNet as their first instance of Internet training. Five of the respondents also listed that they have participated in additional Internet training since their completion of the RuralNet project. Although the survey did not ask for additional information, two of the six respondents added comments to this section about the RuralNet project. One respondent noted, "I thoroughly enjoyed the RuralNet classes. I learned more from them than from all of my other graduate classes!" Another respondent writes, "If I had not taken the RuralNet classes, I still would not be able to use the computer in my classroom; I would love to take more computer classes similar to RuralNet.”

\section{The RuralNet Project}

This section of the survey consisted of ten statements about the RuralNet project to which teachers were asked to respond using a five-point Likert type scale anchored by strongly disagree (1) to strongly agree (5). Responses to all questions fell between the (3) neutral and the (5) strongly agree on the scale, with four of the questions receiving all agree and strongly agree responses. 
Responses indicated that the RuralNet project has had the greatest influence on respondents' knowledge about the Internet as a teacher resource and how it might be integrated into the classroom as well as acquisition of locating and retrieving Internet resources. All of the respondents (100\%) indicated that they agree or strongly agree that the RuralNet Project has helped them; 1) increase their knowledge of Internet as a teacher resource, 2) increase their knowledge about how the Internet might be integrated into classroom instruction, 3) become skilled in locating Internet resources, and 4) become skilled in retrieving Internet resources. $86 \%$ of the respondents also indicated that they agree or strongly agree that the RuralNet project has helped them; 1) understand why they would want to integrate the Internet into their classroom, 2) become skilled at integrating the Internet into the classroom and, 3) establish professional collaborative relationships. Responses indicated that the RuralNet project has had the least effect on teachers skills in organizing and managing a classroom where students are involved using the Internet, and in helping them use the Internet in school-based collaborative project instruction with only $71 \%$ of the participants rating these items as agree or strongly agree. Overall, responses indicate that the RuralNet project has affected participants' knowledge, skills and usage of the Internet (see Table 1). 
Table 1

Survey Participants RuralNet Project Question Responses

\section{Question}

Mean Median Mode

4.43

5

the INTERNET into school instruction.

2. The RuralNet project has helped me increase my knowledge about the INTERNET as a teacher resource.

3. The RuralNet project has helped me increase my knowledge about how the INTERNET might be integrated into classroom instruction.

4. The RuralNet project has helped me become skilled in locating INTERNET resources

5. The RuralNet project has helped me become skilled in retrieving INTERNET resources.

6. The RuralNet project has helped me become skilled in integrating the INTERNET into instruction.

7. The RuralNet project has helped me become skilled in organizing a classroom where the students are involved using the INTERNET.

8. The RuralNet project has helped me become skilled in managing a classroom where the students are involved using the INTERNET.

9. The RuralNet project has helped me establish professional collaborative relationships with other teachers via the INTERNET.

$\begin{array}{lllll}4.57 & 5 & 5 & 0.54 & 4 \text { to } 5\end{array}$

$\begin{array}{lllll}4.57 & 5 & 5 & 0.54 & 4 \text { to } 5\end{array}$

$\begin{array}{lllll}4.57 & 5 & 5 & 0.54 & 4 \text { to } 5\end{array}$

$\begin{array}{lllll}4.57 & 5 & 5 & 0.54 & 4 \text { to } 5\end{array}$

$\begin{array}{lllll}4.29 & 4 & 5 & 0.76 & 3 \text { to } 5\end{array}$

$\begin{array}{lllll}4.29 & 5 & 5 & 0.95 & 3 \text { to } 5\end{array}$

$\begin{array}{lllll}4.29 & 5 & 5 & 0.95 & 3 \text { to } 5\end{array}$

$\begin{array}{lllll}4.14 & 4 & 4 & 0.69 & 3 \text { to } 5\end{array}$




\begin{tabular}{lccccc}
\hline Question & Mean & Median & Mode & STDEV & Range \\
\hline $\begin{array}{l}\text { 10. The RuralNet project has helped me use } \\
\text { the INTERNET in school-based } \\
\text { collaborative project instruction. }\end{array}$ & 4.14 & 4 & 5 & 0.90 & 3 to 5 \\
\hline
\end{tabular}

\section{Impact Responses}

The Impact Responses portion of the survey asked participants to check items that applied to changes in classroom preparation and teaching practice as a result of participation in the RuralNet project. A total of seventeen check-box statements were provided, eight of the statements pertained to class preparation and nine pertained to teaching practice. All of the respondents reported that their classroom preparation and teaching practice have changed as a result of participation in the RuralNet Project, with the most change being reported in the area of classroom preparation.

In regards to changes in class preparation, all seven (100\%) of the respondents checked that they utilize the Internet to: find hands-on activities for their students, download materials for classroom teaching/presentations, and download materials for student use, such as handouts. Six of the seven respondents, or $85.71 \%$, indicated that they use the Internet to research class lecture topics and communicate with peers to share information. Five, or $71.43 \%$, of the respondents use the Internet to find collaborative projects for their students. Table 2 shows the number and percentage of respondents that checked each statement pertaining to teaching preparation. 
Table 2

Survey Participants Teaching Preparation Statement Responses

How has your CLASS PREPARATION changed as a result of participation in the RuralNet Project?

\begin{tabular}{lcc}
\hline Statement & Number & Percentage \\
\hline * $\begin{array}{l}\text { I used the Internet to prepare classroom instruction prior to } \\
\text { joining RuralNet. }\end{array}$ & 3 & $42.86 \%$ \\
2. I use the Internet to research class lecture topics. & 6 & $85.71 \%$ \\
3. I use the Internet to find hands-on activities for my students. & 7 & $100.00 \%$ \\
4. I download materials for classroom teaching/presentations. & 7 & $100.00 \%$ \\
5. I download materials for student use, such as handouts. & 7 & $100.00 \%$ \\
6. I use the Internet to communicate with peers to share & 6 & $85.71 \%$ \\
$\quad$ information/ideas. & & \\
7. I use the Internet to find collaborative projects for my students & 5 & $71.43 \%$ \\
8. My teaching preparation has not changed because of & & $0.00 \%$ \\
\hline
\end{tabular}

Note. * Designates a statement indicating use of the Internet for class preparation prior to joining the RuralNet project.

Respondents also indicated a change in teaching practice because of RuralNet participation. See Table 3 for the number and percentage of respondents that checked each statement pertaining to teaching practice. Four of the respondents used the Internet in the classroom with students prior to joining RuralNet, with one of the respondents commenting that he/she uses the Internet "more extensively now." All seven respondents (100\%) indicated that they now supplement traditional textbook materials with Internet materials. Five respondents $(71.43 \%)$ checked that they allow students to use the Internet during class to conduct research, 
and three of these same five respondents, require students to conduct research using the Internet. $42.8 \%$ or 3 respondents reported that; 1$)$ they have replaced traditional textbook materials with Internet materials, 2) students are involved in collaborative learning experiences, 3) more handson activities are being used in class, and 4) more project-based learning is being used in class.

Table 3

Teaching Practice Statement Responses

How has your TEACHING PRACTICE changed as a result of your participation in the RuralNet Project?

\begin{tabular}{|c|c|c|c|}
\hline & Statement & Number & Percentage \\
\hline 1. & $\begin{array}{l}\text { I used the Internet in my classroom with students prior to } \\
\text { joining RuralNet. }\end{array}$ & 4 & $57.14 \%$ \\
\hline 2. & $\begin{array}{l}\text { I allow my students to use the Internet during class to conduct } \\
\text { research. }\end{array}$ & 5 & $71.43 \%$ \\
\hline 3. & $\begin{array}{l}\text { I require my students to use the Internet during class to conduct } \\
\text { research. }\end{array}$ & 3 & $42.86 \%$ \\
\hline 4. & $\begin{array}{l}\text { I have replaced traditional textbook materials with Internet } \\
\text { materials. }\end{array}$ & 3 & $42.86 \%$ \\
\hline 5. & $\begin{array}{l}\text { I supplement traditional textbook materials with Internet } \\
\text { materials. }\end{array}$ & 7 & $100.00 \%$ \\
\hline 6. & Students are involved in collaborative learning experiences. & 3 & $42.86 \%$ \\
\hline 7. & More hands-on activities are being used in class. & 3 & $42.86 \%$ \\
\hline 8. & More project-based learning is being used in class. & 3 & $42.86 \%$ \\
\hline 9 . & $\begin{array}{l}\text { My teaching practice has not changed because of participating } \\
\text { in the RuralNet project. }\end{array}$ & 0 & $0.00 \%$ \\
\hline
\end{tabular}

Note. * Designates a statement indicating use of the Internet with students prior to joining the RuralNet project 
Two of the statements (designated in Table 2 and Table 3 by an *) are indicators of respondents' use of the Internet for class preparation and with students prior to joining RuralNet. Three of the respondents or $42.86 \%$ indicated that they used the Internet to prepare classroom instruction prior to RuralNet, however, one respondent noted, "but it has validated this source of information for me so that I depend on it more and more." Four of the respondents or $57.14 \%$ indicated that they used the Internet with students prior to joining RuralNet. Respondents who indicated both Internet usage to prepare classroom instruction, and Internet usage with students prior to joining RuralNet reported a greater amount of change. Individuals who reported both types of usage prior to RuralNet participation checked an average of thirteen change statements, while respondents who indicated either one type of prior Internet usage or no prior Internet usage checked an average of eight change statements.

\section{The Teachers}

Qualitative data was collected via interviews and classroom observations. Classroom observations of three of the interview/observation participants were conducted so that accurate descriptions of the classroom settings, instructional practices, and teacher participants could be presented as part of the data. Four females and one male teacher were self-selected and participated in the interview process with three of the five interviewees participating in classroom observations. A fourth teacher, who volunteered to participate in classroom observations, was teaching at the $8^{\text {th }}$ grade level and thus did not meet criteria for participation. The fifth teacher, who was self-nominated to participate in the interview portion of the study, did not volunteer for observations. Upon further inquiry, via a telephone call, this teacher noted that she would be more than happy to have me observe her classroom, but with the current technology situation at her school there wouldn't be much for me to observe. Following the 
initial interview and observation, the researcher concurred and dropped her as an observation participant. All interview and observation participants instructed elementary school during their participation in the RuralNet project and each teacher completed RuralNet training during the 1998-1999 training year.

Since issues surrounding instructional practices are tied to the cultural context of the school, the researcher utilized the qualitative methods of interviews and observations to describe rituals, behavior patterns, and cultural phenomenon that are often undetectable through quantitative methods (Patton, 1987). The following descriptions of teachers' behavior patterns and the observed classroom processes are an attempt by the researcher to describe the classroom milieu and situate the data within the context of the school so as to provide a common ground for all readers of this study. While the interview and observation participants and schools are real, the names have been changed to provide confidentiality.

\section{Melissa Sidehorn}

The first interview participant was Melissa Sidehorn. Melissa, an elementary school teacher, was self-nominated to participate in the interview portion of the study. Upon further inquiry via a telephone call, Melissa noted that she would be more than happy to have the researcher observe her classroom, but with the current technology situation at her school there wouldn't be much to observe. Following the initial interview and observation, the researcher concurred with Melissa and eliminated her as a possible future observation candidate.

The information contained below was recorded during the initial visit and interview with Melissa on September 17, 2001 between noon and 3 p.m., and an additional classroom visit on September 18, 2001 from 8 a.m. until 1 p.m. During these visits, the researcher attempted to assess the school and classroom climate, computer and Internet technology available for the 
teacher's usage, and the teacher's willingness to participate in at least five additional observations when she would be utilizing the Internet with her students. Following the initial visits, the researcher was left with the impression that Melissa wanted to assistance with the research because she believed it was a worthwhile venture, but that she was not comfortable having someone observe her Internet usage. Melissa indicated that she did not feel totally qualified to be the technical coordinator at her school and that she felt embarrassment at the fact that she had not been able to use her skills to integrate technology into the classroom curriculum. During regular class lessons Melissa appeared to be relaxed and at ease with the students. In contrast when we discussed technology access and usage Melissa appeared somewhat uncomfortable, she fidgeted in her seat and began to offer excuses as to why technology integration just didn't work in her classroom. She also stressed the fact that she loves computers and was trying to use technology but that things often failed during her attempts to utilize the Internet. Additionally, Melissa stressed her loyalty to maintaining a positive school image by offering examples of other teachers in her district that had much newer and better functioning computers that those located in her classroom. Following the initial interview and observation with Melissa, it was concluded that this experienced classroom teacher often felt overwhelmed and inadequate to perform as the technology coordinator, and that she became easily embarrassed and frustrated when she had difficulty during an Internet-based lesson. Her apparent discomfort, the lack of adequate technology, and the fact that she rarely attempted to utilize the Internet in her classroom and would have to fabricate a lesson for the researcher to observe led to her elimination as an observation candidate.

Melissa Sidehorn was a teacher for twenty-two years. She obtained a Bachelors of Science degree from West Virginia University and a Masters of Arts from Salem-Teikyo 
University in West Virginia. She continued her education to obtain a total of 45 credits above the Master's degree. Melissa spent the last twelve years of her teaching career at Apple Wood Elementary. At the time of the interview, she was instructing at the third grade level. Apple Wood Elementary is located in the southern part of West Virginia and enrolls approximately 400 students in kindergarten through sixth grade. It is one of twenty-two elementary schools that serve a county of approximately 79,000 people.

It was a sunny fall afternoon when the researcher arrived at Apple Wood to conduct the interview. The researcher was greeted at the office and given a brief tour of the building by Mr. Smith, the principal. The tour ended at Melissa's classroom, where the researcher perused the student work displayed in the hallway as she waited patiently for Melissa to "wrap up" a lesson. The hallways were decorated with displays of creative writing papers accompanied by artwork, a butterfly poster and around Melissa's doorway was a sign reading "When you believe in yourself anything is possible!"

After finishing the lesson, Melissa invited the researcher into the classroom where the interview was to be conducted. Melissa's classroom consisted of twenty-five students, most of who were being excused for recess. However, during the interview, Melissa was responsible for monitoring students from all third grade classrooms that had to stay in from recess for varying periods of time to complete late homework assignments or as punishment for poor behavior.

At the far wall of Melissa's classroom stood bookshelves and organization charts. The organization charts were used to remind students of classroom procedures, such as tasks they needed to perform when preparing for dismissal. Located at the front of the classroom were a chalkboard, four computers, and additional bookshelves. On the wall above these items hung a variety of problem-solving posters, a work assistant chart, the class grading scale, and a "steps to 
peaceful conflict resolution" plan. A homework list was displayed on an easel near the doorway. Students' desks were arranged in five rows of five students each. The middle three desks faced the front of the room, and the end desks faced toward the middle. Melissa's desk was located at the back right hand side of the room providing a clear view of the classroom doorway. A table for small group work or student-teacher remediation work was located between the teacher desk and the doorway. Student work was displayed throughout the room and between the four large windows that lined the back classroom wall.

On a typical school day, Melissa's students arrived around eight o'clock in the morning. Students would proceed to the cafeteria where they ate breakfast and then returned to the classroom to complete some independent morning work. Organized class time started at 8:30 a.m. with language and spelling. On alternate days, students attended physical education or music classes from 9:40 a.m. to 10:10 a.m. This was followed by math and reading instruction until noon. After lunch, students participated in the Accelerated Reader program for approximately thirty minutes. In the Accelerated Reader program students choose books and read them at their own pace. When they have completed reading the book, students use the computer to take a quiz that results in an individualized feedback report for the student and the teacher. From 1:00 p.m. until 2:30 Melissa instructed her students in science, math, and integrated subjects. The school day ended with recess and then student dismissal at 3:15. Melissa's classroom technology consisted of what she describes as "four old PS 25s". Three of these computers were connected to the school sever and utilized for basic skills programs and testing purposes. The other computer, a Compaq, was configured for the Accelerated Reader program testing. The classroom Internet connectivity was also limited to the one Compaq computer that was mainly used by the instructor. Melissa commented that others in 
the school had more technology access, "A couple of first grades have three of the larger multimedia computers ... and a couple of the higher grades have three or four computers that have Internet access."

Melissa's first Internet training was the RuralNet project in the summer of 1998, which she attributed with "getting the ball rolling." She followed this up with Phase 9 Technology Standards and Policy 5100/Phase 9 Training offered through the West Virginia Department of Education. During the summer of 2001 she took a class on integrating technology into the math curriculum at Marshall University. Melissa has also taken two online classes through Connected University. One of the online classes was teaching with one computer in the classroom, offered through Tom Snyder productions and the other course was on integrating technology with multiple intelligences and the instructor was Walter McKenzie. Melissa also commented that she subscribes to Walter McKenzie's "Surf aquarium” listserv that she was introduced to during RuralNet.

Melissa stated that the RuralNet project was "appropriate training offered at the right time" and attributed it with stirring her interest in technology. Melissa viewed her RuralNet experience as "a good foundation and a good way to start because it gave me a lot of technology and computer information in windows and Microsoft and all those things, as well as, navigating around the Internet. So it gave me a good basis to start with.” In addition to providing a good foundation, Melissa commented that she "really enjoyed the [RuralNet] online courses where you talked and communicated on the web server." She also mentioned that she would like to have seen the RuralNet project continue and provide teachers with additional skills, noting the need for RuralNet and basic skills training in her county. 
Melissa felt RuralNet had impacted her classroom instruction because "it was an introduction to the Internet and using the Internet for education." She went on to comment on her Internet usage, " I do use RuralNet and the listservs that we were introduced to us as sources of information for classes, and I do use it to find information to include in my classroom." When asked if RuralNet had impacted the way she manages her classroom, Melissa replied, "No, I can't really think of how it's affected management because in my school we don't have a [computer] lab." She went on to discuss how the impact of the RuralNet project and the other training she participated in has been low, noting that the problem lies with instructional mandates and the lack of a computer lab.

“In my school we don't have a lab. We don't have room and therefore, our computers are in our classroom. It's very difficult in the lower primary grades to use three or four computers. You can do centers but you still have so much nowadays that has to be taught. Technology and even integrating it is farther down on your ladder because you have so many things that you are mandated that you have to get in."

Melissa went on commenting about the technology problems as they extend beyond the classroom into her school and the entire school district.

"All the elementary schools in the state, the contract was up on our basic skills machines. We're in the second year that it has been expired and they were offered a new contract on a new program, but the cost of doing all of that is prohibitive in that, how much money do you bring in and how do you start and distribute this amount of funds throughout the county?... the new programs have to be put on new computers so the old ones will have to be pitched. How do you purchase new computers for all classrooms from K to six? So our county person has had to say, 'okay, maybe we can have this small school and maybe a medium school and then we've got these three or four big schools', which we are one of...'we're going to have to do just one of those per year'. So it may be three or four more years before we get the new products, and with the technology evolution, where is that going to be in three or four years?" 
Melissa was well versed on the complexity of technology problems at her school because she serves as their "technology person". The "technology person" job entails keeping inventories of all the equipment in the building, writing the school technology plan and doing the paperwork that goes with keeping up with all the equipment. Melissa remarked that she has full support of her school principal in regards to the technology and that he often assists her by taking care of filing work orders. She attributed RuralNet with impacting the skills she needed to be able to serve as the technology person, but noted that she lacks computer hardware skills. "I'm the technology person here and I'm not well equipped enough to handle the computer hardware problems. I feel I should know how, but I don't want to take on another responsibility. Yet I'm sort of tied with needing it [training on computer hardware]."

When possible, Melissa has attempted to integrate the Internet by projecting materials for her whole class to view, but due to technical issues this hasn't always been feasible. "We're studying the water cycle so we I went into the burningpop.com site and we watched one of those little movies. When I started into the second movie, I got cut off [disconnected from the Internet]... that was another glitch in the system." Melissa expressed that having a classroom helper to assist in monitoring the students utilizing computers would be "gold". She also believed that some of the school technology access problems could be alleviated by the use alternative technologies such as the "new wireless labs." "The reality of our situation with the computers in the classroom limits what you can do and that was the reason I took the class online about working in a one computer classroom." In hope of helping to resolve some of the technology problems her school faces, Melissa has begun pursuing technology for her school in a variety of ways. She applied for an Allegheny Power grant of $\$ 30,000$ to purchase a wireless lab, and also looking for funds to purchase a "PC/TV". "I' $m$ hoping that we can get the PC/TV 
for our school and the connection hook up to the PC and then put it on a cart that we can move around on this floor."

Melissa described her students' computer access as “about 50-50.” Meaning there were $50 \%$ that did and $50 \%$ that didn't have computers. Students at her school had some exposure to computers because" they start out in kindergarten all the way up to sixth grade doing Writing to Read type programs." Once students reach fourth grade they use a program entitled 'Dream Writer' to work on their typing skills. Melissa felt that there were a few students at her school who are "really up-to-date on the technology and that do surf the Internet." Melissa also stated that she believes it is important for her to "keep updated on all the things that are going on educationally with technology and what's going on as far as technology in our world."

When asked what she would include if she were planning the next RuralNet session, Melissa commented on the need to know more about the hardware and the software, "There are just little glitches that someone will say come and do this or look at this and why isn't this working and how do you get into here and how do you go into there." She commented on the need to know these items because it is difficult to get technical support, "we rely so much on people coming to help and they just can't come and help. So it's a good a thing to have how this connects and what this does and where to connect and that stuff." While she believes that her skill level is somewhat advanced, Melissa comments that there is still a need among her colleagues for basic software training:

"Just some good computer basics and maneuvering around windows and files and folders because, I have that knowledge but I find that there is a good percentage who don't, and they are always saying can you give us workshops on this or that and we still have many, many who do not have Office and do not work with a program like Office." 
Melissa appears to be highly committed to her school and to improving the technology situation there. She does not view technology usage as another mandate but rather as something personal, "I just found something that I have an interest in, so I love technology. I like computers and working on them."

\section{Beverly Hand}

The second teacher to participate in interviews was Beverly Hand an eighth grade teacher at Moon Ridge middle school located in north central West Virginia. Moon Ridge enrolled approximately 420 students and was a participating Professional Development School with the Benedum Collaborative of West Virginia University. The initial interview and observation took place on September 19, 220 from 8a.m. until 3:00 p.m. Since Beverly's teaching assignment was now at the eighth grade level, she was not eligible to participate in the recurring classroom observation portion of this study. Although Beverly was not eligible to participate in the extended observations, she maintained email contact with the researcher throughout the 20012002 school year. Through the email communications Beverly shared her continuing struggles to obtain and upgrade computers for her gifted classroom. Beverly was able to utilize faculty senate monies to purchase parts and rebuild some old computers and by January 23, 2002 had one computer connected to the Internet.

Beverly had been teaching for seven years and just this year moved to teaching the eighth grade, gifted classes at the middle school. Prior to this year, Beverly worked in the same county teaching gifted grades one through sixth at various schools. She noted that as a specialist she “tends to move around quite a bit." Beverly's educational background consisted of a Bachelor's degree in education from Fairmont State College in West Virginia, a Master's degree with a Reading specialization and she has completed a specialization in the Learning Disabilities 
curriculum with the exception of student teaching. She indicated that she might pursue a doctorate degree in the future.

In addition to her university training, Beverly has attended many technology-training classes. Her first training, outside of her university degree classes, was the RuralNet Project in 1998. She followed this with the High Tech Consortium's Policy 5100 advanced and Integrating Technology into the Curriculum workshops. Additionally, she participated in a writing project and took a course on Web Page Design. Beverly felt that by the time she participated in the RuralNet project she already had "a good bit of experience with the Internet and computers". However, there were many things that she learned through participation in the project, noting that she acquired 'email skills' as well as 'site evaluation' and 'classroom management techniques'. She also commented on the benefit of networking with other professionals, "Being involved and talking with other people using the Internet and seeing how they were doing it helped a lot."

Beverly's school day began around 7:50 a.m. when she arrived to prepare for the day. At 8:15 a.m. she attended an eighth grade team meeting that lasted for approximately thirty minutes. This team meeting actually took place during the school's first instructional period. Beverly students arrived during the second school period with a different group of students arriving during third period. This was followed by lunch and then office duty. During office duty, Beverly ran the school office so that the regular office staff could take a lunch break. After office duty, Beverly taught three additional class periods of gifted students. Her day ended with some additional planning time. Beverly typically had no more than eight students in her class at any given time. She was responsible for teaching English, reading, language, math, social studies, and science. Each of her students had an Individual Education Plan (IEP) that outlined 
individual goals in all of the content areas. Beverly's job as the gifted instructor was to assist students in meeting the goals outlined in the IEP.

When Beverly joined the RuralNet project in 1998 she already had "a good bit of experience with the Internet and computers." This experience primarily included Internet searching and developing PowerPoint presentations but nonetheless was impacting her instructional preparation. Beverly already "drew a lot of lesson ideas" and did most of her research in preparation for classes on the Internet "I very seldom go to the library anymore, I use the Internet almost exclusively." Beverly perceived the email instruction to be beneficial, but what she found to be the "most helpful" was the evaluation of [Internet] sites, discussions about classroom management and the networking with peers. "Being involved and talking to other people using the Internet and seeing how they were using it helped a lot."

When asked to describe the impact of her experience in the RuralNet project, Beverly described attitudinal as well as instructional implications. Attitudinally, RuralNet affirmed or "validated" what she was already doing with the Internet in her classroom. "A lot of times you hear that things off the Internet are maybe not quite so reliable, but knowing that a lot of other educators were using it as much as I was...it made me feel better about the extent to which I was using it [the Internet] for classroom instruction.” Instructionally, Beverly feels that her participation in the RuralNet project "really helped" her with classroom management issues and that she began to use a projection device to do more whole class presentations of Internet materials. Beverly stated, "The two years following Rural Net I did so many lessons off the Internet that it's hard for me to think about things that I didn't connect with the Internet. With gifted kids they have a lot of interest in computers anyway and it just kind of added to everything 
that we did." She went on to say that the Internet meshed really well with the project type work that she already did with her gifted students.

From a student's perspective, Beverly stated that the RuralNet project impacted the classroom because computers became a part of everything they did. "I can't think of anything that we did, that we still do, that doesn't include computers in some way in part of the project." She noted particularly a change in the application of computer technologies in the math and science content areas. "I really didn't apply computer use as much to math and science as I did after Rural Net because I really hadn't thought about it in those areas. I saw a lot of uses for it in presentations and things with language and social studies, but not as much with math and science until I did Rural Net." She also mentioned that the student's particularly enjoyed the collaborative projects that they participated in as a part of RuralNet. Beverly went on to explain that as she believes the increase in computer use resulted in more kids becoming computer literate and sparking their interest in learning: "I encourage more and more computer use and I had more kids that were computer literate because we were doing more things like that in class. I would have kids that would come back in the fall after having them for a couple years and say, 'well, I took a class in summer.' I never had that before.” This increase in computer use may also be attributed to how Beverly approached utilizing new technologies in her classroom. She indicated a belief in learning with the students rather than being the technology expert “... I'm the type that if I don't know how to do it perfectly it doesn't bother me to pull it out in class and say I don't know exactly how to do this but we are going to try it anyway."

As the interview was wrapping up, the researcher asked Beverly if there was anything she wanted to add. She stated that RuralNet was a "good project" and then began to discuss the technology problems that she is currently facing. "My only problem with technology now is just 
the limited access. That's my biggest problem." While they do have five or six Internet drops in the room, no furniture or computers were present when Beverly arrived at the beginning of the school year. "I came into this room in the fall. There were two tables in here, no furniture, no computers and I kind of had to scrounge for computers." The computers that she obtained were "older" and needed to be serviced. At four weeks into the school year they were still not "up and running" at what Beverly thought of as an acceptable level. Beverly went on to discuss the computer access problems in more detail, describing how she is trying to alleviate some of the problems by bringing in her personal equipment. "On the cart I had a TV that has a TV S video but I don't have a computer that has that capability. So what I'm doing is, I have an old computer at home that I'm getting the card for so that I can project it on to the TV. We're starting CVS projects and I need to project and I can't. So that's our biggest problem is just the lack of technology."

Beverly also described budgeting problems faced by specialists in her county.

"When you talk about specialists and through special ed, that's where it seems to me there is a lack of technology. We're told to talk to Tracy Tremo [District Coordinator of Information Systems and Technology] about computers and she suggested that I put it on the special ed. budget. Our special ed. budget has been made up for the next five years, so my request would be six years from now. It would be the first time they'd consider anything like that...I know the money is there, it's just very slow.... you have teachers who train, I did the technology classes and I'm ready for phase 9, but in order to do those things in the classroom you have to have the tools here to do it with, that's a problem."

Not only is Beverly faced with a lack of access due to budgetary reasons, but also from moving around schools in the district. Moving from school to school exasperates her access problems because she can't take the technology with her, resulting in the mismatch of technology and training.

"Moving from one school to another is a problem because I had an Internet computer, a nice hook-up and had that S Video out but I couldn't bring it with me 
so I left it at my school. So there is a teacher over there that is not trained to use it, that doesn't know how to use it, and I'm here with the training and I don't have access to the machine."

Beverly expressed that she is exploring ways to supplement the technology in her classroom and help alleviate some of the access problems.

"Now I'm looking for classes where I can take a class and get a computer again. After seven years of being around the county and doing that, that's the hard part you know. You do have trained people, but the moving around and things; you may be in a position where you don't have access to it [technology]. A lot of us provide a lot of technology from home to our classrooms."

As a follow-up, Beverly was contacted in December; she was still without Internet capability. It was January $23^{\text {rd }}$ before Beverly notified the researcher that she was finally “online”. Beverly, once again offered to prepare some lessons for observation, stating that she wanted people to know the technology situation in special education classrooms. Unfortunately, eighth grade is considered middle school and thus she was not eligible to participate in observations.

Jon Tarp

The initial interview and observation of Jon's classroom took place on November 16, 2001 between the hours of 8 a.m. and 3:30 p.m. Five additional observations were conducted twice a week in late January and early February of 2002. Three observations were of the fifth grade students who attended class on Monday and Tuesday. The other two observations took place on Wednesday and Thursday when the fourth grade students attended class. These observations lasted from 8:00 a.m. until 1:30 p.m. Jon instructed first, second and third grade students Monday through Thursday from 1:30 p.m. until 3:00 p.m. Although he did not utilize the Internet during these times, the researcher observed instruction during this time on two different occasions to collect data on classroom culture. 
Jon Tarp has been teaching for 26 years, 23 of which have been in special education at the elementary level. At the time of the interview, Jon taught intellectually gifted students in grades one through five at Samson Elementary. Samson Elementary, located approximately 30 miles outside of the state capital of Charleston, enrolled about 480 students. A low-income housing project was recently built nearby and so enrollment has been growing, resulting in the use of portable classrooms to accommodate the addition of a kindergarten and two new special education classrooms. Jon and the other special education teachers' classrooms were located in the portables.

Leaving the main elementary school building and entering the portable building that served as Jon's room, the researcher immediately realized that this was no ordinary classroom. In place of traditional desks were a series of small tables. Student projects and artwork adorned the walls and bookshelves of the room. Maps hung from the walls, models of Mayan temples sat atop the bookshelves like hats and papier-mâché whales dangled from the ceiling. Along the far wall of the room were four multimedia computer stations, two printers, a television, and a VCR. Also located in the classroom were a globe, a stereo and a white board. When the weather permitted, Jon and his team teacher Sherri liked to prop open the classroom door, letting in a lot of fresh air.

Jon's day began each morning when he arrived at school around 7:30 am, deposited his 'bag' on his desk and reported to the school cafeteria where he had breakfast duty until approximately 8:30 am. Students began arriving between 8:30 and 8:45 am, but the students and teaching day varied. His class sizes ranged from four to eighteen students, some of who were bused in from surrounding counties. Monday and Tuesday from 8:30 a.m. until 1:30 p.m. he taught 5th grade, Wednesday and Thursday from 8:30 a.m. until 1:30 p.m. he taught 4th graders. 
On Monday through Thursday each day from 1:30 p.m. to 3:00 p.m. 1st, 2nd, and 3rd graders could be found in Mr. Tarp's classroom. These students arrived at 1:30 and ate lunch with Jon ‘and Sherri then proceeded into class work. Friday's were considered in-school or in-county days where he and his team teacher went to other home schools and worked on team game plans for the county, wrote Individual Education Plans (IEP), or had IEP meetings. Periodically, Fridays were "special" days when a guest presenter delivered training sessions or often Mr. Tarp would give a special presentation to another classroom.

Jon appeared relaxed and 'at home' in the school as he talked and joked with the students, custodians, teachers and even the assistant principal. While leaving breakfast duty one morning, Jon went into the school kitchen and emerged with a bowl of orange slices that he shared with the other teachers and the office staff on the way to his portable classroom. He was highly committed to the school, serving as the basketball league coach, soccer coach, high school ski team sponsor, and head of the school's technology team. In addition to these activities, Jon taught home-based students and managed the schools "snack money". Snack money was money raised from vending machines sales at the school and then used to purchase equipment. Jon said he did all of these things because he "loves to teach".

Jon holds Bachelor's Degrees in speech pathology and special education with a specialization in gifted education as well as a Master's Degree in K -5 Education from Marshall University. His computer experience and training dated back some twenty years ago to when he taught his students basic programming on an Atari system. Jon has participated in the RuralNet project and county sponsored training sessions for the last five years. He viewed his RuralNet experience as "very positive" and has continued to utilize the RuralNet resources. Jon particularly liked the training format that combined online and face-to-face meetings. "I got to 
work in the privacy of my own home and then meeting every once in a while like we did, I really enjoyed that." Jon commented on his and other teachers' use of RuralNet online materials. "A lot of different things I found on the RuralNet site I use in the classroom. You know, ... other people I know in the county who went to RuralNet have done the same things. They talk about how they use little snips of information here and there in the classroom." He went on to comment specifically about the notebook provided to RuralNet participants. "My RuralNet book has become a trusted companion of mine. It's the book I keep coming back to every once in a while and getting something out or getting something that makes a pretty good example. I ask myself, how do I do this one thing, you know? And I have to search my mind and if it's something on the Internet or a search engine I know where I can find it. It's a very good resource guide." Jon said that if there were to be another session of RuralNet it should include more information on how to better define Internet searches. He also suggested that teachers need more experience with troubleshooting and maintenance items like how to clean a mouse and taking care of printers.

Jon believed that his RuralNet experience has impacted his classroom instruction, lesson planning and classroom management because, "It started to change our perceptions of how a classroom was set up." One of these changes included the use of Internet resources rather than books. "The amount of information at your fingertips is amazing. Kids will be on the Internet and use searches and quickly locate materials instead of looking in a book. They look at sites and find the information they need and get a copy of it and put it in a book or write it down on note cards." Now that Jon was relying on students using the Internet for research, he has had to change the way he writes his lesson plans and manages the classroom. Classroom activities were mainly structured in the form of stations with at least two stations involving Internet 
activities. Additionally, he had discovered that more and more of his students access the Internet during their free time, "They run over here on the Internet and look at a new game site or look up things we are studying or a weather site, so it has really changed the way our kids look for information or handle information."

Samson elementary school is technologically rich, each classroom has at least four and sometimes as many as six Internet accessible, multimedia computers. There are three or four scanners and multiple digital cameras also available to the teachers. Jon and Sherri tried to utilize the available technology and create a classroom based on Internet research and resource. At the beginning of the school year they planned a Caving Unit for first, second and third graders and wanted to use the Internet for a lot of the research. However, with the move to the 'trailer court' (their name for the portable classrooms) Jon and Sherri found themselves without an Internet connection. The Internet drops had been added to the classroom, but it was not connected to the router and cable needed to be strung out of the room to the main building and hooked to the server. Jon found his classroom without Internet access until January of 2002. Jon's classroom activities are structured in the form of stations that the students rotate through as they research and study various topics. The younger students had studied caves, while the fourth and fifth grade students participated in "The Voyage of the Mimi" projects. The "Voyage of the Mimi" is an interdisciplinary video series that combines a storyline with minidocumentary expeditions to develop science, math, and social studies skills. Throughout the voyage, crewmembers construct hypotheses, make observations and measurements, and collect and analyze data. The Mimi is the name of the converted tuna trawler outfitted as a modern ocean-going vessel. Fourth graders participated in the thirteen weeklong Voyage of the MIMI I, which focused on whales and survival skills. This voyage followed the adventures of the crew of 
the Mimi as it was chartered to two scientists who were studying humpback whales. As part of his or her project, each student selected a different type of whale to research. Students were the expert on their whale and presented it via a PowerPoint presentation. They also used the information they gathered on the whales to create whale quatrains, whale drawings and paper mache whales in addition to maps of the MIMI I voyage, pictures of the sailing vessel and survival kits. The fifth graders studied the MIMI II, the Mayan Adventure. The twelve episode Mayan Adventure was based in the Yucatan Peninsula where a group of scientists were searching for the "lost" city of the ancient Maya Civilization and tracking looters. As part of the MIMI II project, fifth graders created PowerPoint presentations on various aspects of the Mayan culture and environment of the classic period. The presentations included pyramids, birds and animals, plants and trees, religion and everyday life. They also used Popsicle sticks to create Mayan temples, and drew maps of the Yucatan peninsula. Although the students were at different instructional levels and were studying different topics, the instructional format and use of learning stations was consistent across grade levels.

Classroom observations took place throughout the fourth and fifth graders Voyage of the MIMI projects. Each day's activities were very similar as student's rotated through the various learning stations working to complete their projects. In order to avoid repetition, the researcher selected to present examples from observations of the fourth grade class, but has included reactions to the entire observation process.

Each student in Jon and Sherri's classroom had a class binder that consisted of various items including, note cards they were using to record information for their research projects, computer diskettes, and instructions on how to accomplish various tasks on the computer. In preparation for the day, Jon and Sherri would randomly group the students by placing each 
student's binder on one of the tables. As the students arrived they would find their binder and take a seat at that table, as everyone found their seat, they also discovered who was to be in their group for the day. Typically, the students were placed in four or five groups of three, depending upon the number present that day.

The classroom environment was very relaxed. As the students came into the classroom, they hugged the teachers and took their seats. Since students were bused in from other districts, Jon and Sherri liked to begin the day with free time, in order to give the students a chance to unwind from the long bus ride. The classroom was filled with chatter as the students and teachers made small talk about skiing trips, the weather, math field day competitions, and the spelling bee competition. Teachers acknowledged special achievements or awards given to any of the students over the past week. Students were encouraged to interact with each other and were allowed to have snacks. Some student began looking through books to get a jump-start on their research and others were playing games. After about fifteen minutes of free time, the students were told it was time to get started for the day.

On this particular day, Jon and Sherri gained the students' attention by asking how many note cards of information everyone had completed for their research project. The student with the most note cards got to spend extra time at the Internet station, searching for information for a research report on whales. Next, Jon began the lesson by playing a Voyage of the MIMI video clip. Each day, they began by playing the video clip to see what happened to the crew on their journey. The students and instructors then discussed the video and reviewed any new terms. For example, the captain of the ship on the Voyage of the MIMI I video had fallen into the water and suffered from hypothermia, so they discussed the definition of hypothermia and how it was treated by the crewmembers. 
Following the video, students were given instructions as to where they would begin their learning station rotations and were reminded of classroom etiquette. Classroom etiquette included items such as remembering to work as a team and not to excluding anyone from a group, reading the directions and staying on task. Each day's activities were divided into five stations, Internet Research, PowerPoint, maps and navigation, quatrain, and problem solving. A timer was used to alert students when it was time to change stations. The Internet Research station consisted of two computers that the students utilized to research their whale and print or download text and graphics. These same two computers were also used for the PowerPoint station. At the PowerPoint station, the students worked on their presentations by inserting text and graphics that they downloaded from the Internet or recorded on note cards. The maps and navigation station consisted of one computer on which the students worked as a group utilizing the Lost at Sea software. In this educational game, students take the role of captain of the ship. They are lost and must use the provided tools and clues to plot their location and radio the coast guard to find them. This software game was designed to promote problem solving and teamwork. The fourth classroom computer was reserved for the student who had completed the most note cards to work on as needed. At the quatrain station, students used the information they gathered on their type of whale to develop a quatrain. At the problem solving station, students completed an activity sheet on problem solving and survival skills. This activity sheet varied each day.

Each student worked at his or her individual level. Jon and Sherri served as coaches or guides, monitoring student progress, encouraging students and offering help or suggestions to the students as they rotated through the learning stations. For the most part, Jon monitored the computer stations while Sherri assisted students with the quatrain and problem solving stations. 
The division in instructor classroom responsibilities lies in the fact that Sherri specializes in Language arts and is not trained in the use of computers. Thus, Sherri handles the language arts topics and Jon deals with the technology, math, science, and social studies.

The computer stations were grouped together and Jon sat behind the students so that he could monitor their progress and be there to handle things if someone accessed an inappropriate Internet site. Since groups of three students were sharing two computers, students had to pair up and take turns on the Internet and PowerPoint stations. Jon gave the students verbal direction, reminding them as to what they were supposed to accomplish. Students were directed to use the Google search engine to look for information on their whale type. As students found text and images, they would either print or download the materials to a diskette. Students were previously taught how to download pictures and text, but also had written step-by-step instructions in their binder as a reference. When students got a return on their searches, Jon reminded them to check the top listed sites first because they were more likely to produce valuable information. Students sometimes wandered off task and would begin perusing through sites such as Sea World. Jon calmly encouraged them to stay on task. As students were downloading information, Jon would remind them to save the items to the disk drive rather than the hard drive and to change the filename so as to indicate what the item was. Some students saved the websites they found in the favorites or bookmarks folder. When the timer would sound, students at the Internet station opened the PowerPoint software and began creating their slides. Since they had just downloaded materials, they were able to insert them easily into the presentation. Some student referred to their binders for PowerPoint instructions. The timer continued to sound and students moved about until everyone had completed all five learning station rotations. 
The students asked a lot of questions as they worked through the stations. Jon and Sherri redirected the students and encouraged them to find answers to the questions on their own instead of relying on the teacher. Overall, the students seemed to work well together and were highly self-motivated, but needed to be reminded to stay on task. After students had completed all five learning stations, the lesson concluded with another fifteen minute Voyage of the Mimi video segment and discussion. Students then took turns reporting where they were at on their research projects and cleaned up their classroom materials. As the students left the room for the bus ride to their home school, they were encouraged to obtain parental assistance and work on their research projects at home.

\section{Jane Howes}

The initial interview and observation of Jane's classroom took place on October 4, 2002 at Queensdale Elementary School. Additional classroom observations took place the weeks of March 1, 2002 and March 18, 2002 from 8:00 a.m. until 3:00 p.m. each day. These observations were postponed until March due to a variety of technical problems at the school; ranging from cabling upgrades to faulty wiring and inadequate equipment. Additionally the teacher was awaiting arrival of a 30 computer portable lab that she had been awarded through a grant project. Although Jane had attempted to integrate technology into her instruction prior to obtaining the lab equipment, she was excited about the arrival of the lab and had planned a unit that would provide observational data. Thus observations were postponed until March of 2002.

Jane has been teaching third grade at Queensdale Elementary School for the past 27 years. When the researcher inquired as to why Jane had chosen to remain teaching at the same grade level she replied, "I started at the best age. They are old enough to be independent but not too old to be turned off everything you ask of them." Located in north-central West Virginia, 
Queensdale Elementary School has had between 600 - 750 students. Enrollment at the time of the interview and observations was approximately 610 pupils. Queensdale Elementary School was founded in 1872 and originally consisted of a four-room schoolhouse with toilets located outside. In 1952 a new four-room school was built with plans for expansion. Four additional classrooms were added in 1953, but the planned expansion was never completed. Due to school consolidations, Queensdale became overcrowded and in 1977 a new school consisting of fifteen classrooms, office space, and a library, was built. The present day school was a combination of these building, consisting of the 1977 building, eight portable classrooms, a seven-classroom annex with office space and a multipurpose room, and the 1952 eight classroom building that also housed the cafeteria and kitchen.

Jane's classroom was located at the end of a long cement block hallway that was painted white with a row of children's colorful handprints running horizontally three feet from the floor. As you enter Jane's classroom, to the immediate left are student coat racks, bookshelves and three filing cabinets. The teacher's desk was at the back of the room facing toward the center of the classroom. The student desks were arranged in four pods of four desks each. Located on the front classroom wall was a chalkboard with a pull-down projection screen. In the far left-hand corner was a wall mounted television and videocassette recorder (VCR) and a computer printer. A round table with six chairs was also located in this area. As one followed down the length of the wall there was an additional table with five computers. Two of which were Internet accessible via a 10 Base $\mathrm{T}$ line. Bookshelves containing encyclopedias and other texts, math charts, a calendar, and student work adorned the classroom walls. The classrooms were originally intended to be four open classes, but were currently divided by metal partitions. There was a door in the partition located at the back of Jane's classroom that accessed another third 
grade. While they provide a visual barrier, the partitions do little to keep out the noise often resulting in classroom disruptions. During one observation the students in the next room were having music class resulting in Jane's students being unable to hear their social studies lesson.

Typically, teachers checked in for the day at 8:00 a.m. with students arriving in the classrooms at 8:05 am. The instructional day began at 8:30 with an hour-long session of language arts including: language, reading, and handwriting skills. At 9:30 was extended learning center time. During extended learning center time (ELCT), students from various classes were intermixed for re-teaching and enrichment activities. This year Jane had a combination of higher and lower achieving level children and thus needed to develop a wide variety of activities. Students were working on presenting a book report using a skit. Students who had their skit props prepared and had already been videotaped by the instructor were working in pairs at the Internet stations to do preliminary research on next week's topic of bats. At 10:30 students returned to their homerooms and finished up language arts from the morning. 11:00 until 12:00 consisted of a half-hour recess and lunch period followed by mathematics. At 12:45 students participated in special class that is a rotation of art, music, or physical education. 1:30 until 3:00 encompassed science, health, social studies, and read aloud, followed by silent reading. Jane tried to integrate the science, health and social studies as much as possible. Students prepared for dismissal from 3:00 to 3:15 and by 3:30 the students were gone and Jane was preparing to go home for the day.

Jane's formal education was at West Virginia University where she obtained both a Bachelor of Science and Master of Arts degrees in education. She furthered her education to obtain an additional 66 credit hours above the Master's degree. Since 1998 Jane has participated in more than seven technology related workshops. Jane said that it wasn't until 1995 
that she had even minimal knowledge of the Internet. She decided to begin taking some technology courses to learn more and since then has participated in the RuralNet project, Bell Atlantic and High tech Consortium courses, and the week long Phase nine program in Fairmont where she created a unit that was posted on a website. In the summer of 2001, Jane participated in the West Virginia Instep program at Wheeling Jesuit College. West Virginia Instep was a week -long program that trained teachers to use technology for delivering problem-based learning activities. Immediately following the Instep program, Jane headed to Charleston, WV for three days of technology training offered by the State Department. Jane commented that she took all the technology courses because, "I love it. It is really fun and it amazes me." She also expressed the desire to "continue to learn different things" rather than to just "sit and stagnate".

Jane perceived her experience with RuralNet as being very positive. "I thought the summer class was just wonderful. I was amazed at all the things we got into. It was all the things that I was unfamiliar with." She also thought the mentoring was "very effective". Jane felt that teachers still needed training on various email issues such as file attachments and how to avoid getting unsolicited advertising in one's email account. Jane commented on the fact that she hoped a project similar to RuralNet would be available for teachers in the future, "RuralNet was a wonderful project. I hated to see it end and hope they'll do something like it again."

Jane believed that participation in the RuralNet project really impacted her classroom instruction “Initially, I wasn't using the Internet and I probably wasn't using the Basic Skills computers as much as I should have been. I started seeing how things tied in better." The year following her RuralNet participation, Jane had one computer in the classroom, however it was Internet accessible. She describes her instruction involving technology at that point as "gathering four or five kids at the computer to look at a site." A year ago Jane had a group of 
students in extended learning center time (ELCT) that were really low ability readers. Seven of the nine students also had learning disabilities. She found an Internet site that she describes as "excellent as far as the kinds of things they did with kids and the materials one can download." She had the students use the Internet site to pre-read the story because it was in color and then she would print off a black and white copy for them to work with. The results, "It was a huge improvement in their reading skills and I know a lot of teachers who picked the same site and continue to use it." Jane also used the Internet with her ELCT students this year. Since this current ELTC group was more independent than in the past, Jan began allowing them to conduct Internet searches. The lesson started with the teacher and students discussing bats, their environment and their importance. Next Jane and the students discussed what terms they should use for searching. They decided upon bats plus mammals so as to avoid getting sites about baseball bats. The students hadn't performed many Internet searches and had only begun thinking about the logic of searching. Jane did however find some web sites that help kids in conducting searches and planned on using the sites in the future. Jane didn't feel that her student assessment methods had changed very much since her participation in RuralNet. "Probably a lot of what I do is still paper and pencil type assessment. When it comes to a project, we use a checklist or group list to assess. Upfront, ahead of time, it is this is how you are going to be assessed and then we talk about it."

From a student's perspective, Jane believes the classroom experience has become "more fun" since her participation in RuralNet. Prior to RuralNet Jane describes her instruction as "all pencil and paper". She goes on to provide an example of how the Internet can tie in with pencil and paper type activities to make school more interesting. "For example if they are reading something about American Indians in their social studies book, there are tons of websites they 
can go to get almost like a slide show of actually what was there. The pictures would be much clearer than what was in the textbook and a lot more information was available. I think they enjoy it [school] more. They look at something on the web and they are 'wow'." Jane also believes that her students view working on the computer as playing because it is so much fun. "I have to tell them that we are not going to play on the computers, we are going to work on the computers. They consider it play because it is fun, even with Basic Skills it is fun." Jane noted that participation in RuralNet has also changed her professionally. "RuralNet classes have greatly influenced me in my professional growth and development. I gained the confidence to use the Internet as a teaching resource for my kids and myself. It opened my eyes to other opportunities for growth and development through programs such as those developed by the WV High Tech Consortium." As a member of the school's technology team, Jane also found that other teachers rely on her more. "I don't consider myself an expert, but I am the person other teachers come to with questions." She expressed a passion for technology and sharing her knowledge with fellow teachers. "A lot of things that I have done have been technology related and I really enjoy sharing those things with other people because I think it is so valuable to teachers. It [the Internet] is another resource that is basically free."

The first computer technology that Jane had in her classroom consisted of Atari computers with floppy disks followed by Apple IIE computers and then Basic Skills machines. According to Jane, they have been using Basic Skills computers at Queensdale for the past twelve or thirteen years. However, most of these computers have been DOS based with no hard drives or CD-ROM drives. The most recent group of Basic Skills computers purchased at Queensdale did have CD Rom drives and Internet connection capabilities. At the time of the interview, Jane's classroom technology consisted of two Internet accessible computers, a printer, 
a wall-mounted TV and VCR combo, an overhead projector, and three basic skills computers. There was no lab in the school, so Jane applied for a grant from Allegheny Energy in hopes of acquiring a wireless lab for the school. The Allegheny Energy grant program was offered in five states. Schools could apply for funds to purchase technology that was going to be used in an innovative way with grant awards based on school technology needs and the method of integration.

Jane had experienced continual barriers to using the Internet and computers in general during the past school year. Queensdale Elementary School's server was "ancient" and only runs Windows 3.1. It had been down on at least two occasions for 3-4 weeks each time. Most recently, they were ordered to "shut everything down" due to faulty network cabling. On this occasion, the school computers were down for over 3 weeks. In early February the local RESA was checking out the problems. Basically, half of the school was without computer service until new cabling could be installed. Once the new cabling is in place, many of the older machines will be inoperable. Until new equipment is purchased the classrooms affected by the new cabling will have only one or possibly two computers to use. On the more positive side of this dilemma, Jane's classroom was in the section of the building that continued to have Internet and school network access. It was February $27^{\text {th }}$ when Jane emailed the researcher that her wireless lab had arrived, her Internet connection was working, and one could come into her classroom for observations.

By the time the researcher was able to arrange to classroom observations, Jane had been awarded the $\$ 30,000$ grant and acquired a wireless mobile lab consisting of twenty Gateway laptop computers and two servers. The computers ran on the Windows '98 operating system and held approximately a two-hour charge. The grant was for the third, fourth and fifth grade 
students to use the Internet and CD ROM's to conduct research on butterflies and plants native to their area of West Virginia. Then use the information to design and construct a butterfly garden. It was a pleasure to observe Jane's classroom as the student's began working on the laptops and conducting their butterfly and plant research in preparation of constructing the garden.

In preparation for the project, Jane used the Internet to review websites and communicate with other professionals. She contacted a school in Washington DC that had recently developed a butterfly garden and reviewed their website. She presented the idea to the Parent Teacher Association (PTA) and began ordering materials needed to grow the plants. To prepare for the Internet research, Jane created a desktop folder of materials the students would need, including software and Internet sites, and placed it on all the laptops. Jane also arranged for a parent volunteer to be present each day to assist her in monitoring her sixteen students as they worked on the laptops.

Jane began the butterfly garden project by using a projector to display the laptop folder on the chalkboard and walk student through the steps they would have to take in order to access the butterfly garden materials. The first task was for the students to open the butterfly garden folder and access the butterfly lifecycle website. Students were to discover the three stages of a butterfly's life and what a butterfly needs to sustain each life stage. Once students had reviewed the life cycle of a butterfly, they were to use Inspiration software to create a web of the life cycle information. The parent volunteer assisted Jane in passing out the laptops to all of the students. The students had received prior training in how to "boot up" the laptop and so immediately set to work. This was the first time they had tried to access the Internet from sixteen portable laptops at the same time. Due to the school's old cabling, everyone's computer froze as they all tried to access the same website. Additionally, some students' laptops displayed an odd one-inch square 
cursor and would not function properly. Being a seasoned teacher, Jane was able to maintain a good sense of humor telling the students, "You're hair is going to turn gray before that page loads." This quickly alleviated any anxiety and frustration felt by the students and teacher. Since the planned activity didn't work, Jane quickly had the students shut down their laptops and place them back into the mobile lab. As she was collecting the laptops, Jane asked the students to think about the technical problems they were having and then brainstormed with them by asking the question, "What do you think are some reasons we can't access the information?" Each student had the opportunity to express his or her thoughts on the matter.

As an alternate activity, Jane turned the individual research into a whole class review by projecting the website on the wall for all students to see. Jane called on various students to read the lifecycle information aloud while the rest of the class took notes. Jane then projected the Inspiration worksheet and they completed it as a whole class project, with Jane asking questions and students volunteering the information needed to complete the lifecycle web. Throughout the review of the lifecycle site and the Inspiration web, Jane had the students review basic computer skills by asking them questions like: "What do I need to do to get back to the last web page?" or How do I open the Butterfly folder?" Following the lesson, Jane looked at me and said, "Maybe I'm going to need to rethink these lessons". She had already begun to anticipate future problems and was starting to think how she could alter her instruction to alleviate them.

For the second computer based butterfly garden lesson, Jane had once again arranged for a parent volunteer to assist. She began the lesson by reviewing the stages of a butterfly lifecycle and writing student responses on the chalkboard. Next, highlighters and paper copies of text from a butterfly website were distributed for a pre-computer activity to practice reading for information. Jane used student helpers to assist in managing the distribution and collection of 
classroom materials. As Jane read the article aloud, the students listened and highlighted information they believed to be important about the life cycle stages or something needed to sustain butterfly life at a particular stage. Jane paused after each paragraph and asked the students if there was anything in the paragraph they needed to highlight. As the students responded, Jane added the data to the chalkboard list creating a chart of each stage of a butterfly's life and things needed to sustain that stage. She continued reading and having students highlight what they felt was important until they had reviewed the entire article. Students wrote their names at the top of the papers and turned them into the teacher. Jane reminded the students once again that when they accessed the web sites, they needed to read for information not just look at the pictures. She also directed them too take notes either in their heads or on paper, which was the equivalent to highlighting.

Laptops were distributed and the students were instructed to "boot up" the computers and wait for further instructions. To help alleviate some of the computer problems experienced during the last computer lesson, four students at a time were allowed to access the Internet rather than all sixteen at once. Additionally, students were divided into two groups, with each group accessing a different butterfly website. After the students reviewed the website they had been assigned, they switched places with a student in the other group and reviewed the second website. Laptops stayed in place on each student's desk and the students physically switched seats. This was done to avoid students dropping the laptops and also to avoid students having to change websites rather than access the Internet again. While students reviewed websites, Jane and the parent volunteer circulated throughout the room to assist any students who were having problems and to help students remain on task. As students finished reviewing both Internet sites, they were told they could review one of the numerous butterfly activity and game sites contained 
in the Butterfly project folder. Once all students finished reviewing the two websites, they were reminded how to close the web browser and shut down the computer. Jane "wrapped up" the lesson by discussing with the students things they discovered from reviewing the websites that butterflies need at the various life cycle stages. She then distributed a handout on the painted lady butterfly for the students to read and color, on the back of the handout, students were told to list as many needs as they could think of for each stage of a butterfly's life. The day ended with the parent volunteer and Jane collecting the laptops and plugging them into the cart to charge.

For the third Butterfly garden computer lesson, students would be trying to discover butterflies that are native to West Virginia, the host and nectar plants they required and any additional needs for each butterfly type. Using the overhead projector to display transparencies, Jane presented the concept of butterflies being grouped into various families. She then displayed a transparency of each of the websites the students would be visiting and showed them how to access the information they would need to gather. On one website for example, various icons were displayed under each butterfly listed. To read about the butterfly the students needed to click the book icon and to see a picture of the butterfly, the students needed to click the camera icon. After reviewing how the various websites were structured, students were given laptops and a butterfly chart on which to record the information. Once again, Jane divided the students into two groups and had each group review a different butterfly website. The students were very excited and engaged throughout the lesson. They all wanted to show someone the beautiful and unique butterflies they were discovering. The activity had been planned to last about fifteen minutes with students gathering information on six butterflies. But as the students became more engaged and excited, Jane let them research butterflies for almost an hour. The results, most students gathered information on a dozen or more butterflies. As we were gathering the 
computers for the day, Jane looked at the observer and said, "Things went really well today....and to think during the first lesson, I was so frustrated with the computers that I was ready to just not use them anymore."

In preparation for the next phase of computer research, Jane complied all the studentcollected information on host and nectar plants required to sustain butterflies. She presented the data in the form of a Venn diagram with plants that can serve as both host and nectar providers located in the cross-section. Jane reviewed new terms, such as annual and perennial and had the student brainstorm why it was important to know what plants could serve as both host and nectar providers. They discussed which type of plants would be the least expensive to purchase and the reasons it would be important to know plant size when planning a garden. She modeled the concept of plant size by having two students pretend to be plants. She then 'planted' the tall student in front of the shorter student and inquired what would be the problem. They also discussed the need to have plants that bloomed most of the year in order to provide food for the butterflies all season. Once the concepts of plant size, blooming season, cost, perennial and annual had been thoroughly reviewed, students were given a Garden Chart and laptops were distributed. Today students were divided into three groups, each of which was to access a different website. The Internet connect was very slow and the students became a little frustrated while waiting for the site to load. Once the websites had loaded, the students appeared to enjoy the activity and worked diligently to complete their garden charts by recording the plant name, size of plant, growing season, and planting instructions. The following day, the researcher received a call from Jane that her school's computer network was inoperable and she would be unable to connect to the Internet for approximately seven days. 
Once, they were able to access the Internet again, Jane's students completed their Garden charts and then looked up prices for each plant. They were now ready to begin designing their butterfly garden. With the help of a landscaping software package entitled "Flowerscape", students used the Internet data they collected on butterflies and plants to each plan a butterfly garden. They had to computer the volume of mulch that would be required, a list of plants and their growing season, and a price list. Students were then to vote on which garden plan they felt was the best. Master gardeners would visit the school to teach the students about composting, and the PTA had arranged for a consulting firm to develop environmental area for the garden on school grounds. The culminating activity for the project was for students to begin the plants in the classroom and then construct the butterfly garden with the help of parents and financial support of local organizations.

Throughout the interviews and observations, Jane spoke with a tone of excitement and passion in her voice. This same passion was evident as she circulated around the room assisting her students in their butterfly garden research. In fact her passion seemed to rub off on the students as they became engrossed in their work. At times, the students didn't want to shut down the computers and get ready to go home for the day. Many students were holding up their hands waiting for the Jane or the parent volunteer to see what they had discovered. The butterfly garden was a fun interdisciplinary project that allowed students to research, design and create a project that would benefit the school and community.

\section{Aubrey Temo}

The last teacher to participate in interviews and observations was Aubrey Temo. Aubrey's initial interview and observation took place on September 26, 2001 with subsequent observations once a month from December 2001 through April 2002. Although Aubrey was 
aware that the observations were to be of Internet usage, she often did not prepare a lesson or changed the lesson to be non-Internet related. Additionally, she would ask the observer if it was necessary to actually observe the Internet lesson or if she should just discuss what she intended to do with the students. Aubrey had the most technology available for her daily classroom usage, yet the observations lacked richness and depth. Aubrey's displayed apprehension to the observation of Internet related lessons might stem from a variety of reasons. First, Aubrey defined herself as "spontaneous" attributing for her continual change in planned lessons. Secondly, Aubrey views technology usage as taking more time than traditional lessons because of the required organization and planning. Finally, Aubrey is involved in a wide variety of school sponsorships and activities that take away from the time available for her to develop lessons. The combination of Aubrey's spontaneity and view of technology as time intensive paired with her involvement of school activities appears to greatly impact her planning and instruction related to technology usage. The researcher also noted that the observed lessons often seemed fabricated and disjointed from the rest of the day's lessons appearing to be done only for the observer's benefit and not as part of the regular curriculum.

Aubrey was a 1971 graduate of West Virginia University with a Bachelor of Science degree in Physical Education. She graduated from Fairmont State in1983 with an AB in Elementary Education. She went on to further her education and graduated from West Virginia University in 1989 with a Masters degree in Mental Retardation and again in 1991 with a second Masters Degree in Learning Disabilities curriculum. In addition, she obtained instructor's papers in professional CPR and First Aid and she was a state trainer for the life skills program. Formally, Aubrey had been teaching for eighteen years, however, she was a dance instructor during high school and college and taught religion classes within her church system for several 
years. At the time of this study, it was Aubrey's seventh year at West Lane Elementary where she instructed sixth grade English. West Lane is located in north-central West Virginia and was the largest elementary school in its county with an enrollment of 600 students in kindergarten through sixth grade. It is a rural school, modeled after the open-school concept where several classes share a large open area rather than be divided into individual classrooms. This open classroom concept is designed to promote collaboration of students and teachers while allowing each class to remain somewhat autonomous. West Lane has been named a West Virginia Exemplary School, a National School of Excellence, a Bell Atlantic World School, and has been a WVU Benedum Professional Development School for more than ten years.

Aubrey appeared to be a dedicated teacher. She participated as a school representative for the State Departments Safe Schools program. She coached junior and senior high athletic teams and sponsored a Destination Imagination team participating at a West Virginia University competition. She stated a belief in constructivist learning and saw herself as a facilitator for her students learning. She described herself as spontaneous stating, "I like to use teachable moments". She often branched out with items her students found interesting, particularly when they were on the Internet. Aubrey also viewed herself as an innovative teacher stating, "If it's out there I'm going to try it." She often finds herself testing or piloting new technology at the school. Next fall, Aubrey will be piloting a desktop word processing lab in her classroom. These 28 laptop word processors will be used basically for spelling, word processing, and keyboarding skills. Additionally, Aubrey stated that she was a problem solver. She described how other teachers have always come to her with problems because she is "not afraid of trying new things" thus making her "good at troubleshooting." She stated, "I'm notorious for finding other ways of doing things. I'm a real trial and error person." For example Aubrey figured out 
how to access the cable television through the VCR when the television cables weren't working and no one else knew what to do.

Aubrey's typical school day started at 8:25. She joked that 8:25 is the time that teachers are supposed to arrive, but everyone knows that she arrives at 8:25.29 or something there about. “The students are coming in one door and I'm coming in another." From 8:25 to 9:00 o'clock, Aubrey handled "secretarial duties". That's the time that she took role, lunch count, and absences, and collected any forms or monies from students. During this time, she normally had an activity on the board that the students would get involved in. Some students did not participate because they attended breakfast or had hallway patrol duties occurring at the same time. Also, some students were also leaving for speech or choir practice. Although the morning board activity often ended up as "busy work," Aubrey hoped it would "enhance or help them [the students] along the way." On one occasion, the students' morning activity was to write a letter to the rescue workers in New York thanking them for a good job done. Sometimes the students completed word searches, and occasionally a coloring sheet that went along with current topics of study. To assist her "home base" or homeroom students' vocabulary, Aubrey would put a word of the day up everyday for her students to learn. At 9:00 a.m. Aubrey had a planning period. The sixth grade classes are departmentalized, Aubrey was responsible for teaching language, spelling and reading. Aubrey's instructed three language classes each morning at 9:40 a.m., 10:20 a.m. and 11:00 a.m. Language class basically entailed work on English language and grammar. At 11:40 she taught spelling skills, followed by lunch from 12:20 to 1:00 o'clock except for Tuesdays, when she had playground duty. At 1:00 o'clock her home base students returned for a reading class. Aubrey then instructed two additional spelling skills classes at 1:40 and 2:20. Her schedule read that from 3:00 to 3:15, home base students were to have recess, but 
Aubrey noted, "If my students don't get into our home base and get their act together we rarely get to go out. I am going to initiate to read to them during that time while they are getting ready to go home. This has worked well in the past." First buses and walkers were called around 3:17 and by 3:30 Aubrey's official day ended, unless she happened to have evening bus duty, which lasts until 4:00 o'clock. Also, in April, Aubrey had three weeks of morning bus duty. This meant that she had to arrive at school around 7:50 a.m. and monitor students until 8:25 a.m. when they were dismissed to their classrooms.

Aubrey has attended a variety of Internet training projects including RuralNet, Phase 9 Standards, Phase 9 Training, and the Reinvent Project. She credited these programs for her initial interest and involvement with computers and the Internet. Aubrey is on her third home computer and attributed her home computer access to much of her computer use in school. She indicated that this wasn't a planned outcome but happened rather serendipitously. "I think it's kind of like, okay, I bought myself a computer and lets see how far I can go at home and then all these other little things transpired." Aubrey also related that she was exposed to computers in the 1960's during her undergraduate college years, "when the computers took up a whole room and the printers took up another whole building".

Aubrey perceived her RuralNet experience as very positive and noted that she still utilized her RuralNet notebook. "I still use my manual, believe or not. It sits under my computer at home and when I get in a pinch I'll pull it out and think I know I had that somewhere and so it's right there." She noted that the weeklong training was "intense" but "enjoyable". Aubrey felt that one of the most positive points of RuralNet was getting to work on a project that interested her. "We did things that interested us and I think that was the real positive point of it...It was something that we wanted to do and we could approach it any way 
wanted at that particular time, unlike some of the other classes that I've taken since then that you have to follow this guideline and this particular program and what not."

Aubrey felt that her RuralNet experience enhanced her awareness of instructional strategies and available resources. "I think what it did it made me more aware of the fact that yeah this is a route to take. Time constraints being what they are, it's a route to take but we don't always get to take it. I found some really neat sites just by hit and miss." Aubrey noted that she tries to pass what she learns on to her student acknowledging that her students' experiences are "only going as far as she can push them or take them."

Aubrey's classroom is one of the four pods that make up the sixth grade instructional cluster. The sixth grade cluster was full this year with approximately 125 students. As one enters the cluster, Aubrey's classroom is the first one on the left hand side. Partitions provided a meager separation from the rest of the cluster. Along the partition was the teacher's desk and computer. On the left hand sidewall was a bulletin board and shelves. Following along to the corner is a 25-inch cable television and VCR. Along the front classroom wall was a chalkboard and another bulletin board. Above the chalkboard area were a variety of learning aids, including; the alphabet in cursive, parts of speech, and punctuation displays. At the far right of the chalkboard was a door leading to the outside. The next wall, the one to the far right, housed blue cubbies for students to store their personal items followed by tables holding six instructional computers. Aubrey also had a 32-inch television and wireless keyboard on a tall black cart that she was waiting to have set up for whole class projection during Internet projects. The student desks were assembled in the center of the room in six groups of four desks each. Aubrey used a sports motif throughout her classroom, changing the sport to match the sport currently in season. Aubrey appeared to have a trusting relationship with her students. She had them work 
independently while she participated in the interview. When they needed disciplined for being noisy and not staying on task she used sports references such as "you now have two strikes and a foul ball.” The students replied, “A foul ball after two strikes doesn't count.” Aubrey responded by saying, "It was a tip foul and the catcher caught the ball so they had an out." Aubrey never had to raise her voice at the students and appeared to have a relationship with them that was based on mutual respect.

Aubrey was fortunate enough to have 24 Internet accessible, instructional computers in her sixth grade cluster. Six of the computers were located in her direct instructional area or pod, and the other eighteen were located in the remainder of her cluster. Additionally, each of the sixth grade teachers also had an Internet accessible machine for their individual use. When one first enters Aubrey's pod you notice a 32" TV with a wireless keyboard sitting on a tall black cart. She also had a wall mounted 25" cable access television and VCR combo. A computer lab is not available to Aubrey. In the past, Aubrey and the other sixth grade teachers have used designated computer times to accommodate the need for more than six computers at a time. Each teacher could schedule one or two forty-minute periods per week when they may have utilized all twenty-four computers in their cluster. Next year all but two computers will be pulled from each pod and put into a computer lab. Aubrey said that she is anxious to see how well this works.

While West Lane School appeared to be technologically rich, teachers often encountered access problems. For example, West Lane School's Internet access consisted of a T-1 line, but teachers often complained of the Internet being very slow making it difficult to accomplish instructional goals. West Lane School also experienced a variety of electrical problems often resulting in power failure. When electrical failure occurred the server went down and everything 
at the school had to be restarted. Another concern expressed by Aubrey is that some of the computers are much older than others and thus slower, resulting in instructional setbacks as some students fall behind. The 32" TV with a wireless keyboard located in Aubrey's classroom was obtained in May of 2001. Unfortunately, by April of 2002, she still did not have a line drop nor had the Television been wall mounted for group instruction. Aubrey was hopeful that her TV and wireless keyboard would be ready for instructional use by the next school year.

For Internet activities, Aubrey often used all 24 computers in her grade level cluster. She would typically bookmark sites for her students to use but sometimes they wondered. Aubrey did not use parent volunteers, but rather walked between the pods to monitor her students' work. She also relied on her fellow teachers to alert her if a student has accessed something inappropriate. Aubrey said that she didn't have many problems with students accessing inappropriate material and that they typically let her know immediately if they get into something they shouldn't. She attributed this to students in the past losing their Internet privileges. Sometimes, Aubrey grouped her students by two or three around a computer so that she could better monitor them as they reviewed Internet sites. The downside to having students distributed throughout the cluster was that Aubrey had to contend with the other students and classes that were occurring. This could be particularly troublesome and often distracting to both groups of students.

Some activities the researcher observed Aubrey's students participating in, included online Scavenger hunts and writing to an Indonesian girl who had attended their school for four months. They students composed a letter as a group and sent it using the teacher's email account. Aubrey said that many of her students have email accounts of their own and sometimes write to the Indonesian girl from home. Students also completed a poetry unit that lasted for 
about a week and a half. In conjunction with learning about different types of poetry, students used the Internet to view some examples of poetry. On one occasion the students worked in groups of two or three at each computer to add to the poems that they had found. Particularly when working on limericks, the students and instructor would banter with each other. One group would find a limerick and then they would add to it and then another group would find a limerick on a different site. Aubrey would bookmark the sites prior to class, but sometimes they came across a great site by accident and Aubrey would just "go with the flow" of instruction and make use of the "teachable moment".

Aubrey also used the computer to develop and manage classroom materials. She maintained her grade book on the computer and in the past students could access it over the Internet. Unfortunately, the company began to charge for that service so she used it to maintain classroom grades without student access. Aubrey also developed most of her exams on the computer. "That way if the Xerox machine isn't working I can just print the exams off on my printer." She hopes to use the wireless word processing lab next year for her spelling exams. Aubrey will also be utilizing the Accelerated Reader (AR) program with her sixth grade students next year. AR is currently only in the fourth and fifth grade classes. Aubrey has two web pages that she maintains. One page was through the reinvent schools project and the other was through the school's website. She didn't use web pages for communicating homework assignments to parents because she doesn't use a standard schedule. For example, her students didn't get spelling words every Monday and have a test every Friday. Aubrey preferred to be more spontaneous and wanted to allow for teachable moments in her classroom. 


\section{Discussion}

In order to situate the study, this discussion begins with an overview of study participants and their technology access, followed by presentation of data in terms of studydefined themes and emerging patterns. Discrepancies in data collected through the various methods are presented and discussed throughout.

\section{Overview of Study Participants}

Demographic information was collected on both the survey and during the interview process. Table 4 shows a summary of all study participants. The level column indicates level of participation as (S) survey, (I) interview, and (O) observation. All study participants were between forty and fifty-five years of age. The five interview participants graduated with degrees

from a university in the state of West Virginia and reported that they have a Master's degree plus additional credits with one of the teachers having an additional 66 credits above the Master's degree. 
Table 4

Overview of Study Participants

\begin{tabular}{cccccccc}
\hline Level & Participant & $\begin{array}{c}\text { Age } \\
\text { range }\end{array}$ & Gender & $\begin{array}{c}\text { Highest } \\
\text { degree } \\
\text { earned }\end{array}$ & $\begin{array}{c}\text { Years } \\
\text { teaching }\end{array}$ & $\begin{array}{c}\text { Years at } \\
\text { current } \\
\text { school }\end{array}$ & $\begin{array}{c}\text { Current } \\
\text { grade level }\end{array}$ \\
\hline O-I-S & 1555 & $40-55$ & Female & M.Ed. + & 18 & 7 & 6 \\
O-I-S & 1708 & $40-55$ & Male & M.Ed. + & 26 & 14 & Gifted K-5 \\
O-I-S & 1181 & $40-55$ & Female & M.Ed. +66 & 27 & 27 & 3 \\
I-S & 1702 & $40-55$ & Female & M.Ed. +45 & 7 & 1 & Gifted 8 \\
I-S & 1026 & $40-55$ & Female & M.Ed. +45 & 22 & 12 & 3 \\
S & 1557 & $40-55$ & Female & N/A & 29 & N/A & K \\
S & 1730 & $40-55$ & Female & N/A & 24 & N/A & 2 \\
\hline
\end{tabular}

Note: Survey only participants have an N/A in the degree and years at current school columns because these data were collected during the interview process.

$\mathrm{S}$ = survey participant; $\mathrm{I}=$ interview participant; $\mathrm{O}=$ observation participant.

The demographic portion of the survey indicated that respondents ranged from six to twenty-nine years of teaching experience with five teachers having twenty-two or more years in the classroom. Demographic data collected during the interview varied slightly from that reported on the survey instrument. Table 5 shows the years of teaching service for each participant as self-reported on the survey and during the interview process. The three participants indicated with an asterisk had a discrepancy between the years of service reported on 
the survey and the years of service reported during the interview. The Year Discrepancy Note column explains the reason for the discrepancies. Interview participants' number of years at the current school ranged from one to twenty-seven with one teacher reporting that she has spent her entire twenty-seven years of service at the same school and at the same instructional level.

Table 5

Participants' Years of Teaching Service

\begin{tabular}{|c|c|c|c|c|c|}
\hline & Participant & $\begin{array}{l}\text { Survey } \\
\text { reported }\end{array}$ & $\begin{array}{c}\text { Interview } \\
\text { reported }\end{array}$ & $\begin{array}{c}\text { Current } \\
\text { school }\end{array}$ & Years discrepancy note \\
\hline \multirow[t]{3}{*}{$*$} & 1702 & 6 & 7 & 1 & $\begin{array}{l}\text { Survey in summer/interview once school } \\
\text { year started... noted in interview that this } \\
\text { makes the } 7^{\text {th }} \text { year teaching. }\end{array}$ \\
\hline & 1555 & 18 & 18 & 7 & \\
\hline & 1026 & 22 & 22 & 12 & \\
\hline$*$ & 1708 & 23 & 26 & 14 & $\begin{array}{l}23 \text { years teaching Special Education gifted } \\
\text { at the elementary school level, } 26 \text { years } \\
\text { total teaching experience }\end{array}$ \\
\hline \multirow[t]{3}{*}{$*$} & 1181 & 26 & 27 & 27 & $\begin{array}{l}\text { Survey in summer/interview once school } \\
\text { year started...noted in interview that this } \\
\text { makes the } 27^{\text {th }} \text { year teaching. }\end{array}$ \\
\hline & 1557 & 29 & N/A & N/A & \\
\hline & 1730 & 24 & N/A & N/A & \\
\hline
\end{tabular}

Note. * Indicates a discrepancy between the years of service reported on the survey and the years of service reported during the interview.

Teachers in this study were at the middle adult stage of life. They all appeared to be comfortable with themselves as individuals and to have established themselves as professionals in the field of teaching. Five of the seven participants had been teaching school for twenty or 
more years, with the other two participants starting their careers later in life because of a desire to stay at home until their children had grown. All of the interview participants had furthered their education beyond the level of a master's degree. Although continuing education is government mandated, these individuals have discussed a personal desire to improve their teaching skills for the benefit of their students and exceeded state requirements. Some of the participants also indicated a desire to acquire a doctorate degree in their field.

\section{Technology Training}

Information about technology training attended by participants was collected on the surveys and during the interview process. On the survey, participants listed the training they attended and the dates that such training took place. During the interview, participants were asked to describe training or other experiences they have had related to using the Internet. Five of the survey respondents listed RuralNet as their first instance of Internet training. This was confirmed during the interview process, with all five interviewees stating that their first Internet training was RuralNet. When analyzing the surveys there did not appear to be any overlap in technology training other than RuralNet, however the interview process helped clarify the results. Table 6 shows technology training as reported by participants on both the survey (S) and during the Interview (I). Six of the seven participants indicated that they had participated in additional technology training since their completion of the RuralNet project. Participant 1557 reported RuralNet as the only technology training she had attended. Note that participant 1181 did not complete the Internet Training portion of the survey and thus has an N/A in the survey column. 
Table 6

Summary of Technology Training Participation

\begin{tabular}{|c|c|c|c|c|c|c|c|c|c|c|c|c|}
\hline \multirow[b]{3}{*}{ Technology training program } & \multicolumn{12}{|c|}{ Participant number } \\
\hline & \multicolumn{2}{|c|}{1026} & \multicolumn{2}{|c|}{1702} & \multicolumn{2}{|c|}{1708} & \multicolumn{2}{|c|}{1555} & \multicolumn{2}{|c|}{1181} & \multirow{2}{*}{$\begin{array}{c}1557 \\
\mathrm{~S}\end{array}$} & \multirow{2}{*}{$\frac{1730}{\mathrm{~S}}$} \\
\hline & I & $\mathrm{S}$ & $\mathrm{I}$ & $S$ & I & $S$ & I & $\mathrm{S}$ & I & S & & \\
\hline RuralNet & $\mathrm{x}$ & $\mathrm{x}$ & $\mathrm{x}$ & $\mathrm{x}$ & $\mathrm{x}$ & $\mathrm{x}$ & $\mathrm{x}$ & $\mathrm{x}$ & $\mathrm{x}$ & N/A & $\mathrm{x}$ & $\mathrm{x}$ \\
\hline High tech consortium & & & & & & & & & $\mathrm{x}$ & N/A & & \\
\hline Basic computer instruction & $\mathrm{x}$ & $\mathrm{x}$ & & & & & & & & N/A & & \\
\hline Adv. computer instruction & $\mathrm{x}$ & $\mathrm{x}$ & & & & & & & & N/A & & \\
\hline Integrating tech./ curriculum & & & $\mathrm{x}$ & $\mathrm{x}$ & & & & & & N/A & & \\
\hline University computer courses & $\mathrm{x}$ & $\mathrm{X}$ & $\mathrm{x}$ & $\mathrm{x}$ & & & & & & N/A & & \\
\hline On-line courses & $\mathrm{x}$ & & & & & & & & & N/A & & \\
\hline Writing project & & & $\mathrm{x}$ & $\mathrm{x}$ & & & & & & N/A & & \\
\hline Web page design & & & $\mathrm{x}$ & $\mathrm{x}$ & & & & & & N/A & & \\
\hline County provided training & & & & & $\mathrm{x}$ & $\mathrm{x}$ & & & & N/A & & $\mathrm{x}$ \\
\hline Phase 9 tech. standards & & & $\mathrm{x}$ & & & & $\mathrm{x}$ & $\mathrm{X}$ & $\mathrm{x}$ & & & \\
\hline Policy 5100/Phase 9 & & & $\mathrm{x}$ & & & & $\mathrm{x}$ & $\mathrm{x}$ & $\mathrm{x}$ & N/A & & \\
\hline Bell Atlantic training & & & & & & & & & $\mathrm{x}$ & N/A & & \\
\hline WV Instep (PBL \& Tech.) & & & & & & & & & $\mathrm{x}$ & N/A & & \\
\hline State Dept. tech. training & & & & & & & & & $\mathrm{x}$ & N/A & & \\
\hline Reinventing Education & & $\mathrm{x}$ & & & & & & $\mathrm{x}$ & & N/A & & $\mathrm{x}$ \\
\hline
\end{tabular}

Note. Participants 1730 and 1557 participated in the survey only. Participant 1181 omitted the training program data from the survey. $\mathrm{I}=$ Interview; $\mathrm{S}=$ Survey; $\mathrm{N} / \mathrm{A}=$ no response. 
While Table 6 shows that the participants went on to participate in extensive technology training, much of the training was geared toward computer technology, not specifically the Internet. Notice that the two individuals (1557 and 1730), who did not elect to participate in interviews and observations, had participated in significantly fewer training programs than did individuals whom were willing to allow the researcher into their classroom. Their lack of participation in technology related professional development might be part of their hesitation to participate in interviews and observations. They may not be as confident in their ability to integrate and utilize technology as individuals whom have had extensive training. The exception is participant 1708 whose only training besides RuralNet has been provided by his county of employment. The county training he participates in is extensive and on-going making it quite effective. As you can see from Table 6, study participants' technology training varied significantly, as did their classroom technology access.

\section{Technology Access}

Technology access is a part of the classroom context and a direct factor related to one's ability to integrate the Internet into instruction. All study participants reported on the survey instrument that they had access to the Internet at home and at school with school access varying significantly. Four of the respondents reported only one Internet accessible classroom computer while the other three respondents reported two, four, and six Internet accessible classroom computers. Interview and observation data supported the survey results in terms of the quantity of Internet accessible computers, and also shed some light on the quality, and consistency of technology access in general. Table 7 below, shows a breakdown of classroom technology available to each study participant. An asterisk (*) indicates that the participant did not participate in interviews and classroom observations and therefore data on classroom technology 
is unavailable. While the data presented in Table 7 represents the quantity of technology available in participants' classrooms, it does not address the condition or functionality of such technology.

Table 7

Classroom Technology Access by Participant

\begin{tabular}{|c|c|c|c|c|c|c|c|}
\hline \multicolumn{8}{|c|}{ Participant number } \\
\hline Technology & 1702 & 1555 & 1026 & 1708 & 1181 & $* 1557$ & $* 1703$ \\
\hline $\begin{array}{l}\text { Total number of } \\
\text { classroom } \\
\text { computers }\end{array}$ & 2 & 6 & 4 & 4 & 5 & 1 & 1 \\
\hline $\begin{array}{l}\text { Number of Internet } \\
\text { accessible } \\
\text { classroom } \\
\text { computers }\end{array}$ & 1 & 6 & 1 & 4 & 2 & 1 & 1 \\
\hline $\begin{array}{l}\text { Number of } \\
\text { computer labs }\end{array}$ & 1 & 0 & 0 & 0 & 0 & 0 & 0 \\
\hline $\begin{array}{l}\text { Number of } \\
\text { computers in Lab }\end{array}$ & 30 & - & - & - & - & - & - \\
\hline \multirow{5}{*}{$\begin{array}{l}\text { Other classroom } \\
\text { technologies }\end{array}$} & & Television & Printer & Television & Television & & \\
\hline & & VCR & & VCR & VCR & & \\
\hline & & $\begin{array}{l}32 \% \mathrm{TV} \text { and } \\
\text { wireless }\end{array}$ & & 2 Printers & 1 Printer & & \\
\hline & & keyboard & & Stereo & $\begin{array}{l}\text { Overhead } \\
\text { projector }\end{array}$ & & \\
\hline & & $\begin{array}{l}1-\text { Teacher } \\
\text { only } \\
\text { computer }\end{array}$ & & & & & \\
\hline
\end{tabular}

* = Participant did not participate in interviews or classroom observations.

All the teachers in this study indicated experiencing frustration while attempting to integrate the Internet and technology in general into their instruction. Problems included 
everything from outdated computers to electrical outages. The paragraphs below, present a summary of the technology situation in each of the interview participants classrooms.

Melissa was the technology coordinator for her school. Her classroom technology consisted of four classroom computers three of which were outdated and used only for basic skills testing. She taught at the primary grade-level and did not have access to a computer lab. Her use of the Internet had basically been as a teacher resource or for whole class instruction using a projector. When trying to use the Internet for whole class instruction, she was often disconnected from the Internet. Melissa stated that instructional mandates cause time restrictions and limit her ability to include Internet technology into her classroom instruction. Additionally, her entire school district was facing the dilemma of funding the replacement of basic skills computers in grades K-6. The projected timeline to replace the computers and software was between three and four years. Although Melissa lacked adequate classroom technology, she indicated that a few of the classrooms in her school had three or four multimedia computers with Internet connections. Melissa was pursuing grants in hopes of obtaining alternative technologies, such as a wireless computer lab or a PC/TV.

Beverly taught gifted students. She transferred to a new school in her district and was excited to discover that her classroom had six Internet hookups. Unfortunately for Beverly, her classroom furnishings consisted of two tables, and no computers. Being resourceful, Beverly managed to obtain two old computers that were inoperable and with the help of her two sons got enough parts donated to make them function. It was January twenty-third before she managed to upgrade the computers enough to have Internet connectivity. Beverly was often transferred between schools and found that this creates a mismatch of training and technology. She frequently attended technology training in order to develop skills and acquire new technology, 
but when she gets transferred to a new school, the technology stays behind. Budgetary issues only exasperate Beverly's problems. The special education budget was already submitted for the next five years, making her technology requests six years old before they would even be considered. Beverly was trying to locate training she could attend that would give her classroom technology for participating.

Jon headed the technology team at his school where he team-taught gifted students. He had access to a variety of classroom technology including four Internet accessible multimedia computers, a television, VCR, two printers and a stereo. Although his school did not have a lab, teachers had access to multiple scanners and digital cameras. Unfortunately, Jon's school enrollment was rapidly growing resulting in his classroom relocation to a portable trailer unit. Internet drops were made to his classroom before the school year had started, but remained disconnected from the router until January of 2002. Jon and his team-teacher have a classroom curriculum based on Internet resource and research. Being resourceful, Jon was able to follow through with his curriculum by gathering Internet information at home and brining it in to share with the students.

Jane is also a member of the technology team at her school. Her schools Internet connection was via a 10 Base $\mathrm{T}$ line and an old server running Windows 3.1. The Internet connection at Jane's school was inoperable three to four times a week. Additionally, faulty cabling resulted in the school being ordered to shut down all Internet activity until the cabling could be replaced. With the new cabling, came a new problem. Many of the computers were old and now inoperable, leaving most classrooms with one or possibly two working computers. There is no computer lab at Jane's school, so she applied for a grant to obtain a portable, wireless computer lab. The lab arrived in February, providing enough laptop computers for the students 
to work individually. Unfortunately the portable lab did not correct the problems created by the slow Internet connection. The result, Jane had to develop creative management techniques so that all students can work on the computers without accessing the Internet simultaneously.

Aubrey was fortunate to have six Internet accessible computers for her students as well as an instructor's machine. While her school did not have a lab, they were grouped in open pods, which meant that she could have access to as many as twenty-four computers at one time. Although Aubrey's school has a T-1 line to the Internet the teachers often complained of slow Internet connections. The school often has electrical failures, leaving the technology inoperable for a time, while everything is restarted. In addition to the problem of power failures, Aubrey indicated that the computers are older and quite slow, often aggravating the problem of time constraints. She stated that while technology is a route she can use to teach, time constraints often inhibit her from implementing the Internet in her instruction. In addition to computers, Aubrey's classroom has a wall-mounted television and VCR, as well as a 32-inch TV and wireless keyboard for whole class Internet instruction. Unfortunately, the TV and wireless keyboard has been inoperable since 2001, Aubrey is hopeful it will be working in the near future.

The above paragraphs are intended to supplement and provide a clearer description the quantitative data presented in Table 7 . Teachers in this study were similar in that they all experienced frustration in attempting to integrate Internet technologies into their individual classrooms. They were quick, however, to indicate that their specific technology situation did not necessarily reflect the access experienced by other teachers in the school. Technology access both in number of computers and location has been identified by the U.S. Department of Education as impacting teachers' likelihood to use educational technologies (2000). The education report noted that teachers were more likely to utilize computers when the technologies 
were available in their classrooms and available in greater numbers. Additionally, participants' perceptions about technology training programs in which they participated appear to remain unaffected by their technology frustrations and remained positive in nature.

\section{Perceptions of the RuralNet Experience}

When asked to share their perceptions of their RuralNet experience, both positive and negative, interview participants shared a wealth of information. All participants indicated that they had no negatives to report except for the fact that they would have liked RuralNet to continue. One participant said, "It would've been nice to carry on and have more contact and more classes to advance the knowledge that they gave you". Other participants inquired as to the likelihood of another RuralNet Project. Overall the Interview participants agreed that RuralNet was a positive experience and laid the foundation for technology learning. One teacher said, "I thoroughly enjoyed the RuralNet classes. I learned more from them than from all my other graduate classes!" Another teacher remarked, "If it had not been for the RuralNet classes, I still would not be able to use the computer in my classroom; I would love to take more computer classes similar to RuralNet." Another teacher commented, "It was a good beginning and I really benefited from the program."

When discussing their perceptions of the RuralNet project, participants continually referred to RuralNet as a "beginning," "start," or "foundation," so I used the theme RuralNet as a Foundation for Technology Learning as an organizer for teacher remarks regarding their RuralNet perceptions. One teacher summarizes her RuralNet experience, "I thought RuralNet was a good foundation and a good way to start because it gave me a lot of technology and computer information in windows and Microsoft and all those things, as well as, navigating around the Internet. So it gave me a good basis to start with." Teachers tended to view 
RuralNet as a foundation for technology learning because it was their first instance of Internet training and because of the various components that it entailed. While individual comments covered a variety of topics, two main categories emerged under the theme RuralNet as a Foundation for Technology Learning: resources and communication with peers.

The majority of comments about resources focused on the RuralNet training manual/notebook, and on the RuralNet website. As one teacher describes the manual, "My RuralNet notebook has become a trusted companion of mine. It's the book that I keep coming back to every once in a while and getting something out of, or you know, getting something that makes a pretty good example. I ask myself, how do I do this one thing, and I have to search my mind and if it's something on the Internet or a search engine, I know where I can find it. It's a very good resource guide." Another teacher states, "I still use my manual, believe it or not. It sits under my computer at home and when I get in a pinch I'll pull it out and think I know I had that somewhere and so it's right there." Teachers also commented on the fact that they also still utilize the RuralNet website, "Part of what I found on the RuralNet site, I've used. A lot of stuff, a lot of different things I found on RuralNet I use in the classroom. Other people I know in the county who went to RuralNet have done the same thing." Overall, teachers perceive RuralNet resources in the form of the training manual and the website as still valuable and applicable to their use of the Internet.

The other category of comments, under the theme RuralNet as a Foundation for Technology Learning, was communicating with peers. This communication, whether online or in person, was important for the sharing of strategies and ideas. One teacher commented, "The networking was real helpful. Being involved and talking to other people using the Internet and seeing how they were doing it really helped a lot." A few teachers' comments highlight the 
importance of face-to-face meetings in the sharing of ideas. "It was nice after being on-line and talking to people to meet them face-to-face and see the projects that they'd been talking about. That was really nice. It makes more of an impact that way." Still another teacher commented, "One thing that I really enjoyed was that last conference that we had in Charleston, especially the fact that we could see other people's projects. I would like to see more of that, maybe yearly would be nice. I know it's expensive to get something like that together, but that I thought was really helpful. I used a lot of the ideas that I saw when we came back to school.” Throughout RuralNet training, participants were able to share information on a variety of topics through discussion forums. One teacher's remarks are related to activities completed and shared online via a discussion forum, "What I really liked was the evaluation of sites and the fact that they talked about management of classes using the Internet and using computers because I was at the point where I was using computers a lot and I was addressing those issues in the classroom and I hadn't had a class that really addressed that. I thought that part of it was really helpful.” In summary, study participants reported that the RuralNet Project provided them with valuable skills needed to establish a foundation for technology learning through access to quality resources and a means of communicating with peers in a meaningful manner. While participants indicated that RuralNet provided a foundation for technology learning, they also expressed that a need exists for various types of training for themselves and their peers.

\section{Training Needs}

Participants' training suggestions dealt primarily with utilization of software and hardware, covering everything from basic computer troubleshooting to protection from advertising junk mail. One teacher expressed that her school colleagues still need basic skills training, "Just some good computer basics and maneuvering around windows and files and 
folders because, I have that knowledge but I find that there is a good percentage who don't... and we still have many, many who do not have Office and do not work with a program like Office." All of the teachers in this study served on the technology committees at their schools and agreed that teachers need more training and experience in troubleshooting and simple maintenance of computers like cleaning a mouse and taking care of printers. Such training would allow classroom teachers to avoid and resolve simple problems without the help of limited outside resources. Two participants made suggestions for training regarding the Internet. One participant felt teachers needed more information on how to better define searches, while the other stated that teachers need to understand safety issues and software for avoiding unwanted content. While participants' perceptions of the RuralNet project were positive, these data did not express their perceived impact of the project on instructional practices.

\section{Impact of the RuralNet Project}

Data regarding the impact of the WV K-12 RuralNet Project was collected both via the survey instrument and through interviews and observations. The self-reporting survey provided quantitative data on the impact of the WV K-12 RuralNet project on participants' Internet skills, Internet knowledge, and changes in classroom preparation and teaching practice. Interviews provided discourse on how participants' viewed the impact of RuralNet on their instructional practices. Observations were utilized to provide examples and detailed descriptions of participants' Internet instructional uses.

Survey data were collected through Likert-type scale items and two series of check-box statements. Using a Likert-type scale, respondents' rated a series of statements regarding the impact of the RuralNet project on their Internet skills and knowledge. All respondents indicated the greatest influence on; 1) knowledge about the Internet as a teacher resource and how it might 
be integrated into the classroom, and 2) skills for the acquisition of locating and retrieving Internet resources. Additionally, eighty-six \% of the respondents indicated that the RuralNet project helped them understand the implications for and become skilled at integrating the Internet into the classroom, as well as establish professional collaborative relationships. Respondents reported that the RuralNet project had the least effect on their skills in organizing and managing a classroom where students are involved using the Internet, and in helping them use the Internet in school-based collaborative projects.

Seventeen check-box statements pertaining to change in classroom preparation and teaching practice as a result of participation in the RuralNet project were also provided to participants. All of the respondents reported that their classroom preparation and teaching practice have changed as a result of participation in the RuralNet Project, with the most change being reported in the area of classroom preparation. One-hundred $\%$ of the respondents reported that they utilize the Internet to: find hands-on activities for their students, download materials for classroom teaching/presentations, and download materials for student use, such as handouts. Six of the seven respondents also indicated that they use the Internet to research class lecture topics and communicate with peers to share information. Five of the respondents use the Internet to find collaborative projects for their students. Respondents also reported a change in teaching practice because of RuralNet participation. All of the respondents indicated that they now supplement traditional textbook materials with Internet materials. Five respondents reported allowing students to use the Internet during class to conduct research, and three of these same five respondents, require students to conduct research using the Internet. Three respondents reported that; 1) they have replaced traditional textbook materials with Internet materials, 2) students are involved in collaborative learning experiences, 3) more hands-on activities are being 
used in class, and 4) more project-based learning is being used in class. Table 8 presents a summary of self-reported survey data regarding RuralNet project impact. Data was compiled from three different survey sections; RuralNet Project Impact Likert-type items, Classroom Preparation, and Teaching Practice checklists. This data supports earlier findings by Falvo (1999) that indicated RuralNet project teachers were primarily utilizing the Internet as a resource, supplementing text-based materials and as a means of communicating with peers. Since the survey data used pre-defined categories of impact, the researcher conducted interviews and observations in attempts to collect more detailed information on actual instructional practices related to the Internet.

During the interview process, participants were asked to describe the impact of their RuralNet experience. Probes such as; how did it impact lesson development, and how did it impact classroom preparation, were used in attempts to pull data from the interviewees. Participants were also posed with the following question; from a student's perspective, how has the classroom experience changed due to your RuralNet participation? Participant interview responses fall under two major categories, instructional impact and professional impact. Most interview statements regarding instructional impact were characterized by participants' descriptions of changes in their instructional practices and student classroom experiences. The majority of these comments centered on the transition from reliance on text materials to online resources for lesson development and student research. Melissa and Aubrey provided the least amount of discourse on the topic of instructional change. Aubrey stated that she had an increased awareness of the Internet as an instructional method she could use, but one that she didn't always choose. Melissa reported using the Internet more as a source of information to include in her classroom. She feels that the impact of the RuralNet project has been low because 
of the technology situation at her school and not necessarily because of her skills. Jon reported that his classroom began to rely on the Internet as a source of information for student research. This resulted in changes to the way he writes his lesson plans and manages the classroom. Classroom activities began to be structured mainly in the form of stations with at least two stations involving Internet activities. Beverly reported that in the year following RuralNet she began to use a projection device to do more whole class presentations of Internet materials. She also stated, "The two years following RuralNet I did so many lessons off the Internet that it's hard for me to think about things that I didn't connect with the Internet. With gifted kids they have a lot of interest in computers anyway and it just kind of added to everything that we did". Jane reported her instructional changes in the most detail. She stated that in the year following RuralNet she only had one Internet accessible computer in the classroom. She described her instruction involving technology at that point as "gathering four or five kids at the computer to look at a site." Next, Jane described how she began using the Internet to find sites for lower ability students to pre-read stories resulting in improvement in reading skills and adoption of the Internet site by fellow teachers. More recently Jane reported directing students toward web sites that help kids in conducting searches and allowing students to conduct Internet searches independently. Jane also reported that her student assessment methods had not changed very much since participation in RuralNet. She still does paper and pencil type assessments, but also uses checklists and rubrics when assessing projects.

Participants' described their classrooms from a student's perspective, as "more fun" since participation in RuralNet. One participant described instruction prior to RuralNet as "all pencil and paper," reporting that students think of school as more interesting now and view working on the computer as playing because it is so much fun. Another teacher reported that 
computers became a part of everything they did following RuralNet participation, noting particularly a change in the application of computer technologies in the math and science content areas. This increased computer use is credited for increasing the number of computer literate students and sparking an interest in learning.

Throughout the interviews, participants frequently mentioned changes in themselves as professionals. They reported that the RuralNet project impacted them professionally by increasing their knowledge and self-confidence. Comments include statements such as: "It [RuralNet] started to change our perceptions of how a classroom was set up." or; "It [RuralNet] validated what I was doing. It made me feel better about the extent to which I was using it [the Internet] for classroom instruction." Another participant reported, "RuralNet classes have greatly influenced me in my professional growth and development. I gained the confidence to use the Internet as a teaching resource for my kids and myself. It opened my eyes to other opportunities for growth and development." Three of the five participants reported writing grants in attempts to fund classroom technology since their participation in the RuralNet project. Additionally, all five-interview participants reported that they have led or actively participated in the technology teams at their school. 
Table 8

Summary of Survey Responses Regarding RuralNet Project Impact

\begin{tabular}{|c|c|c|c|}
\hline $\begin{array}{c}\text { Impact } \\
\text { level }\end{array}$ & Likert-type items & Classroom preparation & Teaching practice \\
\hline Greatest & $\begin{array}{l}\text { Knowledge about the } \\
\text { Internet as a teacher } \\
\text { resource } \\
\text { - Knowledge about how } \\
\text { the Internet might be } \\
\text { integrated into } \\
\text { classroom instruction } \\
\text { - Skilled in locating } \\
\text { Internet resources } \\
\text { - Skilled in retrieving } \\
\text { Internet resources }\end{array}$ & $\begin{array}{l}\text { 100\% } \\
\text { - Use the Internet to find } \\
\text { hands-on activities for } \\
\text { students. } \\
\text { - Download materials for } \\
\text { classroom } \\
\text { teaching/presentations } \\
\text { - Download materials for } \\
\text { student use, such as } \\
\text { handouts }\end{array}$ & $\begin{array}{l}100 \% \\
\text { - Supplement } \\
\text { traditional textbook } \\
\text { materials with } \\
\text { Internet materials. }\end{array}$ \\
\hline Middle & $\begin{array}{l}\text { - Understand why to } \\
\text { integrate the Internet } \\
\text { into school instruction } \\
\text { - Integrating the Internet } \\
\text { into instruction } \\
\text { - Organizing a classroom } \\
\text { where the students are } \\
\text { involved using the } \\
\text { Internet } \\
\text { - Managing a classroom } \\
\text { where the students are } \\
\text { involved using the } \\
\text { Internet }\end{array}$ & $\begin{array}{l}86 \% \\
\text { - Use the Internet to } \\
\text { research class lecture } \\
\text { topics. } \\
\text { - Use the Internet to } \\
\text { communicate with peers } \\
\text { to share } \\
\text { information/ideas. }\end{array}$ & $\begin{array}{l}71 \% \\
\text { - Allow students to use } \\
\text { the Internet during } \\
\text { class to conduct } \\
\text { research. }\end{array}$ \\
\hline
\end{tabular}




\begin{tabular}{|c|c|c|c|}
\hline $\begin{array}{c}\text { Impact } \\
\text { level }\end{array}$ & Likert-type items & Class preparation checklist & Teaching practice checklist \\
\hline Least & $\begin{array}{l}\text { - Establish professional } \\
\text { collaborative } \\
\text { relationships with other } \\
\text { teachers via the Internet } \\
\text { - Use the Internet in } \\
\text { school-based } \\
\text { collaborative project } \\
\text { instruction }\end{array}$ & $\begin{array}{l}71 \% \\
\text { - Use the Internet to find } \\
\text { collaborative projects } \\
\text { for my students }\end{array}$ & $\begin{array}{l}43 \% \\
\text { - Require students to use } \\
\text { the Internet during } \\
\text { class to conduct } \\
\text { research } \\
\text { - Replaced traditional } \\
\text { textbook materials with } \\
\text { Internet materials } \\
\text { - Students are involved } \\
\text { in collaborative } \\
\text { learning experiences } \\
\text { More hands-on } \\
\text { activities are being } \\
\text { used in class } \\
\text { More project-based } \\
\text { learning is being used } \\
\text { in class }\end{array}$ \\
\hline
\end{tabular}

Table 9 presents a summary of cross-case comparisons for interview data related to the impact of the RuralNet project. Interviews were transcribed into a database with a single record for each teacher. Teacher cases were presented as narratives, eliminating redundancies, organizing the topics and summarizing the relevant issues for each teacher. In order to make sense of the data, interviews were then broken down into tables utilizing the major survey topics. The tables provided a data display mechanism for cross-case analysis of each of the survey topics and logical analysis to identify emergent themes. Finally, the data were analyzed for emergent themes and issues. 
Table 9

Summary of Cross-case Comparison for RuralNet Project Interview Data

\begin{tabular}{|c|c|}
\hline Participant & Interview Statement Theme \\
\hline Melissa & $\begin{array}{l}\text { - Internet as an Information source } \\
\text { - Grant writing in attempts to get school technology } \\
\text { - Technology team member }\end{array}$ \\
\hline Aubrey & $\begin{array}{l}\text { - Internet as an information source } \\
\text { - Views Internet as an instructional option } \\
\text { - Technology team member }\end{array}$ \\
\hline Jon & $\begin{array}{l}\text { - } \text { Student research } \\
\text { - Change in classroom management techniques } \\
\text { - Change in lesson planning } \\
\text { - Utilizes learning stations } \\
\text { - Changed perceptions of how a classroom was set up. } \\
\text { - } \text { Technology team member }\end{array}$ \\
\hline Beverly & $\begin{array}{l}\text { - Using projection system } \\
\text { - Internet lesson plans } \\
\text { - Connected everything with Internet - Computers became a part of all activities } \\
\text { - Greatest change in the application of computer technologies in the math and } \\
\text { - Science content areas. } \\
\text { - Student's enjoyed the RuralNet collaborative projects } \\
\text { - } \text { andieves increased computer use resulted in more kids becoming computer literate, } \\
\text { - } \text { "Var role is not one of computer expert, she learns with the students } \\
\text { - Grant writing in attempts to get classroom technology. } \\
\text { - Technology team member }\end{array}$ \\
\hline
\end{tabular}

Jane

- Reported change in three major steps.

$\circ 1^{\text {st }}$ Gathered students around one computer

$\circ 2^{\text {nd }}$ Internet Pre-reading for lower ability students

- $3^{\text {rd }}$ Students began to do independent Internet searches

- Students view school as more fun

- Influenced professional growth and development.

- Gained confidence to use the Internet as a teaching resource for my kids and myself.

- Opened my eyes to other opportunities for growth and development through other programs.

- Grant writing - awarded $\$ 30,000$ for wireless lab

- Technology team member 
Through observations, attempts were made to verify self-reported survey and interview data by seeing first-hand how study participants were utilizing Internet technologies in their instructional practices. Jon's classroom was based on Internet research and resource with activities structured in the form of learning stations. Students were randomly grouped and a timer was used to queue students through the learning station rotations. Jon's role was one of a coach or facilitator. He modeled technology procedures and then provided students with printed, step-by-step instructions to keep for future reference. His classroom used an interdisciplinary approach, encompassing social studies, geography, science, art, language arts, and mathematics. Students worked at individual levels to conduct research and become the expert on their topic. They then presented what they had learned to their classmates. Students were encouraged to solve their own problems and to work at home with parental assistance.

Jane's students were involved in a Butterfly garden project that was an interdisciplinary unit incorporating math, science, reading, and language arts. In preparation for the Butterfly project, Jane used the Internet to review websites and communicate with other professionals. To guide students' Internet research, Jane created a desktop folder of materials the students would need, including software and Internet sites, and placed it on all the laptops. Students were also provided with data collection materials in the form of charts, graphs and Venn diagrams. Students utilized the Internet to research West Virginia butterflies, the butterfly life cycle, and items needed to sustain butterflies at various stages of life. They also researched plant types, sizes, growing cycles, and the cost of each plant. The final product was creation of a butterfly garden. Each lesson began with a preparation activity to review procedures, record what the student already knew, and to bridge the activity from the familiar classroom concepts to the unfamiliar computer concepts. Jane often utilized a projection system for modeling of 
procedures and whole class review both prior to and following lessons. When technical problems arose, Jane maintained a good sense of humor, easing the students' tension. She utilized problems as teachable moments by asking students to brainstorm what may have caused the technical failure and ways to resolve the problem. Jane would quickly come up with an alternative lesson and restructure future lessons. Student grouping and group rotation were used to alleviate problem caused by a whole class trying to access the same Internet site. To assist with classroom management during computer activities, Jane utilized student helpers for the distribution and collection of materials and parent volunteers to assist students and help keep them on task. Each lesson was concluded with either a group activity or individual assignment to review what the students had learned. Students were highly motivated and excited about the project throughout.

Aubrey used the Internet as a source of information in developing her lesson plans. She maintained two web pages and has kept her grade book online. Aubrey does not use the Internet to communicate with parents. Students in her classroom often participate in Internet scavenger hunts or work in groups of two or three to review poetry or research a topic. Research may be guided using bookmark sites or open research where the students conduct searches. Students also send group email to a former student who is living overseas. Aubrey likes to be spontaneous and often changes her lesson if the students encounter something on the Internet that she feels should be shard with the whole class. When technical problems arise, she alters her lesson and uses the teachable moment to brainstorm what can be done to alleviate the problem.

During observations, the researcher simultaneously recorded classroom events and initial interpretations about the learning environment. Each observation was entered into a record and filed by individual teacher. In order to makes sense of the data, observations were broken down 
into data displays and analyzed for examples that would support survey and interview data regarding the impact of the RuralNet project. Cross-case comparisons were conducted, and data was logically analyzed for emergent themes. The cross-case comparison displays of observation data are presented in tables 10 and 11.

Table 10 presents cross-case comparisons of observation data regarding the representation of teacher and student roles as well as information on classroom organization and management techniques. This data is presented to assist the reader in comprehending the instructional context of each observation participant's classroom. All three-observation participants served as coaches or facilitators in their classroom while the students conducted research. In two of the classrooms, students typically worked in groups of two or three huddled around a computer while Jane was fortunate enough to have acquired a wireless lab, resulting in each of her students having an individual laptop. 
Table 10

Summary of Cross-Case Comparison of Classroom Structure Observation Data

\begin{tabular}{|c|c|c|c|}
\hline \multirow[b]{2}{*}{ Teacher/Student Roles } & \multicolumn{3}{|c|}{ Observation participant } \\
\hline & Jon & Jane & Aubrey \\
\hline Teacher as coach/facilitator & $\mathrm{X}$ & $\mathrm{X}$ & $\mathrm{X}$ \\
\hline Student researchers & $X$ & $\mathrm{X}$ & $X$ \\
\hline \multirow[b]{2}{*}{ Classroom Organization/Management } & \multicolumn{3}{|c|}{ Observation participant } \\
\hline & Jon & Jane & Aubrey \\
\hline Learning Stations & $\mathrm{X}$ & & \\
\hline Grouped $2 / 3$ students around each computer & $\mathrm{X}$ & & $\mathrm{X}$ \\
\hline Random grouping & $\mathrm{X}$ & & \\
\hline Each student worked at his or her individual level & $\mathrm{X}$ & & \\
\hline $\begin{array}{l}\text { Redirected the students and encouraged them to find } \\
\text { answers to questions on their own instead of relying on the } \\
\text { teacher for answers. }\end{array}$ & $\mathrm{X}$ & & \\
\hline Parent Volunteers & & $\mathrm{X}$ & \\
\hline Classroom helpers for distribution/collection of materials & & $\mathrm{X}$ & \\
\hline Individual laptops & & $\mathrm{X}$ & \\
\hline
\end{tabular}

Each participant's classroom was structured differently based upon the instructional grade-level and technology available. Table 11 presents a cross-case comparison of observation participants' Internet instructional approaches, Internet activities, technical problem solving methods, and approach for keeping students out of inappropriate Internet materials.

Although available technology, grade level and content matter varied significantly, there was some overlap in their Internet instructional approach, Internet activity types, and approach to 
protecting students on the Internet. Observations indicate that the teachers were attempting to transform their instruction to utilize more constructivist techniques. The researcher observed teachers attempting to serve as a coach or facilitator, with students working as researchers. Students often worked in cooperative groups of two or more around a computer to complete interdisciplinary units of instruction. Following the data collection process, two of the observation participants even requested researcher suggestions as to how they could improve their classroom instruction to be more constructivist based. Participants' expressed concern about inappropriate materials on the Internet and took precautions to prevent students from accessing such materials. Each of the teachers actively monitored his or her students while they were engaged in Internet usage, additionally all three teachers also utilized bookmark sites as a method for keeping students out of inappropriate Internet materials.

Internet instructional approaches always began with a class review of procedures and frequently included direct instruction on technical skills required to complete the activity. Observed examples of Internet activities supported survey data suggesting that teachers primarily use the Internet as a source of information for themselves and their students. Internet information was utilized for teacher lesson preparation and student research projects. All three teachers had their students conduct guided research, using bookmark web sites and two of the teachers allowed students to conduct open research on the Internet. Aubrey was the only participant whom I observed engaging students in Internet activities that were not research based. While some survey participants indicated finding and participating in online collaborative projects, at no time did the researcher observe participation in such projects. Observation participants' approaches to technical problems were as varied as the problems they experienced. Jane experienced the greatest amount of technical difficulties during the observations. However, 
Jane and Aubrey both used technical problems as teachable moments, discussed the problem with the students and brainstorming for possible solutions. 
Table 11

Cross Case Comparison of Internet Specific Observation Data

Observation participant

Approach to keeping students out of inappropriate Internet materials

Jon Jane Aubrey

Teacher monitor

$\mathrm{X} \quad \mathrm{X} \quad \mathrm{X}$

Students self-monitor

X

Parent volunteers monitor

$\begin{array}{lll} & \text { X } \\ \text { X } & \text { X } & \text { X }\end{array}$

Bookmark sites

Observation participant

Internet Instructional Approach

Jon Jane Aubrey

Interdisciplinary

X $\quad \mathrm{X}$

Direct Internet instruction

X $\quad \mathrm{X}$

Written step-by-step instructions for reference

$\mathrm{X}$

Binder for organization of technology instructions and information

$\mathrm{X}$

Encouraged students to work at home with parental assistance

$\mathrm{X}$

Class review of procedures

X $\quad \mathrm{X}$

X

Practiced note taking with paper \& highlighter prior to taking notes

$\mathrm{X}$

online.

Used transparencies to walk students through website structure and

X activity procedure

Extended activity time when students were highly engaged.

$\mathrm{X}$

Altered activity when students found great website to share.

X 


\begin{tabular}{|c|c|c|c|}
\hline \multirow[b]{2}{*}{ Internet Activities/Usage } & \multicolumn{3}{|c|}{ Observation participant } \\
\hline & Jon & Jane & Aubrey \\
\hline Student information source & $X$ & $X$ & $X$ \\
\hline Teacher information source & $\mathrm{X}$ & $\mathrm{X}$ & $X$ \\
\hline Lesson preparation & $X$ & $X$ & $\mathrm{X}$ \\
\hline Guided Research - Bookmark sites & $\mathrm{X}$ & $\mathrm{X}$ & $\mathrm{X}$ \\
\hline Open Research & $\mathrm{X}$ & & $X$ \\
\hline Professional collaboration & \multicolumn{3}{|c|}{$\mathrm{X}$} \\
\hline Teacher maintained web pages & & & $\mathrm{X}$ \\
\hline Grade book & & & $\mathrm{X}$ \\
\hline Scavenger Hunts & & & $X$ \\
\hline Group email to pen pal & & & $\mathrm{X}$ \\
\hline & \multicolumn{3}{|c|}{ Observation participant } \\
\hline Approach to Solving Technical Problems - Internet & Jon & Jane & Aubrey \\
\hline Teachers brought in printed copy of Internet materials & $X$ & & \\
\hline $\begin{array}{l}\text { Teachable moment - brainstormed why they were having } \\
\text { technical problems }\end{array}$ & & $X$ & $X$ \\
\hline $\begin{array}{l}\text { Four students at a time accessed the Internet rather than the whole } \\
\text { class }\end{array}$ & & $\mathrm{X}$ & \\
\hline Grouped students with each group accessing a different website & & $X$ & \\
\hline Restructured lessons & & $\mathrm{X}$ & \\
\hline $\begin{array}{l}\text { Turned individual activity into group activity using projection } \\
\text { system. }\end{array}$ & & $\mathrm{X}$ & \\
\hline Maintained sense of humor & & $\mathrm{X}$ & \\
\hline Students rotated between groups to view the different websites & & $\mathrm{X}$ & \\
\hline
\end{tabular}


This chapter offered survey data, individual cases for each teacher situated in the classroom context, and cross-case comparisons of interviews and observations. Data presented in this chapter indicates that the teachers in this study are at a stage of life when they have the time and energy to be committed to their students, schools, and the teaching profession in general. They each demonstrated a self-motivated desire to improve themselves as individuals and as professionals. In order to acquire new skills, teachers in this study often participated in professional development programs. Since the RuralNet project was the first Internet related training program participants attended, all agreed that it laid a foundation for technology learning, assisted them in developing technical skills, providing them with quality resources and an opportunity to meaningfully communicate with other professionals. Regardless of the amount of training each had attended, participants' still perceived a need for additional training for themselves and their peers.

Participants' indicated that the West Virginia K-12 RuralNet Project did have some impact on their instructional practices and views of themselves as professionals. Teachers most frequently reported using the Internet to prepare classroom lessons by obtaining materials, finding activities and sharing ideas with peers. A few teachers also indicated using the Internet to find collaborative projects for their students. The greatest impact on classroom instruction appears to be the supplementation of traditional textbook materials with Internet materials, followed by allowing students to conduct Internet research during class time. Professionally, data suggests that the RuralNet project increased teachers' knowledge about the Internet as a classroom resource and skills related to locating and retrieving Internet resources. Teachers also reported using the Internet to communicate with their peers in the sharing of information and ideas. In addition, all of the interview participants have gone on to become instrumental in their 
school's technology team and many have gone on to write grants and obtain funding for classroom technology. Study participants also indicated that their students have an increased enthusiasm for learning since they have begun incorporating the Internet into class instruction.

Classroom observations supported the idea that participants were making an effort to integrate Internet technologies and to transform their instruction. Unfortunately, numerous barriers restricted their accomplishments. The main barrier faced by each observation participant appeared to be technology access followed by lack of preparation time. Participant's technology access varied, however each teacher did have at least one Internet accessible classroom computer as well as home Internet access. The quantity, location and functionality of school computer technology varied significantly and appeared to have impacted participants' perceived ability to integrate the Internet into their classroom instruction. Teachers' preconceptions about the appropriate quantity and location of computers, as well as skills needed to integrate technology may have also impacted their accomplishments. The participants frequently discussed the absence of a computer lab, the need for additional training, and the lack of preparation time as items that interfered with their technology integration.

Teachers in this study perceived participation in the RuralNet project as a catalyst to professional and instructional changes. They were attempting to utilize Internet technologies, but were also aware that they were not using them to their full capacity. Outside factors such as quantity, location and functionality of technology as well as lack of planning time were presented as reasons for the absence of integration. Even in classrooms, where the teacher had access to multiple computers with Internet connections, technology integration was often absent. Although participants viewed the RuralNet project as impacting their classroom instruction, teachers in this study primarily used the Internet as a source of information for themselves and 
their students. While the nation has made great strides in providing Internet access to schools, classroom teachers are still not capitalizing upon the collaborative nature of the technology to transform their instructional practices. 
Chapter V: Conclusions, Implications, and Recommendations

The purpose of this study was to examine the effects of the West Virginia K-12 RuralNet project on elementary school teachers' instructional practices, including, but not limited to: lesson development, classroom preparation, classroom management techniques, instructional delivery methods, and student assessment. The study sought to answer the following research question: What effect has the West Virginia K-12 RuralNet Project had on elementary school teachers' instructional practices?

Using a mixed method approach, data for the study came from a self-reporting survey instrument, interviews and classroom observations taken between September 2001 and April 2002. The surveys provided numerical data while the use of narratives painted a picture of each classroom and the ways in which the teachers attempted to utilize technology. Miles and Huberman's (1994) data analysis and coding were used to draw meaning from the data and cross-case analysis provided verification of findings.

\section{Conclusions \& Implications}

This study provided insight on a variety of problems and concerns faced by classroom teachers as they attempted to integrate technology into their instruction. Based on the data presented and discussed in chapter four, the following conclusions have emerged from the data.

Conclusion 1: Participants' perceived that the WV K-12 RuralNet Project has impacted their instructional practices. Survey, interview, and observation data all support the idea that participants in this study perceived the RuralNet project as having an impact on their instructional practices. All study participants reported that participation in the RuralNet project had impacted their knowledge about integrating the Internet into instruction and skills in locating and retrieving Internet resources. They also reported increased use of Internet resources for 
preparation of instructional materials and for communicating with peers to share information. Each participant reported some change in instructional practices with the greatest change being reported in the area of supplementing traditional textbook materials with Internet resources and allowing students to use the Internet to conduct research during class. Qualitative data supports this by showing that study participants primarily use the Internet as a source of information for themselves and their students, supplementing traditional textbook materials with Internet resources. These Internet resources are typically utilized for teacher lesson development or student research papers. $71 \%$ of participants indicated that they use the Internet to find collaborative projects for their students and $43 \%$ of the survey participants indicated that their students are involved in online collaborative learning experiences, however no evidence of this was found during classroom observations. Some study participants reported that students perceived their educational experiences as "more fun" since they began integrating the Internet into classroom instruction and one participant reported that Internet integration has sparked her students learning and led to an increase in the number of computer literate students at her school. Students did show enthusiasm for learning and a high level of engagement in classroom activities during observations. Falvo (1999) noted similar findings indicating that RuralNet participants primarily used the Internet as an information resource and as a means of communicating with peers. He suggested lack of preparation time and poor professional development models as two possible factors contributing to the under-use of Internet technologies. Research by Lane-Kelso (2000) also reported that teachers involved in a training program shifted from text only resources to using the Internet as an information source.

Conclusion 2: The RuralNet Project provided teachers with a foundation for technology learning. Study participants perceived the RuralNet Project as a positive experience, providing 
them with the skills needed to establish a foundation for technology learning and implementation through access to quality resources and a means of communicating with peers in a meaningful manner. The WVK-12 RuralNet Project was the first instance of Internet training for five of the study participants. Six of the study participants went on to attend additional technology training following participation in the RuralNet project with the majority of additional training reported as being directed toward computer technology in general and not specific to the Internet. While study participants have attended a variety of training programs, they also indicated that there is still a need for teacher professional development in the area of technology. Teachers' perceived need for continued technology related training is consistent with the findings reported by Davenport (2000), and Berkowitz (2000), who both reported teachers' desire for additional professional development opportunities. This desire for additional training may be a result of teachers beliefs about training and technology integration.

\section{Conclusion 3: Participants believe there is still a need for basic skills and Internet}

training. During the interview process, study participants discussed their beliefs that there is still a need for technology training for themselves and their colleagues. The teachers' perceived need for training is not surprising since West Virginia ranked the second highest state in the percentage of schools where at least half the teachers reported being "beginners" when it comes to using technology (Skinner, 2002). Basic computer software literacy, Internet, and hardware troubleshooting were the primary focus of suggested technology training. None of the teachers indicated that there was a need for training in pedagogy although they did not provide evidence of utilizing best practices. The strong indication by participants that they and fellow teachers still need extensive technology skills training may stem from a view that teachers must be technology experts in order to integrate computer technology into their classroom. Burns (2002) 
indicated that this view of the teacher as a technology expert may be fostered in professional development activities that presented technology separate from classroom practice. Additionally, Burns indicated that excessively long training sessions may foster the belief that teachers must have technology skills advanced above those of their students in order to integrate technology into their instruction. The RuralNet project summer workshops were excessive in time lasting eight hours per day for five days followed by two online courses, all of which presented technical skills separately from integration techniques. In retrospect this combination of intensive training with emphasis on skills appears to have been a weakness on the training model.

Conclusion 4: Teachers still face barriers to utilizing technology. Teachers in this study identified access and time as the two main barriers they face in integrating the Internet into their instructional practices. This supports earlier findings by Dias (2000) who also identified access and time as two factors impacting technology integration. Although, the number of computers and Internet connections in the public schools continues to rise, the quality and functionality of these technologies needs to be addressed. All participants in this study reported having a minimum of two classroom computers with at least one being Internet accessible. One participant had as many as six Internet accessible computers in her area and another participant had acquired a wireless lab. However, each of the interview participants frequently mentioned access as a major problem they faced. Some complained that they did not have access to a computer lab while others commented on the age and condition of the computers in their classroom and all participants experienced some form of networking problem. The richest data for this study came from the classroom that had acquired the wireless lab. This supports findings by the U.S. Department of Education (2000), who reported that teachers' are more likely to 
utilize computers when the technologies were available in their classrooms and available in greater numbers. In contrast to the U.S. Department of Education's findings is the fact that the teacher whose classroom was equipped with six Internet accessible computers and the least amount of technical barriers demonstrated the least usage with activities often being fabricated for the benefit of the researcher.

Since technology access is intertwined within the school context, numbers alone do not paint a clear picture of the situations experienced by the teachers in this study. Each of the teachers in the qualitative portion of this study frequently mentioned the lack of access as a major barrier to their technology integration efforts. Access barriers experienced by participants comprised both the physical computers and the infrastructure required to connect to the Internet. Teacher concerns frequently mentioned non-functioning Internet access, electrical failures, outdated computers, and faulty wiring. Impact of the WV K-12 RuralNet project, or any attempt to integrate Internet technologies into instruction, may have been greatly effected by the various access problems each individual faced. Although study participants faced less than ideal technology access situations, they were dedicated to their schools and attempted to foster a positive attitude about the school in general. This was often done by balancing their comments regarding frustration about technology access problems, with examples of other classrooms in their school that had more and newer Internet accessible computers.

Preparation time has been identified in previous studies as a factor that greatly impacts teachers' ability to integrate technology into their instruction (Falvo, 1999; Dias, 2000). Study participants also identified time is an important issue in their integration efforts. State mandates and pressures from school administration to achieve high scores on achievement tests force teachers into a situation where they must choose between integrating technology and producing 
required scores so that they can maintain their employment. Technology is view as one technique they can use to accomplish a goal, but one that isn't always used. Additionally, teachers in this study indicated a belief that planning technology lessons was more time consuming than preparing traditional lessons. The perception that technology related lessons are more time consuming might be related to the belief that a large amount of curriculum time must be devoted to training students in the use of technology. Burns (2002) found this belief to be the result of excessively long training sessions that focused on skill acquisition, two components evident in the RuralNet project training.

Conclusion 5: There is a difference in teachers' perceptions about their practices and their actual classroom practices. Although teachers indicated on the survey that RuralNet had impacted their instruction in a variety of ways, observations provided a different perspective. At first glance, classrooms appeared to be shifting toward the more constructivist paradigm that reformers and cognitive theorists believe are supported by technology integration. Teachers were serving as facilitators and students were actively engaged. A closer look at classroom observation data however, showed that while the teachers had shifted their role to one of a coach or facilitator, they were still basically having the students use the Internet to gather information or find facts. Researching on the Internet is a worthwhile task, but one that could have been accomplished via another medium, such as books or magazines. In this sense, teachers' did not show any major change in their instructional methods, only the medium used to accomplish the task. On the survey instrument, five of the participants reported using the Internet to find collaborative learning experiences and three of the participants reported that their students are involved in online collaborative learning experiences, however no evidence of students being involved in collaborative learning experiences was observed in the classroom or reported during 
interviews indicating that self-reporting data may have been somewhat exaggerated or unreliable in this study. Cuban (2001) reported that the discrepancy between self-reported data and actual practice is common among teachers (p. 201). He noted that few researchers actually enter the classroom to observe how teachers and students actually use technology and the researchers who did reported a great deal of variance between what teachers said they did with computers and what was actually observed in the classroom. Cuban's observations were made while he was reviewing ethnographies and classroom studies; he did not however, provide any reasoning for the discrepancy in findings.

\section{Other}

- Various reasons may account for the differences in self-reported data and actual classroom observations: First, teachers view the Internet primarily as a source of information, not realizing its true potential as a tool for communication and collaboration. While attempts were made during RuralNet training to foster online communication, this communication was basically in the form of assignment submission, separate from actual learning. This may have resulted in participants viewing information and communication as separate components of the Internet rather than as mutually supportive tools. Second, teachers in this study were facing a variety of technical problems that may have limited their ability to successfully complete collaborative online activities. Thus, lessons may have been altered to eliminate frustration caused by technology failures. Finally, teachers may have felt an attachment to the RuralNet project and to the researcher as one of their instructors and mentors. Self-reporting data may have reflected this attachment and loyalty to the project or to researcher as an individual, making the data somewhat unreliable. 
- Utilization of technology in the classroom appears to lead to increased student motivation. Teachers reported that students view their learning experiences as more fun. Observations also revealed that students were highly engaged and active in technology related lessons. This may also be in part because students often look at working on the computer as 'play' or possibly because technology related activities provide a change from the regular classroom learning experiences.

- Participation in programs such as the RuralNet project may support teachers' views of themselves as professionals, fostering the self-confidence needed to support other activities such as grant writing and participation in professional development activities. Studies by Falvo (1999) and Lane-Kelso (2000) made similar findings noting that teacher selfperceptions may have been improved due to increased contact and collaboration with peers.

\section{Recommendations}

The nature of this study does not allow for broad generalizations, but rather provides insight into a number of issues that one should consider when developing technology related professional development programs, or when researching the impact of such programs.

\section{Technology Training}

Training modeled after the RuralNet project could help teachers establish a foundation for technology learning, particularly if it incorporates a variety of print and online materials that can serve as resources for teachers once training has ended. However, technology training must also provide opportunity for teachers to collaborate by sharing ideas, problems, and practices. While the RuralNet project attempted to present best practices during technology training, technology skills and classroom methods were presented separately. In order to impact instruction, technology training must be developed within the constructivist paradigm, where teachers 
actually learn technology skills while participating in activities that model best classroom practices. Rather than tell teachers about collaborative projects, have them learn technology skills while participating in a collaborative project. This restructuring would eliminate the separation of skills and activities. Additionally, Internet training must extend teachers' perception of the Internet as more than just a source of information and build on the ideas of communication and community. Internet training must go beyond skills and knowledge by immersing teachers in activities that model best classroom practices and eliminate the misconception that teachers need to be technology experts in order to incorporate the Internet into their instruction.

\section{Research}

Additional research seems to be needed that addresses the impact of training programs on teachers' instructional practices, as well as technology access in schools. Since one cannot apply training to classroom practices without adequate technology, it is essential to address both issues together. Research that combines quantitative and qualitative methods provides a clearer picture of classroom practices by adding description and verifying self-reporting data. Qualitative data can also elaborate on the educators' technology access, by addressing the quality and functionality of technology in schools, rather than just counting pieces of equipment. Research that examines classroom practices before, during and after training would be especially beneficial in recording the change process and obstacles teachers experience as they attempt to integrate technology into classroom instruction. Information from such a study could be used to establish training programs that meet the real problems encountered by teachers as they attempt to change instructional practices. 
Researchers investigating a project to which they are associated and to which participants feel an attachment or loyalty may obtain self-reporting data that reflects such feelings rather than the actual situation. To avoid unreliable data, the researcher should consider implementing one or more of the following techniques: 1) have an individual not related to the project administer the survey, 2) use qualitative data to confirm or verify self-reported information, and 3) use a population of individuals other than those with whom you have a close affiliation. Implementing one or more of these steps may help provide data that is reliable. 


\section{References}

Beaver, J. F. (1990). A profile of undergraduate educational technology (in) competence: Are we preparing today's education graduates for teaching in the 1990's? Buffalo, NY: State University of New York College. (ERIC Document Reproduction Service No. ED332985).

Becker, H. J., and Ravitz, J. (1999). The influence of computer and Internet use on teachers' pedagogical practices and perceptions. Journal of Research on Computing in Education, 31(4), 356-385.

Berkowitz, R. J. (2000). Effects of inservice training on the technology practices and attitudes of physical education teachers. Doctoral dissertation, The Ohio State University.

Burns, M. (2002, June). From black and white to color: Technology, professional development and changing practice. T.H.E. Journal. Retrieved October 1, 2002, from http://www.thejournal.com/magazine/vault/a4070.cfm

Carvin, A. (n.d.). EdWeb hyperbook. Retrieved February 15, 2000, from http://edweb.gsn.org

Catchings, M. H. (2000). Models of professional development for teachers: Factors influencing technology implementation in elementary schools. Doctoral dissertation, The Louisiana State University and Agricultural and Mechanical College.

Chisolm, I. M., \& Wetzel, K. (1997). Lessons learned from a technology-integrated curriculum for multicultural classrooms. Journal of Technology and Teacher Education, 5(4), 293317.

Cronbach, L. J. (1975, February). Beyond the two disciplines of scientific psychology. American Psychologist, 30(2), 116-127. 
Cuban, L. (2001). Oversold and underused: computers in the classroom. Cambridge, Massachusetts: Harvard University Press.

Darling-Hammond, L. \& McLaughlin, M. W. (1996). Policies that support professional development in and era of reform. In McLaughlin, M. W., \& Oberman, I. (Eds.), Teacher learning: New policies, new practices (pp.202-218). New York, NY: Teachers College Press.

David, J. L. (1994). Realizing the promise of technology: A policy perspective. In B. Means (Ed.), Technology and Education Reform (pp. 169-198). San Francisco, CA: Jossey-Bass.

Davenport, M. K. (2000). Factors related to the Tennessee K-12 educators' implementation of the Internet into classroom activities and professional development. Doctoral dissertation, East Tennessee State University.

Dias, L. B. (2000). Best practices of technology integrating teachers: Pictures of practice from four elementary classrooms. Doctoral dissertation, Georgia State University.

Drazdowski, T. A. (1990). Preservice teachers and computer technology: A case study perspective. Journal of Technology and Teacher Education, 2(4), 251-263.

Dupagne, M. \& Krendl, K. A. (1992). Teachers' attitudes toward computers: A review of the literature. Journal of Research on Computing in Education, 24(3), 420-429.

Falvo, D. (1999). A qualitative study of five West Virginia K-12 RuralNet project teachers merging the Internet into their instruction and how the Internet affects professional practice. Doctoral dissertation, West Virginia University.

Fawson, C. \& Van Uitert, D. (1990). The technology enhanced learning environment. Technology Trends for Readers in Education and Training 35, 29-34.

Fetterman, D. M. (Ed). (1984). Ethnography in educational evaluation. Beverly Hills, CA: Sage. 
Fullan, M. G. (with Stiegelbauer, S.). (1991). The new meaning of educational change. New York, NY: Teachers College Press.

Goals 2000 Educate America Act, H.R. 1804 (1994, January). Retrieved February 22, 2000, from http://www.ed.gov/legislation/GOALS2000/TheAct/intro.html

Gore, A. (1994, January). Remarks by Vice President AL Gore at Royce Hall, UCLA. Los Angeles, CA. Retrieved February 22, 2000, from http://www.pub.whitehouse.gov/ uri-res/I2R?urn:pdi://oma.eop.gov.us/1994/1/11/4.text.1

Green, D. W., \& O'Brien, T. (2002, June). The Internet's impact on teacher practice and classroom culture. T.H.E. Journal. Retrieved October 1, 2002, from http://www.thejournal.com/magazine/vault/a4081.cfm

Guba, E. G., \& Lincoln, Y. S. (1981). Effective evaluation: Improving the usefulness of evaluation results through responsive and naturalistic approaches. San Francisco, CA: Jossey-Bass.

Guba, E. G., \& Lincoln, Y. S. (1988). Do inquiry paradigms imply inquiry methodologies? In Fetterman, D. M. (Ed.), Qualitative approaches to evaluation in education: The silent scientific revolution. (pp. 89-115). New York, NY: Praeger Publishers.

Hoepfl, M. (1997). Choosing qualitative research: A primer for technology education researchers. Journal of Technology Education, 9(1), 47-63.

Hoffman, R. P. (1996). Levels of technology use and instructional innovation. Doctoral dissertation, The Claremont Graduate School.

Lane-Kelso, M. E. (2000). Integrating technology in to the classroom: Teacher training case study. Doctoral dissertation, Northern Arizona University. 
Lieberman, A. (1996). Practices that support teacher development: Transforming conceptions of professional learning. In McLaughlin, M. W., and Oberman, I. (Eds.), Teacher learning: New policies, new practices. (pp.185-201). New York, NY: Teachers College Press.

Lillie, D., Hannum, W., \& Stuck, G. (1989). Computers and effective instruction: Using computers and software in the classroom. White Plains, NY: Longman.

Lincoln, Y. S., \& Guba, E. G. (1985). Naturalistic Inquiry. Newbury Park, CA: Sage Publications.

Lockard, J., Abrams, P. D., \& Many, W. A. (1997). Microcomputers for twenty-first century educators ( $4^{\text {th }}$ ed.). New York: Longman.

Lofland, J. (1971). Analyzing social settings. Belmont, CA: Wadsworth Publishing.

Marshall, C. \& Rossman, G. B. (1995). Designing qualitative research $\left(2^{\text {nd }}\right.$ ed.). Thousand Oaks, CA: SAGE Publications.

Means, B. (Ed). (1994). Technology and education reform: The reality behind the promise. San Francisco, CA: Jossey-Bass.

Means, B. (1994). Introduction: Using technology to advance educational goals. In B. Means (Ed.), Technology and Education Reform (pp. 1-21). San Francisco, CA: Jossey-Bass.

Mergondoller, J. R. (1997, April). Technology and learning: The research. The Education Digest, 1215.

Merriam, S. B. (1998). Qualitative research and case study applications in education. San Francisco, CA: Jossey-Bass.

Merriam-Webster Online (2000). WWWebster Dictionary. Retrieved February 9, 2002, from http://www.m-w.com

Miles, M. B., \& Huberman, A. M. (1994). Qualitative data analysis: An expanded sourcebook (2 ${ }^{\text {nd }}$ ed.). Thousand Oaks, CA: Sage. 
Miles, M. B. and Huberman, A. M. (1988). Drawing Valid Meaning from Qualitative data: Toward a shared craft. In D. M. Fetterman (Ed.), Qualitative approaches to evaluation in education: The silent scientific revolution (pp. 222-244). New York, NY: Praeger Publishers.

Milman, N. B. (2000). Typical teacher use of technology in an elementary school. Doctoral dissertation, University of Virginia.

National Governors’ Association Center for Best Practices, Education Policy Studies Division, (August 1999). Education Technology: Changing the Way America Learns. Theresa Clarke and Karen Dixon. Retrieved September 23, 2000, from http://www.nga.org/Pubs/IssueBriefs/1999/990719EdTech.asp\#EducationTechnology

O’Donnell, E. (1996). Integrating computers into the classroom: The missing key. Lanham, MD: Scarecrow Press, Inc.

Office of Technology Assessment (1988). Power On! New tools for teaching and learning (OTA-SET379). Washington, DC: U.S. Government Printing Office.

Office of Technology Assessment (1995). Teachers and technology. Making the connection (OTAHER-616). Washington, DC: U.S. Government Printing Office.

President's Committee of Advisors on Science and Technology, Panel on Educational Technology (1997, March). Report to the President on the Use of Technology to Strengthen K-12 Education in the United States. New York, NY: D.E. Shaw \& Co. Retrieved February 19, 2000, from http://www.whitehouse.gov/WH/EOP/OSTP/NSTC/PCAST/k-12ed.html

Patton, M. Q. (1987). How to use qualitative methods in evaluation. Newbury Park, CA: Sage Publications. 
Patton, M. Q. (1988). Paradigms and pragmatism. In D. M. Fetterman (Ed.), Qualitative approaches to evaluation in education: The silent scientific revolution (pp. 116-137). New York, NY: Praeger Publishers.

Patton, M. Q. (1990). Qualitative Research and Evaluation Methods (2 ${ }^{\text {nd }}$ ed.). Newbury Park, CA: Sage Publications.

Quality Education Data. (1992). Technology in Public Schools, 1991-1992 (QED's Annual Installed Base Report on Technology in U.S. Schools and Districts). Denver, CO: Quality Education Data.

Quality Education Data. (1991). Microcomputer usage in schools, a QED 1989-1990 Update. Denver, CO: Quality Education Data.

Roberts, N., \& Ferris, A. (1994). Integrating technology into a teacher education program. Journal of Technology and Teacher Education 2(3), 215-225.

Sandholtz, J., Ringstaff, C., \& Dwyer, D. C. (1997). Teaching with technology: Creating studentcentered classrooms. New York, NY: Teachers College Press.

Schrum, L., \& Fitzgerald, M. (1996). A challenge for the information age: Educators and the Internet. International Journal of Educational Telecommunications, 2(2/3), 107-120.

Sheingold, K., \& Tucker, M. S. (Eds). (1990). Restructuring for learning with technology. New York: Bank Street College of Education, Center for Technology in Education.

Skinner, R. A. (2002, May 9). Tracking tech trends. Education Week, XXI(35), 53-67.

Strauss, A. \& Corbin, J. (1990). Basics of qualitative research: Grounded theory procedures and techniques. Newbury Park, CA: Sage Publications. 
Technology and Education Reform, A Research Project Sponsored by Office of Educational Research and Improvement, U.S. Department of Education. Retrieved February 26, 2000, from http://www.ed.gov/pubs/EdReformStudies/EdTech/

The Power of the Internet for Learning: Moving from Promise to Practice.

(2000, December). Report of the Web-Based Education Commission to the President and the Congress of the United States. Retrieved March 3, 2001, from http://www.ed.gov/offices/AC/WBEC/FinalReport/index.html

Thompson, M. (1983). Beyond the computer: reading as a process of intellectual development. (ERIC Document Reproduction Service No. ED 236 555).

U.S. Department of Education. (2002, March 11). Guidance on the Enhancing Education Through Technology (Ed Tech) Program. Retrieved September 30, 2002, from http://www.ed.gov/offices/OESE/SST/edtech.html

U.S. Department of Education. National Center for Education Statistics. (2002)._Internet Access in U.S. Public Schools and Classrooms: 1994-2001. (NCES 2002018). Washington, DC: Anne Kleiner and Elizabeth Farris. Retrieved September 30, 2002, from http://nces.ed.gov/pubs2002/2002018.pdf

U.S. Department of Education, National Center for Education Statistics. (2001). Internet Access in U.S. Public Schools and Classrooms: 1994-2000 (NCES 2001-07`). Washington, DC: Anne Cattagni and Elizabeth Farris. Retrieved July 7, 2001 from http://nces.ed.gov/pubs2001/internetaccess/

U.S. Department of Education, National Center for Education Statistics. (2000). Internet Access in U.S. Public Schools and Classrooms: 1994-99 (NCES 2000-086). Washington, DC: Catrina 
Williams. Retrieved February 20, 2000, from

http://nces.ed.gov/pubsearch/pubsinfo.asp?pubid=2000086

U.S. Department of Education, National Center for Education Statistics. (2000a). Teachers' Tools for the 21st Century: A Report on Teachers' Use of Technology (NCES 2000-102). Washington, DC: Becky Smerdon, Stephanie Cronen, Lawrence Lanahan, Jennifer Anderson, Nicholas Iannotti, \& January Angeles.

U.S. Department of Education, Office of Educational Research and Improvement (April, 2002). Issue brief: Beyond school-level Internet access: support for instructional use of technology (NCES 2002-029). Washington, DC. Retrieved, October 1, 2002, from http://nces.ed.gov/pubs2002/2002029.pdf

U.S. Department of Education, Office of Educational Research and Improvement. (1999). Teacher Quality: A report on the Preparation and Qualifications of Public School Teachers (NCES 1999-080). Washington, DC: Laurie Lewis, Basmat Parsad, Nancy Carey, Nicole Bartfai, Elizabeth Farris, and Becky Smerdon. Bernie Greene, project officer. Retrieved February 22, 2000, from http://nces.ed.gov/pubsearch/pubsinfo.asp?pubid=1999080

U.S. Department of Education, Office of the Under Secretary, Planning and Evaluation Service, Elementary and Secondary Education Division. (2000b). Does professional development change teaching practice? Results from a three-year study. Washington, D.C. Retrieved May 2001, from http://www.ed.gov/inits/teachers/eisenhower/execsum/endnotes.html

U.S. Department of Education, Office of the Under Secretary, Planning and Evaluation Service. (1999a). Designing effective professional development: Lessons from the Eisenhower program. Washington, D.C. Retrieved March 2001, from http://www.ed.gov/inits/teachers/eisenhower/execsum/endnotes.html 
U.S. Department of Education, Office of Educational Research and Improvement. (1993). Using Technology to Support Education Reform. Washington, DC: Barbara Means, John Blando, Kerry Olson, Teresa Middleton, Catherine Cobb Morocco, Arlene R. Remz, Judith Zorfass. Retrieved February 25, 2000, from http://www.ed.gov/pubs/EdReformStudies/TechReforms/ VanProoyen, N., \& Clouse, R. (1994). Three approaches to teaching reading: Basal, common language experience, and computer-assisted instruction. (ERIC Document Reproduction Service No. ED 366 910).

Webopedia. (2000). Dictionary and search engine for computer and Internet technology. Retrieved February 9, 2000, from http://webopedia.internet.com

West Virgina Department of Education (WVDE). Internet and K-12 Intranet information. Retrieved October 1, 2002, from http://access.k12.wv.us/internet/index.htm

Zappone, R. (1991). Using technology in education: Step to the future. Computers In The Schools, 8, 83-87. 
Appendix A

RuralNet Course Detail 
1998 - WV K12 RuralNet Summer Training Schedule

\begin{tabular}{|c|c|c|c|c|c|}
\hline$D_{x y}$ & Mondzy & Tuesd ay & Wednesday & Thursd $x y$ & Friday \\
\hline $9-12$ & $\begin{array}{l}\text { Check-in: } \\
\text { Nametags } \\
\text { Distnbute Hotebooks } \\
\text { Introduction: } \\
\text { Instructors/Participants } \\
\text { Project Overview } \\
\text { Course Regirtration } \\
\text { TIE BA Questionnaire } 1 \\
\text { Course Overview: } \\
\text { Review Schedule } \\
\text { Notebook Overview } \\
\text { Facility Oriertation } \\
\text { Internet Integration } \\
\text { Project }\end{array}$ & $\begin{array}{l}\text { Review \& (S tructured) } \\
\text { Independert Practice } \\
\text { Advanced Email: } \\
\text { Attachunerts } \\
\text { Address Books } \\
\text { Listaev: wvrkl2 } \\
\text { Subscnbe } \\
\text { Set Topic Groups } \\
\text { Practice } \\
\text { World Wide Web Baxics: } \\
\text { Introduction } \\
\text { Browser Software } \\
\text { Oriertation } \\
\text { Surfing Basics } \\
\text { Rurallet Orline Resources }\end{array}$ & $\begin{array}{l}\text { Review \& (Structured) } \\
\text { Independent Practice } \\
\text { Curricuhum Integration: } \\
\text { Concepts of Intemet } \\
\text { Integration } \\
\text { Models and Examples of } \\
\text { Internet Integration } \\
\text { Collaborative Projects }\end{array}$ & $\begin{array}{l}\text { Review \& (\$ tuctured) } \\
\text { Independent Practice } \\
\text { Considerationfor } \\
\text { Inplementing Web } \\
\text { Based Instruction: } \\
\text { Class morn Management } \\
\text { Cormuter Access } \\
\text { Time Management } \\
\text { Techrical Support } \\
\text { Acceptable Use }\end{array}$ & $\begin{array}{l}\text { Review \& (S tructured) } \\
\text { Independert Practice } \\
\text { Liskev: } \\
\text { Update wrrkl2 } \\
\text { rubscription } \\
\text { Small Group Works } \\
\text { Internet Integration } \\
\text { Project Work } \\
\text { TIE BA Quextionnaire } 2 \\
\text { Project Presentations }\end{array}$ \\
\hline & LUHCH & LUHCH & $\begin{array}{l}\text { LUHCH } \\
\end{array}$ & LUNCH & LUHCH \\
\hline $1-5$ & $\begin{array}{l}\text { Lab/Computer } \\
\text { Orientation: } \\
\text { Operating System } \\
\text { File Manzement } \\
\text { Introduction to Email: } \\
\text { Introduction } \\
\text { Distrbution of accounts } \\
\text { Email Bas ics } \\
\text { Netiquette }\end{array}$ & $\begin{array}{l}\text { Narigating the Web: } \\
\text { Bookmarls } \\
\text { Search Engines } \\
\text { Developing Search } \\
\text { Strategies } \\
\text { URL Review Activity }\end{array}$ & $\begin{array}{l}\text { Small Group Work } \\
\text { Internet Integration } \\
\text { Project Work }\end{array}$ & $\begin{array}{l}\text { Advanced Web } \\
\text { Techniques: } \\
\text { Capturing and } \\
\text { Downloading Internet } \\
\text { Resources and S oftw ane } \\
\text { Phrg-ins for B rowsers } \\
\text { Small Group Work } \\
\text { Internet Integration } \\
\text { Pmject Wouk }\end{array}$ & $\begin{array}{l}\text { Wripp ing up the week: } \\
+ \text { Bookmank transfes } \\
+ \text { Maibox clooure } \\
\text { + Computer clearnop } \\
\text { Fall Course Regirtration } \\
\text { Course Paperwork }\end{array}$ \\
\hline
\end{tabular}



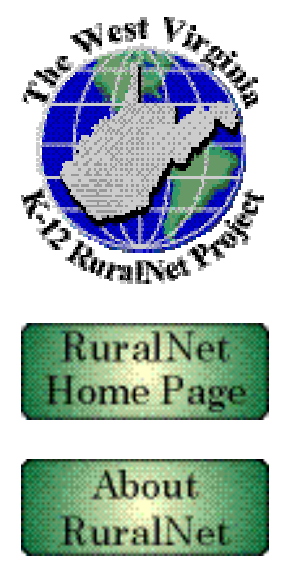

Teaching

Resources

\section{On-Iine \\ Couras}

\section{Watershed \\ Switchboard}
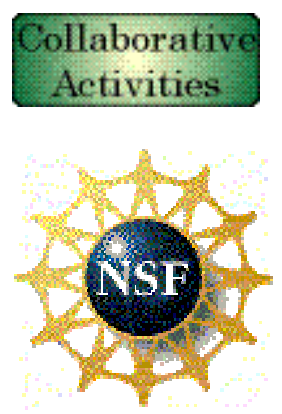

\section{Fall '98 - Skills Course Index Page \\ Course Information}

- Course Syllabus

- Assignment Checklist

$\circ \quad$ Graded Option (C\&I 380 or CI 582-101)

○ CE Pass/Fail Option (C\&I 930 or CI 564-101)

- No Credit Option

- Grading Information

\section{Assignment Detail}

- Lessons (All Course Options)

- Lesson 1 - Establishing Communications

- Lesson 2 - Review of Internet Tools

- Lesson 3 - Internet Search Strategies

- Lesson 4 - Retrieving Media/Resources

- Term Projects (All Course Options)

○ Journal Entries

- Participation in a Collaborative Project

- Draft Curriculum Framework

- $\quad$ Framework Report Paper (Graded Option Only)

\section{Evaluation}

- Post-Fall '98 On-Line Course Questionnaire For Peer Teachers

This questionnaire is being used to collect evaluative input from the WV K-12 RuralNet Project peer teachers on the Fall 1998 On-Line course, as well as the Project To Date (including Summer 1998). Please complete each of the items in this survey prior to December 4, 1998. Thank you very much for your participation in this effort. 


\section{Skills Course (Fall '98): Course Syllabus}

Start Date: September 7, 1998

End Date: December 7, 1998

Course Director:

Dr. Randall Wiesenmayer

West Virginia University

609E Allen Hall

P.O. Box 6122

Morgantown, WV 26506-6122

Phone: (304) 293-7022 x 1815

(888) 272-2843 x1815

E-mail: $\underline{\text { rlw@wvnvm.wvnet.edu }}$
Course Coordinator:

Marcia L. Marcolini

West Virginia University

609A Allen Hall

P.O. Box 6122

Morgantown, WV 26506-6122

Phone: (304) 293-7022 x1819

(888) 272-2843 x1819

E-mail: mmarcoli@wvu.edu

\section{Course Registration}

To obtain college credit for the fall on-line course, you must register for graduate credit at either Marshall University or West Virginia University. If you have not already registered, please contact the RuralNet office for the proper forms.

\begin{tabular}{||l||c||l||c||c||c||}
\hline Course Title & Credit & WVU & WVU CRN\# & Marshall & MU CRN\# \\
\hline \hline Advanced Internet Skills (Graded*) & 3 & C\&I 380 & 85522 & CI 582-102 & 3626 \\
\hline \begin{tabular}{l} 
Internet Skills for Educators (CE/PF**) \\
\hline $\begin{array}{l}\text { Internet Skills for Educators (No } \\
\text { Credit***) }\end{array}$
\end{tabular} & 3 & C\&I 930 & 85526 & CI 564-101 & 3625 \\
\hline
\end{tabular}

* Graded option may be used for elective credit in graduate programs if approved.

** CE/PF option may be used for certificate renewal, salary advancement, or continuing education credit if approved by your county school board. This option may not be used towards a M.S. degree.

*** No Credit option does not require registration at either WVU or MU

\section{Purpose/Description}

This course will address the fundamental mechanics of locating and retrieving on-line science and math resources from the Internet and integrating them into a curricular framework. The framework will cover an aspect of watershed investigation, or other science-related subject material. The resources retrieved will be suitable for use in science/math instruction that is consistent with the West Virginia Science Curriculum Framework.

Participants will select a science topic (or science topic with a math component) that will serve as a platform for discussion and focused searches of Internet resources. The topic area should be something you are currently using, or plan to use, during the Spring 1999 semester. A suggested theme throughout the project is watershed investigation, and the examples and resources used in this course will focus on this theme. 
Participants will be involved in three connected, yet distinct sets of activities during the semester:

\section{Internet Lessons}

This set of activities centers around hands-on use and practice using selected Internet tools to refine the participant's technical skills.

\section{Internet Collaborative Activity}

This set of activities will address collaborative models and participation in an on-line collaborative activity during the course of the semester. Participants will be required to participate in some type of science-related collaborative activity with their peers. This activity may be one in which you are currently involved, a new collaborative activity, or participation in a RuralNet sponsored project.

\section{Curriculum Framework}

This set of activities will focus on the development and construction of a draft curriculum framework for instructional use. This framework will serve as the beginning point for the spring 1999 on-line course.

At the conclusion of this course, participants should be able to successfully:

- locate and retrieve science/math resources (text documents, images, graphics, movie clips, sounds) from the Internet.

- communicate via electronic mail, Listservs and other collaborative venues.

- collaborate with peers in the sharing, reviewing, and collection of Internet resources.. 


\section{Course Pre-Requisities}

The following are required in order to participate in the on-line course:

1. Internet access from school OR home which allows for Internet and E-mail access

2. World Wide Web Browser Software (Netscape or Internet Explorer)

3. E-mail Software (Chameleon, Pegasus, Eudora, etc.)

Since the on-line course will be delivered, taken, and completed electronically, lack of the course pre-requisites will preclude successful completion of the requirements. If you have any questions concerning the above items, please contact the WVU RuralNet office at (888) 272-2843 or (304) 293-7022, extension 1819.

\section{Course Mechanics}

All assignments will be posted on this web site and may be accessed at any time by the participants. Participants may work at their own pace and complete assignments ahead of time as long as each assignment is completed by the deadline. A list of assignment deadlines appears later in this syllabus. All assignments must be completed no later than December 7, 1998. Each participant will be assigned an on-line mentor for this course. Participants are expected to regularly communicate with their mentor during the semester so that the RuralNet staff is aware of each participant's progress in the course. Assignment submissions are to be made to the participant's mentor via electronic mail and attachments. Mentors are responsible for reviewing all submissions and determining if the lesson has been completed adequately. Assignment submissions for those in the Graded Option course will also be reviewed by a RuralNet staff member for grade determination.

All lessons will be completed via the Internet, and all assignments will be transmitted via e-mail or posted to the WVRK12 RuralNet listserv.

Each participant is highly encouraged to keep back-up copies of all assignment submissions, as well as hard copies of all e-mail correspondence should something get lost in cyberspace. One way to do this is by sending yourself a copy of all e-mail submissions using the 'cc:' feature of the software.

Required assignments will include Internet lessons, journal entries, participation in a collaborative activity, and the creation of a curriculum framework. A written framework report paper is also required by those participants who elect the Graded Option. All work is to be performed, created, and submitted by the participant, in accordance with the Academic Honesty policy of West Virginia and Marshall Universities respectively.

For any problems with grading, Course Information, or deadlines, please contact the course director or course coordinator via electronic mail, traditional mail, or the telephone.

If a major technical problem arises, such as a continued lack of Internet access, the participant must inform their mentor immediately, or contact the RuralNet office at the phone numbers listed previously. Because of the importance of continuous Internet access, participants should consider this a priority and seek assistance should the need arise. 


\section{Mentor/Participant Responsibilities}

An integral component of the WV K-12 RuralNet Project is the inclusion of a formal mentoring process for peer teachers completing the fall and spring on-line courses. Teacher-leaders (those who have completed the cycle and participated in workshop training) will provide one-to-one assistance and support for each peer teacher during the on-line course. Generally, mentors will be one of the Teacher-Leaders from the workshop you attended during the summer.

Participants:

- are expected to regularly communicate with their mentor by e-mail, at least once per week.

- should discuss their progress, their successes, and any problems encountered.

- should save an electronic copy of each e-mail sent and received.

Mentors are provided as a bridge between the traditional college classroom and the totally electronic course. Mentors can provide assistance and guidance, but they cannot conduct the process alone. Mentors are not intended to be watchdogs or supervisors-rather they should be viewed as a resource in helping the participants complete the course successfully.

\section{Acceptable Use Policy}

All communication during the on-line course should be in compliance with the WV State Department of Education Policy 2460, Use of the Internet by Students and Educators. Postings to the Listserv and the RuralNet website are to be professional and related to educational materials and processes.

\section{Social Justice Statement}

West Virginia and Marshall Universities are committed to social justice. The RuralNet staff concur with that commitment and expect to foster a nurturing learning environment based upon open communication, mutual respect, and non-discrimination. Our Universities do not discriminate on the basis of race, gender, age, disability, veteran status, religion, sexual orientation, color, or national origin. Any suggestions as to how to further such a positive and open environment in this class will be appreciated and given serious consideration.

If you are a person with a disability and anticipate needing any type of accommodation in order to participate in this class, please advise your mentor and make appropriate arrangements with the Disability Services office of the University in which you are enrolled. 


\section{Skills Course (Fall '98):}

\section{Lesson 1: Establishing Communications}

\section{Assignment Due Date: September 20, 1998}

\section{Objective:}

To get participants connected with, and using, the communication resources that will be utilized during this course and to review the technical aspects of each.

\section{Outline:}

- $\quad$ Review the RuralNet Fall On-Line Course Materials

- $\quad$ Selecting a Science Topic

- $\quad$ E-mail (Electronic Mail)

○ $\quad$ Assignment 1.1

- $\quad$ RuralNet Listserv

- $\quad$ Assignment 1.2

- $\quad$ Joining a Collaborative Activity

- $\quad$ Assignment 1.3

\section{Assignment Summary:}

\section{Assignment 1.1:}

Create and send an e-mail message to your on-line mentor, sending a copy to yourself. Assignment 1.2:

Post a message to your listserv group that provides an introduction of yourself, and some information about the topic group you have chosen. (Remember to send a copy to your mentor)

Assignment 1.3:

Email your mentor with the name of the collaborative project that you are signing up for. Explain why you have chosen this project and what you hope to achieve by participation. 


\section{Review the RuralNet Fall On-Line Course Materials}

Now is a good opportunity to review all of the materials and resources for the successful completion of this course. Having a good idea about what is to be done, what assignments are required, and what projects must be completed will allow you to plan your schedule for the fall. In addition, some of the projects require you to work on them as you progress through the course rather than waiting until November to begin them. In fact, some aspects of the projects will not be able to be completed later.

Carefully review the following:

- The Course Syllabus (note the course mechanics section)

- The appropriate Assignment Checklist (includes deadlines)

- $\quad$ Graded Option (C\&I 380 or CI 582-101)

- $\quad$ CE Pass/Fail Option (C\&I 930 or CI 564-101)

- $\quad$ No Credit Option

- Lessons 1 through 4

- $\quad$ Lesson 1 - Establishing Communications

- $\quad$ Lesson 2 - Review of Internet Tools

- $\quad$ Lesson 3 - Internet Search Strategies

- $\quad$ Lesson 4 - Retrieving Media/Resources

- The Term Projects

- Journal Entries

- $\quad$ Participation in a Collaborative Project

- Draft Curriculum Framework

- $\quad$ Framework Report Paper (Graded Option Only) 


\section{Selecting a Science Topic}

The following guidelines are designed to assist you in selecting a topic that can be used for this course. Although you may change your topic during the semester you will benefit more if you can maintain the same topic throughout. The topic you select will provide a central focus for researching the expanses of the Internet while completing the course assignments. In addition, the final project for this course is to develop a draft curriculum framework on your selected topic using Internet resources gathered during the semester. Thus, selecting a topic now will save you countless hours later in the semester.

Note: Some of you may have already selected a topic based on the draft syllabus or as a result of your experiences during the summer workshop. If so, you are ahead of the rest. You may still want to review the following guidelines to help fine tune your selection.

\section{Guidelines:}

- The topic may be appropriate for a lesson, thematic unit, special project, or some other classroom activity.

- * Select a science topic, or a science topic with a math component for math teachers.

- $\quad$ Select a topic for which you have an interest and some previous knowledge.

- Select a topic that you will be teaching during the Spring 1999 semester or are teaching this fall.

(The Spring 1999 Online course will focus on integrating internet resources into instruction and will require use of internet resources in your classroom. It would be easiest to base this instruction on the materials you gather during this semester.)

- Select a topic or subject area that is broad enough to allow for flexibility in your information searches.

- Select a topic which relates to thematic science and the West Virginia State Science Curriculum Framework (the CATS project offers some good examples).

- Select a topic that provides you with several related instructional sessions for your class.

Whatever the topic you choose for your Internet exploration we hope you enjoy it. The RuralNet office staff and online mentors are excited about the semester, as we hope you are. Please let us know what we can do to help you build your electronic library and online skills.

* NOTE: The topic you select must be a science topic, or a science topic with a math component for math teachers.

\section{E-mail (Electronic Mail):}


Most of the dynamic discussions and posting of assignments for this course will be done via email. This section is not a "how to" session but rather a self paced review of the important techniques of e-mail. The following is a list of e-mail techniques that you should be familiar with for this course:

- Establishing a local mailbox to receive mail

- $\quad$ Creating and sending messages

- Retrieving and reading messages

- Replying to and/or forwarding messages

- Sending, viewing and saving file attachments

- $\quad$ Filing messages using folders

- Creating and using address books

\section{Activity:}

The following exercise will walk you through each of the e-mail techniques to test your knowledge. If you are unfamiliar with any of the methods listed, please refer to the help files for your e-mail software package (Netscape users may refer to the RuralNet summer workshop noteook).

1. Setup your email software. For instructions on setting up Netscape mail see your RuralNet Summer Workshop notebook (pages D3-D8), for other e-mail packages, seek help from your mentor or service provider.

2. Review the operations of your e-mail software. You can do this series of steps by yourself or with a partner if you know their address

- Create and send a message to yourself (or your partner) Note: When sending official mail it is recommended that you always retain a copy for your records. Setting up a folder for copies to yourself and CC:ing yourself is an easy way of doing this.

- Retrieve and read the message.

- Create a folder and file the message in that folder.

- Reply to the message and/or forward it to yourself.

- Send a message to yourself (or your partner) with an attached file.

- Retrieve and read the message and attachment.

- Create an entry in your address book for your online mentor.

\section{Assignment 1.1:}


Send an e-mail message to your online mentor. This note should include the following items (make sure you cc: yourself):

- Your permanent e-mail address (the address you will be using for this course)

- A brief introduction (include your county, school, grade(s) taught, subject(s) taught...etc.)

- A note on your comfort level with Internet software and what you have done to this point in the lesson.

- A note confirming you have reviewed all course materials, resources, and requirements.

\section{RuralNet Listserv}

We will be utilizing the WVRK12 listserv for our group discussions and official mailings during this course. You should have already subscribed to the WVRK12 listserv during the summer workshop.

NOTE: If you have NOT already subscribed to the WVRK12 Listserv you can refer to your RuralNet summer notebook (section F) or click here for on-line instructions.

\section{Step 1: Check your Current Account Settings}

Before posting messages, you will need to query the listserv to check your current account settings. Account settings include both the topic group subscriptions and mail delivery options.

\section{A. Query Your WVRK12 Subscription:}

Send an e-mail message as follows:

- Message requirements:

1. To: listserv@wvnvm.wvnet.edu

2. From: your Internet address

3. Subject: leave blank

4. Message Body: QUERY WVRK12

5. Remove your signature file from the message.

- Example:

○To: listserv@wvnvm.wvnet.edu

○From: jteach@access.k12.wv.us 


\section{○ Subject:}

○ Message Body: QUERY WVRK12

The listserv will send you a reply message showing your settings for WVRK12. You will need to refer to this message to verify your topic group preferences and mail delivery settings.

\section{B. Verify Topic Group Preferences:}

To verify the topic group(s) that you are subscribed to, look for the following line in the listserv reply message.

The topics you subscribe to are: $T, S$

There will be different letters after this statement or possibly none depending on when you were originally subscribed to WVRK12. These letters are the Topic Group IDs. The only IDs you want here are those which represent the affinity groups you want to receive mail from. Remember, if you are subscribed to more than one group you will be receiving A LOT of mail. For instructions on changing your subscription preferences by adding or deleting topic groups, refer to the RuralNet summer notebook, page F9 - Setting Topic Group Preferences or click here for on-line instructions.

\section{B. Verify Mail Delivery Settings:}

It is possible to temporarily "turn off" your subscription to the WVRK12 listserv if you are away from your email for an extended period of time. Some groups did this during the summer by sending the command "SET WVRK12 NOMAIL" to the listserv. This command allowed you to stop receiving messages without actually unsubscribing from WVRK12. In order to proceed with the course you should have your mail delivery set on.

To verify your mail delivery settings, look for the following in the listserv reply message.

NOMAIL You have temporarily turned off your subscription and will not receive any mail from the list

OR

MAIL You are sent individual postings as they are received

If your options say "MAIL" you are set to go. If your options read "NOMAIL" you will need to turn off the set nomail command to resume receiving messages from the discussion forum.

For instructions on resuming listserv mail, please refer to the RuralNet summer notebook, page F3 - Resuming Listserv Mail or click here for on-line instructions.

\section{Step 2: Review WVRK12 Posting Protocols}

Review the material on posting and responding to messages on listservs (see Guidelines for the WVRK12 Listserv). Please pay particular attention to sections on "Posting a Message" and "Replying to Messages". 


\section{Assignment 1.2:}

Post a message to your group on the WVRK12 listserv which contains the following:

- One line saying who you are, what you teach, and where you teach.

- A brief description of the topic you will be focusing on for this online course (See note on "Choosing a Topic").

- A brief description of how you might use this topic in your classroom and what types of internet based information might be of use.

\section{For example:}

If I were a Middle School (M: group) teacher I might post the following:

Subject: M: Fall Course Topic

Joe Teacher, Science Education, WV K-12 RuralNet, Morgantown, WV

I am interested in looking at the physical features of a watershed: Plants, animals, soils, topography, land use, and pollution sources. We have a stream near our building which continually floods and I would like to look at the relationship between the physical features and flooding.

My hope is to design a 3 week long series of lessons that identify the area of our watershed and the variety of land uses within it. With this information identified we will then research each use for its contribution to or reduction of flooding.

From the Internet, I hope to get maps of our watershed, information on land use and erosion, and contact scientists who do this type of research.

Note: Remember to put your group ID, colon, space (i.e.: M:) at the beginning of the Subject line. Also, be sure to CC: your mentor so that they get a copy.

\section{Joining a Collaborative Activity}

In order to enhance the collaborative component of this on-line course, all participants must join, and participate in, some type of collaborative science activity during the semester. This may be a local, regional, or national activity; it might be a collaboration between students, teachers, or schools. during the course of the semester you will update your mentor about the progress of your collaborative group, and document your participation.

For a more complete description, along with suggested activities, please see the section on the Collaborative Project.

\section{Assignment 1.3:}


Send an e-mail message to your mentor discussing the collaborative activity you have joined, why you decided to join it, and how it will fit into your curriculum framework. Don't forget to cc: yourself.

\section{Skills Course (Fall '98):}

\section{Lesson Two: Web Browser Software Review}

\section{Assignment Due Date: October 11, 1998}

\section{Objective:}

- To review resource areas of the Internet and the software utilized to access them.

- To become comfortable using web browser software.

\section{Outline:}

- $\quad$ Review of Internet Resources

- $\quad$ Introduction to Web Browsers

$\circ \quad$ Assignment 2.1

- $\quad$ RuralNet Teaching Resources

- $\quad$ Assignment 2.2

- Bookmarks

- $\quad$ Assignment 2.3

\section{Assignment Summary:}

Assignment 2.1:

Find and explore your school's home page on the World Wide Web. If you can't find your own school's web page - find another local school's page. Look at two other school's pages and compare and contrast them to your school's page.

Assignment 2.2: 
Explore teaching resources on the RuralNet web site. Send an e-mail message to the listserv and cc your mentor listing three URLs that are new to you and that you will find useful in creating your framework.

\section{Assignment 2.3:}

Create a bookmark folder with at least five web sites related to your chosen framework topic. Create a file, save it, and send it to your mentor.

\section{Review of Internet Resources}

The "Internet" is a collection of informational resources, linked together by computer networks. Some of these resources include electronic mail, Internet relay chat (IRC), file transfer protocol (FTP), Usenet newsgroups, and the World Wide Web. All of these segments of the "Internet" serve specific purposes; that is, they each provide a different means of accessing information. To cover each of these would require a course in itself. For this reason, this course will concentrate on the World Wide Web.

The World Wide Web is one of the most commonly used segments of the Internet at the present time. Information is collected in groups of "pages" otherwise known as web sites. Users navigate the Web using a special type of software called a 'browser.' The two most commonly used browsers today are Microsoft's Internet Explorer, and Netscape Communication's Netscape Navigator. You may choose to use whatever browser software you prefer to 'surf the web'. If you using Netscape Navigator as your browser, additional information can be found in the RuralNet summer notebook (sections G, H \& I).

As mentioned previously, there are many segments of the Internet, and you may wish to investigate them all as you become more comfortable with accessing on-line resources in general. Take the opportunity to explore them all-you never know which vehicle will be the best one to locate that perfect piece of information that will make your students sit up and take notice!

\section{Introduction to Web Browsers}

Using a web browser such as Netscape or Internet Explorer is a fairly simple and straightforward process. In short, you enter a web site 'address' (known as a URL), press the enter key, and then in a few seconds you will be at that site. The most important item is typing the address correctly.

\section{Web site addresses - URL's}

Addresses for the World Wide Web are standardized, with commonly used prefixes and suffixes.

- The most common prefix for an address is 'www', although there are some others in use. 
- The suffix generally indicates the nature of the server where the page is stored.

The following is a list of the most often used suffixes:

$\begin{array}{ll}\text { Suffix } & \text { Description } \\ \text {.com } & \text { commercial } \\ \text {.edu } & \text { educational } \\ \text {.gov } & \text { government } \\ \text {.org } & \text { organization } \\ \text {.mil } & \text { military }\end{array}$

All Web addresses begin with 'http://' followed by the complete address. However, in most newer versions of the software, this portion of the address defaults eliminating the need for you to type it. Remember when typing in an address to pay particular attention to punctuation, especially the tilde $(\sim)$ which often precedes text in an address.

\section{Why can't I get to a web site?}

As you can imagine, if 1000 people tried to dial the same telephone number at the same time, only one could get through. That means that the other 999 will have to wait until the line is free. The same analogy holds for the Web. From time to time you will get a 'busy signal' from Netscape that the server may be busy. This is more likely during certain hours of the day, and with certain web sites (the NASA Mars Landing site received 1 million 'hits' the first day). So, you may have to be patient and keep trying, or come back to the site another time. Less likely, although possible, is that the server where that site is stored is down, the site may have been discontinued, or the address you entered contains errors.

\section{What is a hot link?}

Most Web pages contain 'links' to other sites of interest to the reader. These sites are called 'hot links' if you can click on them with the mouse and go right to the page. These links are often a bright color before they are followed, and change color after they have been followed once. Following these 'hot links' can often save you countless hours of surfing time, or they may go nowhere for a variety of reasons. When investigating a site, you should take some time and follow the 'hot links'.

\section{How do I get back to the original page after I follow a 'hot link'?}

Sometimes, following a link prevents you from returning to the original page you were on, usually because the author did not provide a path for you to return.

There are four ways to get back to where you started:

1. Re-enter the original address and start over.

2. Click the Back button until you are at the desired page. 
3. Look in the history listing that the browser keeps during your active session. Clicking on one of the entries will take you back to that point.

4. Use the Address or Location Entry drop-down arrow. Browsers typically keep track of the last 10 addresses you manually typed and visited.

- Single-click on the small down arrow to the right of the address or location entry line.

- A drop down list of addresses will appear.

- Single-click on one of these addresses to return to that page.

\section{What is a cache file?}

In order to speed up the use of the Internet and reduce connect time, web browsers use a cache system to store temporary Internet files Each time you visit a site, all of the graphics and text are downloaded to a temporary (cache) file on your disk. Thus, when you return to a page during a session, the browser uses the cached files to save time. This has two implications. First, if you return to a page during a session you should get in the habit of clicking on the 'reload' button. This will override the cache and tell the browser to go back out to the Web and read the page again. If anything has changed you will receive the updated information. Second, cached files consume a lot of disk space — sometimes as much as 20 million bytes—and need to be emptied from time to time.

\section{How can I clear temporary (cached) files?}

Netscape users can empty the cache by:

- Single clicking on the 'Options' menu and selecting 'Network Preferences'.

- A Preferences dialog box will appear. Single-click on the 'Cache' tab.

- Single click on the 'Clear Disk Cache Now' and 'Clear Memory Cache Now' buttons.

- Netscape will delete all of the temporary (cached) files, thereby freeing system resources.

Internet Explorer users can empty the cache by:

- Single clicking on the 'View' menu and selecting 'Options'.

- An 'Options' dialog box will appear. Single-click on the 'Advanced' tab.

- Toward the middle of the page is a section entitled 'Temporary Internet files. Single-click on the 'Settings...' button.

- A 'Settings' dialog box will appear. Single-click on the 'Empty Folder...' button. 
- A box will appear verifying that you want to delete all temporary Internet files. Singleclick on the 'Yes' button to clear the cache.

\section{Skills Check}

All of the lessons for this course will be delivered via the world wide web. In addition most of the resources you will be reviewing for this course are web based. In order to "surf" the web effectively you will need to be familiar with the basic navigational methods available through your browser. The following is a list of techniques that you should know for this course:

- Opening a web site using clickable URLs or typing the address.

- Using the Forward and Back navigation buttons.

- Using the Bookmarks or Favorites feature to go to previously visited sites.

- Printing and Saving text from web pages.

- Setting preferences for your default homepage (start page).

- Clearing the cache (temporary Internet files) from your machine.

If you are unfamiliar with any of the items above, contact your mentor or the RuralNet on-line community for assistance. Netscape users may review the RuralNet summer workshop notebook (sections $\mathrm{G}, \mathrm{H}, \& \mathrm{I}$ ).

\section{Assignment 2.1:}

A. Ask your technology contact or your principal if your school has a 'home' page on the Web. If so, enter the address in the address (location) block and press enter to go to the page. 'Surf' around the web site using the forward and back buttons, following links, and scrolling around. Make notes as you go. If your school does not have a home page, find out if a similar school in your district has one and use that address. The Bell Atlantic World School's website lists all the schools in West Virginia that have their own web site or homepage. The URL is http://www.bell-atl.com/wschool/html/whatsnew/colist.htm.

B. Find the addresses for two more schools in your district or in the state. You might want to send a message to the listserv asking for other peer-teacher's school home pages. Review these web sites as you did your own schools.

C. Send your mentor a brief e-mail describing your school's page (or other school in part A). Tell the mentor what you liked, what you did not like, and your overall impression. Next, provide your mentor with a comparison of the site in part A with the sites in part B. Finally, tell your mentor what you might do to improve the site in Part A. As always, don't forget to cc: yourself. 


\section{RuralNet Teaching Resources}

Since the project started, the RuralNet staff has been collecting and organizing educational resources (most of which have been submitted by RuralNet participants). For this part of the lesson, you will explore the Teaching Resources section of the RuralNet website, using it as a 'jumping off point' to locate information for your draft curriculum framework. Teaching Resources at the WV K-12 RuralNet Project are divided into four main components:

- RuralNet Teachers Top 10 URLs

The RuralNet Teachers Top 10 URLs is a list of the current favorite URLs of the RuralNet teachers. The Top 10 URLs for various math and science topics are listed by subject.

- RuralNet Framework Database

The RuralNet framework database is where some of the teaching frameworks that have been developed as part of the WVRK-12 RuralNet Project are kept. Use this database to search for lesson ideas that use Internet resources.

- RuralNet URL Database

The RuralNet URL database lists URLs that have been collected and evaluated by teachers as part of the WV K-12 RuralNet Project. The RuralNet Database is NOT currently being updated. Users will encounter error messages.

- Internet Collaborative Activities

RuralNet has a program of collaborative activities that provide examples of how the Internet may be used in classroom (you should have reviewed most of this information in Lesson 1).

\section{Assignment 2.2:}

Explore the teaching resources on the RuralNet web site. Send an e-mail message to the listserv and cc your mentor listing three URLs that are new to you and that you will find useful in creating your framework.

\section{Bookmarks \& Favorites}

Because there are millions of 'home pages' on the World Wide Web, and because a considerable amount of 'surfing' involves following links from web page to web page, the chance of you finding one particular page later is extremely small. For this reason Web browsers provide a facility that allows you to 'mark your place' so that you can return later without resurfing the web. This is done by setting 'bookmarks' (in Netscape) or 'favorites' (in Internet Explorer) to record the URL (address) of a given page. 
Bookmark and favorites programs allow you to organize URL's by adding, deleting, and grouping them into folders. Bookmark \& favorites files can be shared between different users by easily transferring the files via e-mail.

\section{Activity:}

Practice the following activity until you are comfortable with the basic bookmark/favorites operation:

\section{Netscape users:}

- Open Netscape and single-click the 'Bookmarks' menu.

- Single-click 'Add Bookmark' to create some bookmarks on your machine.

- Single-click on 'Go to Bookmarks' Examine the menu bar and look at the various dropdown menus.

- Single-click the 'Item' menu and practice adding a folder using your name as the title.

- Place some bookmarks in your folder by clicking and dragging.

- Create another folder using a name of your choice and place some bookmarks into it.

- Return the bookmarks to their original location.

- Delete the second folder, leaving the one with your name.

\section{Internet Explorer users:}

○ Open Explorer and single-click the 'Favorites' menu.

- Single-click 'Add to Favorites' to create some bookmarks on your machine.

- Single-click on 'Organize Favorites'. An 'Organize Favorites' dialog box will appear.

- Practice adding a folder using your name as the title.

- Place some favorites in your folder by using the 'Organize:' buttons or clicking and dragging.

- Create another folder using a name of your choice and place some favorites into it.

- Return the favorites to their original location.

- Delete the second folder, leaving the one with your name.

You are now ready to create bookmarks/favorites for your use and place them into your own folder. 


\section{Assignment 2.3:}

17. Create a bookmark or favorites folder using your topic that you selected in lesson 1 as the name.

18. See if you can find at least five web sites that pertain to that topic. You might look in literature, magazines, brochures, or other printed material; you might ask other teachers for suggestions; you might surf around and follow links from pages you have been to previously.

19. Use your browser to load each address. Create a bookmark/favorite for each site and place it into the folder you created above.

20. Save the folder to a disk file called 'Assign23'

21. Send the file to your mentor along with a short description of the contents.

\section{Skills Course (Fall '98):}

\section{Lesson 3: Developing Internet Search Strategies}

\section{Assignment Due Date: November 1, 1998}

\section{Objective:}

To re-introduce some of the common Internet/WWW search tools, and to help the peer-teachers improve the efficiency of their online searches.

\section{Outline}

- Introduction

- $\quad$ Planning a search - some useful strategies.

- $\quad$ Assignment

- $\quad$ Reference: Search Engine Index

\section{Assignment Summary:}




\section{Assignment 3.1:}

Develop and conduct general internet searches on your course topic using 2 different search engines. Evaluate the results and post a report to your wvrk12 listserv topic group including the top 3 url's found and ratings of the search engines used.

\section{Introduction}

Remember this past summer's workshop when you began to understand just how vast the WWW is? Your workshop leaders gave you topics to search, and you found both everything you couldn't use (and some of it was very interesting) and nothing you could use. If you were trying to find some information about watersheds, you probably entered something like "water monitoring on 12-Pole creek using macroinvertebrates" - No resources found. You then probably retreated and typed in "watershed" and - 85,678 unique URLs returned.

As you practiced your searches, you probably began to get a better feel for finding things on the Web. Some search terms were too specific and some too general, some search engines were better than others for specific topics, some were faster and some were easier. You might also have noticed some reacted differently when you used more than one word in your search, some connected the words, and others considered them separate.

The purpose of this lesson is to review some of the things we learned about searches this past summer, introduce some new ideas and concepts, and to give you some practice in searching the Web for resources related to your topic. Just as we did this summer, we will be sharing these results with the other RuralNet teachers.

\section{Lesson Reference:}

An excellent Web site we will be referring to throughout this lesson is from Okanagan University College in British Columbia entitled, "Sink or Swim: Internet Search Tools \& Techniques," written by Ross Tyner and is housed at Okanagan University College in British Columbia.

Tyner, Ross (1996, May 10). Sink or Swim: Internet Search Tools \& Techniques [WWW document]. URL http://oksw01.okanagan.bc.ca/libr//connect96/search.htm.

If you have difficulty connecting to this site here are 2 alternate "mirror" sites of the same document:

- Sink or Swim at the WV K-12 RuralNet Website

- Sink or Swim at the British Mirror Site

\section{Planning a Search:}

This example reflects the discussion in the Sink or Swim article: "Search Strategy" 
The more focused your search the greater likelihood of reaching the types of resources your are interested in. To help you get started, follow through this search strategy sequence utilizing the example of frogs and pollution.

\section{Step 1: Try to build your topic into a question.}

For example, say our topic of interest has to do with frogs that live in and around a small stream. What kind of question can we ask? Some might be:

- What kind of frogs live in and around streams?

- How do those frogs live (what do they eat, where do they stay, what eats them)?

- How are the frogs effected by changes in the stream water quality?

- Do scientist use frogs as a stream health indicator species?

- What types of pollution effect frogs, how?

This looks like we're actually asking several questions. Which may be why when I type "frogs and streams" in as a search topic I get forty thousand URLs. Let's say at this point I decide I really want to know how frogs are effected by water pollution.

\section{Step 2: List the important concepts in your question.}

If we make a list for the example, we would probably come up with: water pollution, streams, frogs, populations, change, pollutants, water quality.

\section{Step 3: List possible synonyms for the terms from step 2.}

Such as:

- $\quad$ frog - amphibian, toad, tadpole

- $\quad$ streams - creeks, tributaries, watersheds, (and we might also consider lakes and ponds)

- water pollution - acid mine drainage, runoff, industrial waste. Acid rain

\section{Step 4: Decide on the types of information you want.}

This step requires some thought as to what you want to do with the resources you find on the web and what task you are working on which has brought you to the 
search. If you are writing an article about the effects of pollution on frogs you may want a broad range of information, but if you are trying to get ideas on teaching a 3rd grade lesson on the topic you may want to look at online lesson plans. Other possibilities are: pictures, sounds, names of scientists working with frogs, frog clubs, frog stories, frog games, research centers, zoo exhibits, research grants, science fair projects,....

Adding such terms as, K12, science, lesson, scientist, agency, zoo, will help locate the type of resource you are seeking This step may also direct you to some specialty search engines or organizations which house the type of information you are seeking (see step 6).

\section{Step 5: Build your search logic.}

This refers to how you will link the terms you have identified. Each search engine has a different syntax of symbols and word sequences which allow you to focus your search request. Link now to the Okanagen site outline page and review the section on Boolean Logic.

My initial search phrase might be amphibians and pollution. I have chosen to start with more general topics rather than the more specific. I may get a few sites I can't use, for example a document about newts, but the results of this search may help me narrow the search topic.

\section{Step 6: Choose a search engine and begin the search.}

Choosing a search engine to match the type of information you are seeking is a helpful part of successful searches. Search engines can be separated into 3 categories: General, Topical, and Special Interest. (See "Search Engine Comparisons" in the Sink or Swim web page)

Different types of search engines generally provide different results, for example:

- A general search in AltaVista on the terms (pollution and frogs) yields 41940 documents listed, websites which have the highest occurrences of these terms appear at the top of the list.

- A general search in Lycos returned 225 documents which at first glance appear to be more highly associated with the topics I was looking for

- In contrast, a search in Yahoo! (a topical search engine) using the same terms returned 1 category which matched (Science:Zoology:Animals, Insects, and Pets:Reptiles and Amphibians:Frogs:Deformed Frogs) containing links to 8 web sites all of which dealt with the effects of pollution on frogs. 
- A search in the Smithsonian Museum of Natural History (a special interest search engine) provided 18 references to frogs.

Math Links for the example:

Some related topics for math teachers might be:

1. amphibian population statistics (a very controversial topic now.) Work could be done involving how the populations change over the year or how they are effected by pollution. This could involve percentage, statistics, graphs, and equations.

2. ecology-related issues such as the number of amphibians that can be supported by streams of different size (which might include the area of the stream, the volume of water, and the velocity of flow.) This could involve graphing, ratios, and statistics.

\section{Assignment:}

1. Develop a written search strategy for your topic. This should include some logical progression similar to the steps listed previously.

2. Select a search engine and conduct an Internet search utilizing the terms and phrases you have developed. Links to search engines are located on the "Net Search" button on your browser, at the "Surf or Swim" site in the Search Engine Comparison section and elsewhere on the Internet. Review the search logic syntax in the help section of the search engine you select before conducting your search to gain an understanding of how you need to organize your terms for the best results.

3. Review the information ("hits") found by the search engine. If you get too many you may wish to refine your search query terms. (Note: as a general rule the first 3 pages of hits provide the "best" matches). Bookmark the "good sites" for later reference.

4. Try your search strategy utilizing another general search engine or a Topical search engine. Review the hits returned.

5. Write a brief message to your WVRK12 listserv topic group sharing the results of your searches. (Don't forget to put your Topic Group ID on the Subject line of your message. Also, be sure to CC: yourself and your mentor.)

Include:

- Your topic and a brief description of the search strategy you used. Include any questions you built, concepts, synonyms, and so on.

- Give a brief rating and comparison of the search engines you used (something like a 1-5, 1 = Excellent, 5 = "lots of potential, could do much better").

- Provide a list of the TOP 3 sites you found for which support your topic area. 


\section{Reference: Search Engine Index}

\section{General Search Engines and Indexes}

$\underline{\text { Alta Vista }}$

$\underline{\text { Lycos }}$

$\underline{\text { Excite }}$

Open Text Web Index

$\underline{\text { Hotbot }}$

$\underline{\text { Yahoo! }}$

$\underline{\text { Infoseek }}$

$\underline{\text { Magellan }}$

\section{Search engines which search multiple search engines}

$\underline{\text { Metacrawler }}$

EZ-Find at the River

$\underline{\text { Dogpile }}$ $\underline{\text { WebCrawler }}$

$\underline{\text { LinkStar }}$

\section{Groupings of many different searching tools}

All in One

$\underline{\text { Search.Com }}$

Beaucoup Search Engines $\underline{\text { Search 4it! }}$

$\underline{\text { iTools }}$

\section{Specialty Education Search Engines}

ED's Web

$\underline{\text { ERIC Database }}$

$\underline{\text { AskERIC }}$

G.R.A.D.E.S.
Eisenhower National Clearinghouse:

$\underline{\text { RuralNet Framework Database }}$

$\underline{\text { RuralNet URL Database }}$ 


\section{Skills Course (Fall '98): \\ Lesson 4: Retrieving Media/Resources}

\section{Assignment Due Date: November 22 ${ }^{\text {nd }}, 1998$}

\section{Objectives:}

- To introduce a few of the many media resources available on the Internet for science and math instruction.

- To locate and save media resources from the Internet which can be used to support in class activities.

- To demonstrate, with online examples, a variety of science modules that contain images for classroom use.

\section{Outline}

- Introduction

- Recognizing File Types

- $\quad$ Capturing Images

- $\quad$ Capturing Text

- Capturing Complete Pages

- $\quad$ apturing Selected Text

- $\quad$ Viewing Saved Graphics or Text Files Using Netscape

*Note The instructions below are designed for Windows '95 and Netscape or Internet Explorer . If you are using different software, please contact your on-line mentor for assistance.

\section{Assignment Summary}

\section{Assignment 4.1:}

Download at least two different media resources from the web that you will include in your Curriculum Framework draft or use in your classroom during the year. The media resources may be:

- Text

- Graphics

- Software 


\section{Assignment 4.2:}

Post a message to your listserv group and cc a copy to your online mentor listing 2 sites that contain image or media resources you might use during the school year with a brief description of each.

\section{Introduction:}

The Internet contains a large variety of media resources available for teachers to download and use to enhance classroom instruction. These media types include software, video, sound, and graphic images to name a few. While some materials are copyright

With the increasing quantity of media available on the Internet, finding and utilizing audio, video and software can be a complex process to new computer users. Audio and video files typically require additional hardware and helper or Plug-in application Due to the wide variety of participant hardware, software, and machine configurations, this lesson will focus on capturing graphics and text and using Netscape to view these captured materials.

- Recognizing File Types:

When using the Internet you are bound to encounter a variety of file types and formats. Recognizing file extensions often helps in locating and retrieving information. The file extension, or the . (period) and letters following the file name let you know

- Example: dolphin.gif dolphin is the file name

.gif is the file extension and indicates an image file type.

(Click here to view a brief list of some common media file extensions.)

\section{Capturing Images:}

Images are stored as binary files. There are various formats for compressing and storing these files, the two most common are GIF and JPEG. GIF (Graphics Interchange Format) is the most widely used and is well matched to the capabilities of the typical computer.

\section{A. Create a folder on your hard drive to store captured web resources.}

\section{Windows 95 Instructions}

\section{Open My Computer}

2. Double click on the Drive where you want to create the folder.

3. Click on the File menu bar, then click New and Folder.

4. A folder entitled New Folder will appear.

5. Type in a folder name and press Enter.

B. Locate an image that you can include in your curriculum framework draft. (Click here for a link to some environmental education resources that contain images.)

C. Download the selected graphic image to your hard drive or a diskette. 


\section{Netscape \& Internet Explorer Instructions}

1. Position the cursor over the graphic you wish to capture.

2. Single click the RIGHT mouse button on the image.

3. Select Save Image As $O R$ Save Picture As...

4. Select the disk and folder where you want the file to be saved.

5. Give the image a name or leave it as the default name.

6. Single click on the Save button

\section{Capturing Text}

Web browsers allow you to save the text from a web page as a file on your computer or diskette.

\section{Capturing Complete Pages:}

While you can capture only a selected portion of text, this often leads to information being taken out of context. To retain accurate context, one may capture the complete Web page text. NOTE: the steps below will save the textual information, but in $\mathrm{m}$ To save a text page using the File menu:

1. Open the web page that you wish to capture.

2. Single click on the File menu select Save As $O R$ Save As File...

3. Select the disk and folder where you want to save the file.

4. Give the file a name or leave it as the default name.

5. Select the Save as type: You can save the current page as a source (HTML) file or a text file.

(A file saved in HTML retains the format coding of the original page and can be reopened in your web browser and some word processors. A fi

6. Single click on the Save button

*TIP*

If you plan to view the text using a web browser, save the file in HTML format (.htm or .html). If you plan to view the text in a word processor, save the file in text format (.txt).

\section{Capturing Selected Text:}

Often a homepage contains too much text for an individual to save. You may want to only capture a portion of the available text and paste it into a text document for future use. (Remember to capture enough text so that the context of the information is Saving Text Using the Copy \& Paste Functions: 
7. Highlight the portion of text you wish to capture. * Note: you may also use the Edit/Select all function to capture all text contained on a specific web page.

8. Single-click on the Edit menu and select Copy.The text is now on the Windows clipboard and can be pasted into a document for future use.

9. Use the Start menu to open a word processor or the Windows Notepad.

10. Single-click the word processor Edit menu and select Paste.

11. Save the File

*Save the file before closing the word processor or the file will be lost.

\section{Viewing Saved Graphics or Text Files Using a Web Browser}

Saved files may be opened using a variety of software packages, inserted into word processing documents, or displayed in a web browser. It is recommended that you always preview a text or graphic file to be sure that you have captured what you intended. Follow the steps below view your saved image and text files.

1. Open Your Web Browser Program

*Note: An Internet connection is NOT needed to view files saved on disk.

2. Single click on the File menu Select Open OR Open File.

3. Select the file location (If using Internet Explorer you may need to select browse).

4. Select the file type or All Files (to get a comprehensive list)

5. Single-click on the file name icon to select it and then click the Open box The selected file will open in the web browser application for viewing.

\section{Assignment 4.1}

Using the instructions above, download at least two different media resources from the web that you will include in your Curriculum Framework draft or use in your classroom during the year. The media resources may be:

- Text

- Graphics

- Software

Assignment 4.2 
Post a message to your listserv group and cc or forward a copy to your online mentor listing 2 sites that contain image or media resources you might use during the school year with a brief description of each.

\section{Fall '98 Term Projects: Journal Entry Assignments}

Each RuralNet participant is required to submit journal entries covering a wide variety of topics related to the Internet lessons, collaborative activity, and curriculum framework. These entries allow us to keep track of your progress, successes, and diff *Submit all Journal Entries via electronic mail to journal@www.ruralnet.wvu.edu on or before the due date. Be sure to CC your mentor.

\section{Journal 1 (Due: September 13)}

How important do you feel it is for teachers to have Internet access? Why?

\section{Journal 2 (Due: September 20)}

How do you see the Internet being incorporated into your curriculum? What changes will need to take place in your school to accomodate the use of the Internet as an instructional tool?

\section{Journal 3 (Due: September 27)}

Compare Internet with traditional resources you use in your classroom/laboratory activities. List some pros and cons of each for classroom use.

\section{Journal 4 (Due: October 4)}

To what extent do you see Internet resources replacing traditional ones?

\section{Journal 5 (Due: October 11)}

What needs to happen to the Internet to make it more useful to the classroom teacher?

\section{Journal 6 (Due: October 18)}

Describe the level and types of interaction you have had with other faculty members about the role of the Internet in the classroom. What have been some of their questions and comments?

\section{Journal 7 (Due: October 25)}

Write about your experiences using the Internet thus far. How are you progressing with your Internet skill development? How are you progressing with the integration of the Internet into your science classes?

\section{Journal 8 (Due: November 1)}

What advice do you have for other teachers who are beginning to use the Internet? What would you tell them are some of the benefits/pitfalls of using the Internet? 


\section{Journal 9 (Due: November 8)}

Describe how you structured and monitored Internet-based activities with your students.

\section{Journal 10 (Due: November 15)}

Describe your students' attitudes toward use of the Internet and some of the ways the use of the Internet has affected students. Please share specific examples.

\section{Journal 11 (Due: November 22)}

What search strategies have been helpful to you as a teacher? Describe some of your successes and frustrations searching for Internet resources.

\section{Journal 12 (Due: November 29)}

What impact has the Internet had on your teaching science? Include your thoughtss related to science process, content, and attitudes.

\section{Fall '98 Term Project: Collaborative Project}

Assignment Deadline: November $30^{\text {th }} 1998$

\section{Objectives:}

1. To be aware of the different ways that the Internet can be used for effective learning in the classroom.

2. To participate in a collaborative project

3. To evaluate a collaborative project

\section{Collaborative Project Outline:}

- What is a Collaborative Activity?

- What are the Benefits of Collaborative Projects?

- What Different Types of Collaborative Projects are there?

\section{Assignment Summary:}

The date for this assignment to be completed is November $30{ }^{\text {th }} 1998$ - you will need to have decided which project you are going join by September $20{ }^{\text {th }} 1998$. There are three parts needed to complete this assignment.

1. Part One - Choose a collaborative project to join (by $20^{\text {th }}$ September 1998).

2. Part Two - Participate in a collaborative project and keep a record of your participation. 
3. Part Three - Post a message, answering questions about the collaborative activity that you joined, to the ListServ and cc your mentor about the collaborative project you became involved with.

\section{What is a Collaborative Activity?}

There are many different ways to integrate the World Wide Web (WWW) into the classroom. The most basic use of the WWW in the classroom is for the teacher to gain access to up to date materials for use in the classroom, or encouraging students to use the Internet as a library resource. While both of these are valid and worthwhile ways of integrating the WWW into the classroom, the WWW is only one component of the Internet, email being another common use of the Internet.

Rather than just using the WWW as an information resource, a growing movement is developing to encourage teacher and students in distinct locations, to work together using email and the WWW. These activities are known as collaborative activities. Today (1998), there are many examples of collaborative activities, and the purpose of this term long project is to introduce you the different types of collaborative projects and how they can be used in your classroom to enhance student learning.

\section{Examples of collaborative activities include:}

- Sharing data with another school via email e.g. two schools in different parts of the state collecting the same information on the wildlife in their area and then sending this to a partner school to compare.

- Electronic Fieldtrip e.g. Bombay Hook National Wildlife Refuge Delaware - Wildthings '98 -Shorebirds: Running on Empty on Thursday, October 8, 1998, 12:00 Noon - 1:30 p.m. ET Grades 4-8

URL: $\underline{\text { http://www.pwnet.org/ }}$

- Collecting data and sending the data to one location. The data is then shared with all participants. e.g. Collecting Acid Rain, this International project is run by Project SWOOPE in Fairmont. Email Terry Kerns on Kanawha@aol.com Terry provides lots of help and curriculum resources to support this activity.

- Online Chat e.g. talking to the Shuttle crew when they are in orbit. See the NASA Quest site at: http://quest.arc.nasa.gov/space/ for more details.

\section{What are the Benefits of Collaborative Projects?}

Regardless of the project subject or content, the process of working online in collaborative efforts is increasingly important to our students. Many will apply these processes and skills in future work or research. Gaining this experience while in school may enhance our students future employability. This is especially true of the science and math fields. In fact, the Internet was originally conceived and designed as a means for research scientists to communicate and share data on ARPAnet, (Advanced Research Projects Agency) the predecessor of today's Internet. 
Other student benefits that have been reported are that student motivation increases and that learning takes place in a meaningful setting, as science is related to real life.

\section{What Different Types of Collaborative Projects are there?}

The most widely referenced list of the different activities of how the Internet can be integrated in the classroom is Judi Harris' Network-Based Educational Activity Structures. Harris breaks down the different Internet activities into three groups:

- Collaborative Problem-Solving Projects

- Information Collections

- Interpersonal Exchanges

When most people refer to collaborative projects or collaborative activities in the classroom, they are referring to an activity in Harris's Network-Based Educational Activity Structures.

On-Line Projects, by W.J. "Rocky" Rohwedder, Ph.D. and Andy Alm, provides broader categories of collaboration project types based on the Harris model. These groupings can be used for any subject area with most of the examples found here related to environmental education. This section is from the online text: Using Computers in Environmental Education.

\section{Asssignment Part One - Choose a collaborative project to join}

Choose a collaborative project to participate in during the Fall 1998 RuralNet on-line course. There are many examples of each of these different types of projects on the Internet. You can choose any project that meets the following criteria:

- The project meets at least some of the instructional goals and objectives of the West Virginia Science Curriculum Framework.

- $\quad$ The project ought to have started by November 15th 1998.

RuralNet has provided a sample list of some collaborative projects you might like to choose from. The list has been divided into three groups, and their descriptions are all found in the main Ruralnet web site, under Collaborative Activities, (you will need to use your Netscape back button to return to this page):

- $\quad$ RuralNet Collaborative Projects

- West Virginia Collaborative Projects

- Finding a Collaborative Project

Below are listed some sites, which provide guidelines for selecting, structuring, implementing, and evaluating online collaboration projects. In reviewing these sites try to glean a handful of questions or criteria which are most important to selecting or implementing a project of this type into your classroom. Think about these questions when you are choosing a collaborative project to join.

- $\quad$ AT\&T Learning Circles Teacher Guide

This guide is recognized as one of the leading models for planning online collaboration in 
$\mathrm{K}-12$ education. There is a lot of material here so you may need to surf to find what you are looking for. In Phase 3 there is an excellent discussion on planning your activity including information on types of activities for specific goals.

- Judi Harris: Organizing and facilitating telecollaborative projects

This is an easy to follow framework for planning your involvement in an online collaborative process.

- Bill Burrall's Integrating Telecomputing into the Curriculum Page

The section on the bottom Bill's website called "The Basics of a Collaborative Telecomputing Project" provides useful guidelines for planning and conducting projects. Many other resources and examples of online collaboration are also available here.

- Considerations For Becoming Involved (evaluation criteria)

Provides a simple checklist of items to consider when thinking about creating or joining an online collaborative project.

Email your mentor with your chosen collaborative project by September 20th 1998.

\section{Assignment Part Two - Participate in a collaborative project and keep a record of your participation.}

Participate in a collaborative project and keep a record of your participation. Submit this record to your mentor by November $30^{\text {st }} 1998$. This record can be submitted electronically or on a disk to your mentor. The record should contain the following:

- Emails on how you joined the activity

- All email sent and received while you participated in the collaborative activity

- All data you collected while part of the activity.

You can combine all the materials into one text file and annotate each section within the document.

\section{Assignment Part Three - Post a message to journal@www.ruralnet.wvu.edu}

The message must answer the questions below about the collaborative activity that you became involved with, and you must cc your mentor. The message must answer the following questions:

- The name and type of project you participated in e.g. is it a key pals project? virtual field trip project (use Judi Harris's Activity Structure)?

- A brief description of the project

- Teaching objective it met for you

- Whether or not your students became more motivated by participating in the project.

- The management skills you need to participate successfully in a collaboration project 
- The Internet skills you need for on-line collaboration

- How would you change/improve the project you participated in?

- What problems do you see in using collaborative projects in your classroom?

- Would you do it again?

\section{Fall '98 Online Course: Draft Curriculum Framework}

\section{Assignment Deadline: December 7, 1998 Objective:}

To design a draft framework for using the selected topic or activity, along with the associated Internet/WWW resources, in the classroom.

\section{Outline:}

- Introduction

- Assignment

- Graded Option (C\&I 380 or CI 582-101)

- CE Pass/Fail Option (C\&I 930 or CI 564-101)

- No Credit Option

- Examples of Integrated Lessons

- Internet Reference Citation Resources

\section{Introduction}

You have come now to the final assignment for this semester. At the beginning of this course you were asked to select some topic or subject that you usually teach or will be teaching this spring. You've used this topic as the focus for revisiting and reviewing many of the techniques and tools we learned this past summer in the workshops. You have talked about how you can gather resources dealing with your topic by using e-mail, listservs, Netscape and search engines. You've shared and discussed your findings with your mentor and with a number of your fellow peer teachers. Now its time to take the great leap and figure out how you can use all of this in the classroom. 
Simply put, that's the assignment: to build a draft framework for teaching your topic utilizing the Internet resources you've identified throughout the semester. This framework could be a traditional lesson plan, an entire unit, a series of activities, or a special project. That's your choice. The framework should reflect how you actually work in your classroom. The detail required for your framework assignment will slightly differ, depending on the grade option for which you are registered. The requirements are listed in the assignment sections below. This framework is intended to be a draft of something you will teach or a review of what you have taught if you have already implemented the activities.

You will be posting your framework to the listserv for the other peer teachers in your affinity group to review. We want as many people as possible to see, learn from, and eventually use, what you have worked to produce. Likewise, you will be able to benefit from the frameworks developed by the other teachers in your affinity group. This framework will also serve as the starting point for next semester's online course on integrating internet resources into instruction.

\section{Graded Option Assignment}

- Part 1. Develop a framework (again, this framework could be a lesson plan, a unit, a project or combination of several formats) for teaching your topic.

The framework should include:

\section{General Information:}

A. Title

B. Author

C. Grade Level

D. Subject

E. School

\section{Framework Body:}

A. Goals or Objectives

B. Introduction

The introduction should provide information on the topic of the lessons, general uses of the internet in this project, student involvement, collaborative partners, approximate time frame, ... etc.

C. Outline of Activities:

In outline format please list the series of activities and highlights of your framework.

III. References:

List at least 10 internet materials (URL sites) which you might use in relation with the above activities. Each reference must be cited using APA format.

- Part 2. Post your curriculum framework to your affinity group listserv. (Be sure to CC: yourself and your online mentor)

\section{CE Pass/Fail and No Credit Option Assignment}


- Part 1. Develop a framework (again, this framework could be a lesson plan, a unit, a project or combination of several formats) for teaching your topic.

The framework should include:

\section{General Information:}
A. Title
B. Author
C. Grade Level
D. Subject
E. School

\section{Framework Body:}

A. Goals or Objectives

B. Introduction

The introduction should provide information on the topic of the lessons, general uses of the internet in this project, student involvement, collaborative partners, approximate time frame, ... etc.

C. Outline of Activities:

In outline format please list the series of activities and highlights of your framework.

\section{References:}

List at least 5 internet materials (URL sites) which you might use in relation with the above activities. Each reference must be cited using APA (American Psychological Association) format.

- Part 2. Post your curriculum framework to your affinity group listserv. (Be sure to CC: yourself and your online mentor)

\section{Examples of Integrated Lessons:}

The following are frameworks developed by RuralNet teachers during the Spring 1996 Online course. While these are full lessons not drafts, the frameworks you develop for this assignment need only include the previously listed items. These examples have been selected because they reflect integration of multiple subjects and present thematic approaches to the topics. Other lesson plans are available at the RuralNet Teacher Generated Lesson Plans archive.

\section{Elementary}

Microorganisms in Our Water (V. Allen)

My Neighborhood is a Wetland (D. Peduto \& D. Wilson)

Endangered Species Awareness (J. Hampton)

\section{Middle School}

The Importance of Waterways (B. Burrall)

Is It Raining Vinegar? (C. J. O'Connell) 
Calendars and Leap Years (P. Ingle \& J. Hopkins)

High School

Watersheds (K. Ash)

$\underline{\text { Stream Reclamation in West Virginia (S. Ashworth) }}$

Ancient Math and Science (P. Lucas)

\section{Internet Reference Citation Resources:}

American Psychological Association (APA) Format Summary [from Prima Community College] http://www.library.pima.edu/apa.htm

Using American Psychological Association (APA) Format [from Purdue Univ.] http://owl.english.purdue.edu/files/34.html

Web Extension to American Psychological Association Style (WEAPAS) http://lamp.cs.utas.edu.au/citation.txt

Guide for Citing Electronic Information http://www.wilpaterson.edu/wpcpages/library/citing.htm

How Do You Cite URL's in a Bibliography? by Jeff Beckleheimer http://www.nrlssc.navy.mil/meta/bibliography.html

\section{Fall '98 Online Course: Framework Report Paper}

\section{Assignment Deadline: December 7, 1998 \\ Framework Report Paper Guidelines:}

Note: This assignment meets the requirement for the Graded Option (C\&I 380 or CI 582-101)* listed in the course syllabus.

For this assignment you will develop a formal paper analyzing and critiquing your framework. Your Paper should include the following components:

- Header:

- Title:

- Author:

- Grade Level:

- Subject: 
- School:

\section{- Introduction:}

A short (1 page more or less) description of your framework, including the type of instructional unit chosen, resources to be used, level of collaboration, and other such material.

\section{- Analysis and Critique:}

In this section your will analyze and critique your framework. What are the strong and weak areas? What is the impact of Internet generated resources? How has your framework used Internet resources to enhance what might normally be covered without such resources? What other questions can you use to examine your framework?

This section could provide support for the design of your framework. Further discussion may include:

A. Review of similar ongoing or completed projects, implementation strategy, time plan, how students will get involved, challenges to implementation, etc.

B. How the items in your framework support the strategies listed in the WV Science Curriculum Framework.

C. A list of TO DO items: resources needed, facts to gather, preparatory lessons, questions to be answered.

\section{- Conclusion:}

End your paper with a conclusion section (1 page more or less). Did the use of Internet resources enhance the framework? Was the enhancement worth the effort? Do you think your students will have a better learning experience? Would you recommend that other teachers use Internet resources when preparing their lesson materials?

\section{- References:}

This section should list both Internet/WWW resources and non-Internet/WWW resources. Your references will probably be for sites you have already reviewed in previous lessons. Most of these will probably be resource sites for preparing your lessons, sites for your students to visit, or the addresses of comparable projects you are reviewing.

Citations should follow the APA standards. Guidelines for citing Internet/WWW resources can be found at the following sites:

\section{American Psychological Association (APA) Format Summary [from Prima} Community College] http://www.library.pima.edu/apa.htm

Using American Psychological Association (APA) Format [from Purdue Univ.] http://owl.english.purdue.edu/files/34.html

Web Extension to American Psychological Association Style (WEAPAS) 
http://lamp.cs.utas.edu.au/citation.txt

Guide for Citing Electronic Information

http://www.wilpaterson.edu/wpcpages/library/citing.htm

How Do You Cite URL's in a Bibliography? by Jeff Beckleheimer

http://www.nrlssc.navy.mil/meta/bibliography.html 


\section{Spring 1999 Online Course - Index Page

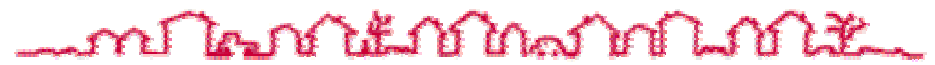

\section{Course Information}

- Syllabus

RuralNet

Home Page

About

RuralNet

Teaching

Resources

\section{On-Line}

Conrings

\section{Watershed \\ Switchboard}

Collaborative

Activities

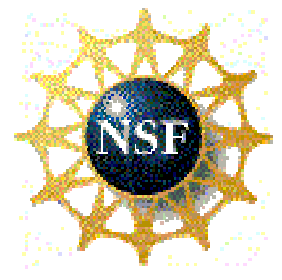

- Participant Registration Information

- Course Evaluation

\section{Assignment Detail}

- Lessons (All Options)

- Lesson Overview

- Lesson 1 - Group Introductions

- Lesson 2 - Group Framework Review

- Lesson 3 - Grade Level Framework Review

- Lesson 4 - Large Group Discussion Forums

- Term Projects

- Revised Curriculum Framework (All Options)

- Scrapbook/Portfolio (Graded Option Only)

- Evaluation Paper (Graded Option Only)

\section{Course Resources}

- Search Frameworks by Grade Level

- WebBoard

\section{Mentor Resources}

- $\quad$ Mentor Guidelines

- Mentor Registration Information

- Assignment Checklists

- No Credit \& CE/PF Options

- Graded Option 
This lesson was written for the West Virginia K-12 RuralNet Project, a National Science Foundation funded project to enhance science education through Internet education.

Course offered by West Virginia University and Marshall University departments of Curriculum and Instruction.

\section{Spring 1999 Online Course - Syllabus}

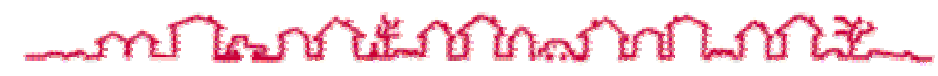

Start Date: January 25, 1999

End Date: April 23, 1999

Course Director:

Dr. Randall Wiesenmayer

West Virginia University

609E Allen Hall

P.O. Box 6122

Morgantown, WV 26506-6122

Phone: (304) 293-7022 x1815

(888) 272-2843 x1815

E-mail: rlw@wvnvm.wvnet.edu

\section{Course Coordinator:}

Marcia L. Marcolini

West Virginia University

609A Allen Hall

P.O. Box 6122

Morgantown, WV 26506-6122

Phone: (304) 293-7022 x 1819

(888) 272-2843 x1819

E-mail: $\underline{\text { mmarcoli@wvu.edu }}$

\section{Course Identification Codes:}

To obtain college credit for the fall on-line course, you must register for 3 hours of graduate credit at either Marshall University or West Virginia University. If you have not already registered, please contact the RuralNet office for the proper forms.

\begin{tabular}{|l|c|c|c||}
\hline \multicolumn{1}{|c|}{ Course Title } & Credit & WVU & Marshall \\
\hline \hline *Integrating Internet into the Curriculum(Graded) & 3 & C\&I 380 & C\&I 582-202 \\
\hline \hline$* *$ Integrating Internet into the Curriculum(CE/PF) & 3 & C\&I 930 & C\&I 564-201 \\
\hline \hline$* * *$ Integrating Internet Curriculum (No Credit) & 0 & N/A & N/A \\
\hline
\end{tabular}

* Graded option: may be used for elective credit in graduate programs if approved.

** CE/PF option: may be used for certificate renewal, salary advancement, or continuing education credit if approved by your county school board. This option may not be applied toward a graduate degree.

***No Credit option: does not require registration at either WVU or MU 


\section{Course Description:}

This discussion-based course focuses on implementation and refinement of the draft curriculum framework developed during the fall on-line course and strategies for organizing and managing Internet tools and resources in the classroom. Through collaboration, via on-line discussions, participants will share ideas, concerns, and provide feedback to assist each other in evaluating and revising classroom activities in ways that utilize Internet resources to engage students in science/math learning.

\section{Purpose of the Course:}

The purpose of this course is to:

- Provide teachers with skills needed to develop and implement an Internet based instructional framework that is useable within their current classroom situation.

- Facilitate on-line peer interaction and collaboration, both small group and in the larger on-line community.

- Identify criteria for evaluating lessons that incorporate the Internet

- Select strategies appropriate for organizing and managing Internet based instruction in the classroom

\section{Pre-requisites:}

In order to participate in the spring 1999 on-line course, individuals must:

- have completed one of the RuralNet Fall on-line courses

- make a commitment to continued on-line communication throughout the course term

(Note: due to the fact that this course is based on peer feedback it is imperative that all participants read and contribute comments on a weekly basis.)

\section{Materials:}

For successful completion of this course, each learner must have:

- A $\underline{\text { draft }}$ curriculum framework developed during the fall on-line course.

- Internet access from either home OR school.

$\circ$ An E-mail account.

- World Wide Web Browser Software (Netscape or Internet Explorer)

- E-mail Software (Chameleon, Pegasus, Eudora, etc.)

If you have any questions concerning the above items, please contact the WVU RuralNet office at (888) 272-2843 or (304) 293-7022, extension 1819.

\section{Evaluation:}

- $\quad$ No Credit \& CE/PF Options

- Graded Option 


\section{No Credit \& CE/PF Options:}

The evaluation for this course will be based upon:

1. Evidence of participation in constructive on-line discussions. *

2. Assignment Reports

3. Completion and posting of the revised curriculum framework.

*Note: Participation is considered to be timely and constructive comments, questions, or explanations.

Full descriptions of each assignment are available from the main Spring Course Index page under Assignment Detail.

\section{Grading Information (CE/PF)}

Assignment Point Value

The final grade for the CE/PF Option will be determined using the following scale:

\begin{tabular}{||c||c||}
\hline Assignment & Total Possible Points \\
\hline \hline On-line Discussion Participation & 120 \\
\hline \hline Assignment Reports & 30 \\
\hline \hline Posting of Revised Framework & 100 \\
\hline \hline Total Points & $\mathbf{2 5 0}$ \\
\hline
\end{tabular}

Scale:

\begin{tabular}{|c|c|}
\hline Points Earned & Grade Assigned \\
\hline \hline $175-250$ & Pass \\
\hline \hline Less than 175 & Fail \\
\hline
\end{tabular}

\section{Graded option:}

The evaluation for this course will be based upon:

1. Evidence of participation in constructive on-line discussions *

2. Assignment Reports

3. Completion and posting of the revised curriculum framework. 
4. Submission of a scrapbook/portfolio

5. Evaluation paper

* Note: Participation is considered to be timely and constructive comments, questions, or explanations.

Full descriptions of each assignment are available from the main $\underline{\text { Spring }}$ Course Index page under Assignment Detail.

\section{Grading Information (Graded Option)}

\section{Assignment Point Value}

The final grade for the Graded Option will be determined using the following scale:

\begin{tabular}{||l||c||}
\hline \multicolumn{1}{|c|}{ Assignment } & Total Possible Points \\
\hline \hline On-line Discussion Participation & 120 \\
\hline Assignment Reports & 30 \\
\hline Posting of revised Framework & 100 \\
\hline \hline Scrapbook/portfolio & 100 \\
\hline Evaluation paper & 50 \\
\hline \hline \multicolumn{1}{|c||}{ Total Points } & $\mathbf{4 0 0}$ \\
\hline
\end{tabular}

Scale:

\begin{tabular}{|c|c|}
\hline Points Earned & Grade Assigned \\
\hline \hline $360-400$ & $\mathrm{~A}$ \\
\hline \hline $320-359$ & $\mathrm{~B}$ \\
\hline $280-358$ & $\mathrm{C}$ \\
\hline \hline $240-279$ & $\mathrm{D}$ \\
\hline \hline Less than 240 & $\mathrm{~F}$ \\
\hline \hline
\end{tabular}

\section{Social Justice Statement:}

West Virginia and Marshall Universities are committed to social justice. The RuralNet staff concur with that commitment and expect to foster a nurturing learning environment 
based upon open communication, mutual respect, and non-discrimination. Our Universities do not discriminate on the basis of race, gender, age, disability, veteran status, religion, sexual orientation, color, or national origin. Any suggestions as to how to further such a positive and open environment in this class will be appreciated and given serious consideration.

If you are a person with a disability and anticipate needing any type of accommodation in order to participate in this class, please advise your mentor and make appropriate arrangements with the Disability Services office of the University in which you are enrolled.

\section{West Virginia K-12 RuralNet Spring Online Course - Lesson Overview}

\section{Tips for Good Grades!}

- This is a discussion based course, therefore it requires a participation commitment on your part.

- Participation is considered to be timely and constructive comments, questions, or explanations.

- Both your success and that of your peers depends on your participation!

- If you are having problems, contact your mentor OR the course coordinator.

\section{OLessons}

Lesson 1: Group Introductions(20Points) All Options

Find Group

Post Personal Introduction

Lesson 2: Group Framework Reviews All Options

Review Group Frameworks (40 Points)

Assignment Report \#1 (10 Points)

Lesson 3: Grade Level Framework Reviews All Options

Review and post comments on two frameworks outside of the group (30 Points) Assignment Report \#2 (10 Points)

Lesson 4: Large Group Discussion forums All Options

General Group Discussion Forum (30 Points)

Assignment Report \#3 (10 Points)

\section{OTerm Project}

\section{Revised Curriculum Framework (100 Points) All Options}


Completion and posting of the revised curriculum framework.

Revisions to the framework should be made with consideration for group discussions and problems experienced during implementation.

The following information is required in the revised curriculum framework:

I. General Information
A. Title
B. Author
C. Grade Level
D. Subject
E. School
F. Approximate time frame

II. Technical Criteria

A. Available Technology

(ex. 1 computer, computer lab, etc.)

B. Type of Implementation

(ex. The lesson incorporates Resources, Web Publishing, Collaboration, Etc.)

III. Framework Body
A. Goals or Objectives
B. Introduction
C. Outline of Activities

IV. References:
A. Internet (URL's)

B. Other

\section{Submission of a scrapbook/portfolio (100 points) Graded Option ONLY!}

The scrapbook/portfolio should be prepared by gathering materials throughout the semester. Materials in the scrapbook/portfolio should provide selected examples of your semester work and evidence of attempts to integrate Internet tools and resources into the classroom.

Examples of appropriate materials include:

- copies of selected/relevant on-line discussions

- lesson plans

- units

- completed student assignments or specific projects

- photographs

\section{OFinal Paper}

Evaluation Paper (50 Points) Graded Option Only! 
A short evaluation paper is due at the end of the term. This paper should address the benefits and problems of using on-line discussions as a means of developing and refining curriculum frameworks. APA format is required.

\section{West Virginia K-12 RuralNet Spring Online Course - Lesson 1}

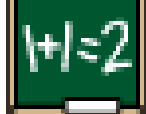

NOTE: It is helpful to print a hard copy of the lesson before beginning. Lesson 1: Group Introductions (20 Points) All Options

The purposes of this lesson are to have you find your main framework discussion group and introduce yourself to that group.

Finding Your Course Group Assignment:

1. Go to the Spring 1999 On-line Course Group Assignment Search Page (http://www2.ruralnet.wvu.edu/sp99/grpsrch.cfm)

2. Type your name in the fields provided and single-click the search button. You will be taken to the List of Sp '99 Online course Participants.

3. Single-click on your first or last name. This will take you to the Spring '99 Online Course Discussion Group Homepage. The individuals listed on this page are members of your discussion group created to review teaching frameworks for the 1999 RuralNet Spring Online Course.

- You may want to bookmark this page for easy reference during the course.

- Clicking on the "hot linked" participant names will take you to the framework discussion page for that individual where you can review their background information and frameworks or add your comments regarding their framework.

- You may also want to add the e-mail address for each person from your group to your electronic address book. A list of the group members addresses is available at the bottom of your discussion group's homepage.

Posting Your Personal Introduction: 
1. Find your name on the Discussion Group Homepage

2. Below your name you will see listed your County, School and Grade. Directly below that is a "hot link" that reads "Click here to submit your Personal Information".

3. Single-click on the line that reads "Click here to submit your Personal Information". This will take you to the Spring 99 Course: Personal Introduction page.

4. The Personal Introductions Page consists of three sections that are designed to help you provide your peers with a better understanding of the challenges you face in implementing Internet technology into your teaching.
Section 1 - Personal Introduction
Section 2 - Internet Resources
Section 3 - Special Circumstances

You must complete all three sections and then single-click the "Submit Button" at the bottom of the Personal Introductions webpage. An explanation of each section is provided on the webpage.

5. After submitting your information, go to your framework review homepage and review the information you submitted.

A. Return to your discussion group's homepage by clicking the back button or by using the bookmark (if you created one).

B. Single-click on your "hot linked" name. This will take you to the framework discussion page where you can review the background information you submitted.

C. If changes to the information need to be made, please notify journal@www.ruralnet.wvu.edu

\section{West Virginia K-12 RuralNet Spring Online Course - Lesson 2}

NOTE: It is helpful to print a hard copy of the lesson before beginning. 


\section{Review Group Frameworks (40 Points)}

\section{Part A: Post comments about group members' frameworks.}

1. Go to your discussion group's homepage.

2. Single-click on the name of the participant whose framework you want to review. This will take you to that individual's Framework Review Page.

3. Single-click on the hypertext that reads "View Full Draft Framework". This will take you to the full framework submitted by the participant.

- You may read the framework on-line or print a hard copy for your review.

4. After reviewing (or printing) the framework, single-click on the Netscape Back button.This will take you to the main review page.

5. Use the scroll bar to advance to the Background Information section of the main review page, and read the information found there. The background information will assist you in getting to know the members of your group and some of the challenges they face in integrating Internet technology into their teaching.

6. Use the scroll bar to advance to the Add Your Comments section on the main review page.

$\circ$ Read the introductory paragraph and points for consideration.

- Add your name, e-mail address, topic of comments and comment detail.

7. Single-click the "Add Your Comments" button to submit your comments. Your comments will now appear under the Framework Review Comments section of the page.

Be sure to complete the above process for all participants in your group!

\section{Part B: Review the comments posted about your framework.}

(You must do this in order to complete your assignment report.)

8. Go to your discussion group's homepage.

9. Single-click on your name. This will take you to your Framework Review Page. 
10. Use the scroll bar to advance to the Framework Review Comments. Read what your group members had to say about your framework, keeping in mind the points for consideration listed under the Add Your

Comments section.

\section{Assignment Report for Lesson 2 (10 Points)}

Assignment Reports are designed to help facilitate discussion. Course participants should use these as an opportunity to share their thoughts and feelings as well as ask for help or clarification from their group members.

1. Write a short paragraph that;

A. Provides feedback about your own framework and the comments made by your discussion group members.

B. Discusses the value of the framework comments provided by your group members.

Did the framework feedback you received consider the following?:

- What do you feel are the strengths and weaknesses of this framework?

- Review the websites used (if any), are they appropriate/quality resources?

- Does the available technology appear to be the best method for teaching this framework, or would a more traditional method be just as effective?

- Do the Internet activities appear to be relevant to learning the content? Are there other possibilities for integrating Internet resources/technology into this framework that are not considered?

- Have classroom management issues been considered as they relate to the use of available Internet resources?

2. Use e-mail to send your Assignment Report to:

3. everyone in your discussion group, including your mentor

4. the RuralNet journal account (journal@www.ruralnet.wvu.edu)

5. the RuralNet listserv (send it to the topic group that you belong to, DO NOT send it to the ALL listserv) 


\section{West Virginia K-12 RuralNet Spring Online Course - Lesson 2}

NOTE: It is helpful to print a hard copy of the lesson before beginning.

Lesson 2: Group Framework Reviews All Options

Review Group Frameworks (40 Points)

Part A: Post comments about group members' frameworks.

1. Go to your discussion group's homepage.

2. Single-click on the name of the participant whose framework you want to review. This will take you to that individual's Framework Review Page.

3. Single-click on the hypertext that reads "View Full Draft Framework". This will take you to the full framework submitted by the participant.

- You may read the framework on-line or print a hard copy for your review.

4. After reviewing (or printing) the framework, single-click on the Netscape Back button.This will take you to the main review page.

5. Use the scroll bar to advance to the Background Information section of the main review page, and read the information found there. The background information will assist you in getting to know the members of your group and some of the challenges they face in integrating Internet technology into their teaching.

6. Use the scroll bar to advance to the Add Your Comments section on the main review page.

- Read the introductory paragraph and points for consideration.

- Add your name, e-mail address, topic of comments and comment detail.

7. Single-click the "Add Your Comments" button to submit your comments. Your comments will now appear under the Framework Review Comments section of the page.

Be sure to complete the above process for all participants in your group! 


\section{Part B: Review the comments posted about your framework.}

(You must do this in order to complete your assignment report.)

8. Go to your discussion group's homepage.

9. Single-click on your name. This will take you to your Framework Review Page.

10. Use the scroll bar to advance to the Framework Review Comments. Read what your group members had to say about your framework, keeping in mind the points for consideration listed under the Add Your

Comments section.

\section{Assignment Report for Lesson 2 (10 Points)}

Assignment Reports are designed to help facilitate discussion. Course participants should use these as an opportunity to share their thoughts and feelings as well as ask for help or clarification from their group members.

1. Write a short paragraph that;

A. Provides feedback about your own framework and the comments made by your discussion group members.

B. Discusses the value of the framework comments provided by your group members.

Did the framework feedback you received consider the following?:

- What do you feel are the strengths and weaknesses of this framework?

- Review the websites used (if any), are they appropriate/quality resources?

- Does the available technology appear to be the best method for teaching this framework, or would a more traditional method be just as effective?

- Do the Internet activities appear to be relevant to learning the content? Are there other possibilities for integrating Internet resources/technology into this framework that are not considered?

- Have classroom management issues been considered as they relate to the use of available Internet resources?

2. Use e-mail to send your Assignment Report to: 
3. everyone in your discussion group, including your mentor

4. the RuralNet journal account (journal@www.ruralnet.wvu.edu)

5. the RuralNet listserv (send it to the topic group that you belong to, DO NOT send it to the ALL listserv)

\section{West Virginia K-12 RuralNet Spring Online Course - Lesson 4}

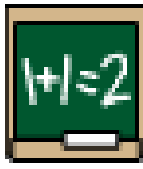

NOTE: It is helpful to print a hard copy of the lesson before beginning.

Lesson 4: Large Group Discussion forums All Options

General Group Discussion Forum (30 Points)

For this lesson we will be bringing all group participants together to discuss ideas \& concerns, answer questions, or make general comments about the class thus far. To help facilitate discussion, we will be utilizing the RuralNet WebBoard, a communication software system on the world wide web.

1. Log onto the WebBoard by following the instructions at http://www2.ruralnet.wvu.edu:70

\section{WebBoard Forums:}

There are five main discussion forums within the WebBoard; Classroom Management, New Technologies, Working the System, Information Literacy, and Merging the Internet and the Curriculum. In addition, a Technical Help Desk has been established.

2. Post at least two questions, comments or issues you discovered during the previous lessons to the webboard forums listed below. Messages should be posted to the appropriate forum.

Classroom Management:

This forum is for the discussion of machine access, managing resources, and dealing with students' on-line behavior.

Below are some example postings:

- I only have one computer in my classroom, how can I get my students involved?

- Does anyone have a good tip for managing URLS? 
- How can I keep track of what my students are doing on-line while I am teaching the rest of the class? (I only have 2 computers in my classroom).

- I was just put in charge of a computer lab, any suggestions on ways to keep my students from deleting files?

- A student may receive an obscene e-mail message or access questionable information on the Internet. How can I prepare students and parents to deal with this effectively?

\section{New Technologies:}

Post messages here if you have questions or comments about new technologies or technologies that are new to you (i.e. chat rooms, virtual adventures, videoconferencing, authoring software, or others). Tried a new technology? Share your findings with peers.

\section{Working the System:}

This forum is for open discussions on navigating administrative barriers to using the Internet.

Below are some example postings:

- How can teachers overcome the "lack of time" barrier to integrating the Internet into their classroom?

- We don't have enough money to purchase new computers. Does anyone know of available grants?

- How can I get my school administrator to see the importance of training teachers to utilize computer technology? Thus far the administration has rejected all spending in this area.

- Our school is developing a school-wide technology plan and I'm on the committee. Any suggestions?

- In what ways can school administrators encourage teachers to experiment with telecommunications?

\section{Information Literacy:}

Learning how to find, retrieve, and understand information. Developing scholarly standards for selecting and evaluating on-line information. Legal issues and policy development.

Below are some example postings:

- Acceptable use policies, does your school have one, and how is it enforced? 
- What are intellectual property rights? should I be concerned about them?

- What are some good methods for teaching students about intellectual property rights, copyright laws, and privacy issues?

- How can we help students determine good information versus sources that are deceptive and unsubstantiated?

\section{Merging the Internet and the Curriculum:}

This forum is for discussion of subject oriented topics and meeting the state standards.

Below are some example postings:

- The state standards say that I have to teach my students graphing techniques. How do I use technology to meet this need?

- I'm developing a framework on frog disection, does anyone know of a site appropriate for nineth grade students?

\section{Technical Help Desk:}

Post your computer woes here for advice from your peers.

2. Browse each of the forums listed above and post at least two follow-up messages to someone else's posting. The follow-up should provide assistance to the original author or add to the discussion clarifying the issue. Postings of Ditto or Me too and the like are not appropriate.

3. Monitor the responses to your postings providing clarification when needed.

\section{Assignment Report for Lesson 4 (10 Points)}

1. In this assignment report, participants should:

- Discuss your feelings and experiences using the Webboard medium for large group discussions.

- Did the discussions help answer your questions and provide ideas for improving your framework or incorporating Interenet resources into your classroom?

2. Use e-mail to send your Assignment Report to:

- everyone in your discussion group, including your mentor

○ the RuralNet journal account (journal@www.ruralnet.wvu.edu) 
- the RuralNet listserv (send it to the topic group that you belong to, DO NOT send it to the ALL listserv)

\section{West Virginia K-12 RuralNet Spring Online Course - Framework Detail}

\section{Revised Curriculum Framework (100 Points) All Options}

ALL course participants must submit a revised curriculum framework in order to receive a grade. Participants should e-mail their frameworks to journal@www.ruralnet.wvu.edu and also to their mentor by April 23, 1999.

Revisions to the framework should be made with consideration for group discussions and problems experienced during implementation.

The following information is required in the revised curriculum framework:

I. General Information
A. Title
B. Author
C. Grade Level
D. Subject
E. School
F. Approximate time frame

II. Technical Criteria

A. Available Technology

(ex. 1 computer, computer lab, etc.)

B. Type of Implementation

(ex. The lesson incorporates Resources, Web Publishing, Collaboration, Etc.)

III. Framework Body
A. Goals or Objectives
B. Introduction
C. Outline of Activities

IV. References:

A. Internet (URL's)

B. Other 


\section{Spring Online Course - Scrapbook/Portfolio Detail}

\section{Submission of a Scrapbook/Portfolio (100 points) Graded Option ONLY!}

The scrapbook/portfolio should be prepared by gathering materials throughout the semester. Materials in the scrapbook/portfolio should provide selected examples of your semester work and evidence of attempts to integrate Internet tools and resources into the classroom.

Examples of appropriate materials include:

- copies of selected/relevant on-line discussions

- lesson plans

- units

- completed student assignments or specific projects

- photographs

Scrapbooks/portfolios must be mailed to the University where the participant is registered for credit (postmarked no later than April 23, 1999).

Those registered for WVU credit should mail their scrapbook/portfolios to:

Marcia L. Marcolini

RuralNet Project

West Virginia University

609A Allen Hall

P.O. Box 6122

Morgantown, WV 26506-6122

Those registered for Marshall credit should mail their scrapbook/portfolios to:

George Watson

Marshall University

College of Education

Jenkins Hall 101-H

Huntington, WV 25755

The scrapbook/portfolio should be prepared by gathering materials throughout the semester. Materials in the scrapbook/portfolio should provide selected examples of your semester work and evidence of attempts to integrate Internet tools and resources into the classroom. 


\section{West Virginia K-12 RuralNet Spring Online Course - Final Paper Detail

\section{Evaluation Paper (50 Points) Graded Option Only!}

A short evaluation paper is due at the end of the term. This paper should address the benefits and problems of using on-line discussions as a means of developing and refining curriculum frameworks. APA format is required.

Participants should e-mail completed papers to their mentor and to journal@www.ruralnet.wvu.edu by April 23, 1999. 
Appendix B

Internet Usage Survey 


\section{Internet Access}

Code:

1. Do you have access to the Internet in your HOME? $\square$ Yes $\square$ No

2. Where do you have Internet access in your SCHOOL?

Please check all that apply and indicate the number of computers that have Internet access:

Location: Number:

$\square$ In my classroom

$\square$ In the library

$\square$ In a computer lab

$\square$ In the office

$\square$ No access at school

3. At your school, approximately how many hours per day do you have Internet access:

$\square$ Less than 1 hour per day

$\square 1$ to 3 hours per day

$\square$ More than 3 hours per day

$\square$ Unlimited access 


\section{Internet Usage}

1. Do you use the Internet with your students for teaching purposes? $\quad \square$ Yes $\quad \square$ No

2. Total experience using the Internet: months

3. Total experience using the Internet for teaching preparation/resources: months

4. Total experience using the Internet with your students months

5. Is ongoing Internet training available to you?

$\square$ Yes $\square$ No

6. Is ongoing Internet technical support available to you?

$\square$ Yes $\square$ No

7. Do you serve as a resource person for other Internet users in your school?

$\square$ Yes $\square$ No

8. List the Internet training you've participated in:

\section{Training}

\section{Dates}




\section{RuralNet Project}

Please use the numerical scale below to rate the following statements.

$1=$ Strongly Disagree $\quad 2=$ Disagree $\quad 3=$ Neutral $\quad 4=$ Agree $\quad 5=$ Strongly Agree

1. The RuralNet project has helped me understand why I $\begin{array}{llllllll}1 & 2 & 3 & 4 & 5\end{array}$ would want to integrate the INTERNET into school instruction.

2. The RuralNet project has helped me increase my knowledge about the INTERNET as a teacher resource.

3. The RuralNet project has helped me increase my

1
knowledge about how the INTERNET might be integrated into classroom instruction.

4. The RuralNet project has helped me become skilled in $\begin{array}{lllllll}1 & 2 & 3 & 4 & 5\end{array}$ locating INTERNET resources

5. The RuralNet project has helped me become skilled in $\begin{array}{lllllll}1 & 2 & 3 & 4 & 5\end{array}$ retrieving INTERNET resources.

6. The RuralNet project has helped me become skilled in $\begin{array}{llllll}1 & 2 & 3 & 4 & 5\end{array}$ integrating the INTERNET into instruction.

7. The RuralNet project has helped me become skilled in $\begin{array}{lllllll}1 & 2 & 3 & 4 & 5\end{array}$ organizing a classroom where the students are involved using the INTERNET.

8. The RuralNet project has helped me become skilled in managing a classroom where the students are involved using the INTERNET.

9. The RuralNet project has helped me establish professional collaborative relationships with other teachers via the INTERNET

10. The RuralNet project has helped me use the 1

2

3
INTERNET in school-based collaborative project instruction. 


\section{Impact Responses}

1. How has your CLASS PREPARATION changed as a result of participation in the RuralNet Project?

Please check all of the items that apply to your use of the Internet.

$\square$ I used the Internet to prepare classroom instruction prior to joining RuralNet.

$\square$ I use the Internet to research class lecture topics.

$\square$ I use the Internet to find hands-on activities for my students.

$\square$ I download materials for classroom teaching/presentations.

— I download materials for student use, such as handouts.

$\square$ I use the Internet to communicate with peers to share information/ideas.

$\square$ I use the Internet to find collaborative projects for my students

$\square$ My teaching preparation has not changed because of participating in the RuralNet project.

2. How has your TEACHING PRACTICE changed as a result of your participation in the RuralNet Project?

Please check all of the items that apply to your use of the Internet.

$\square$ I used the Internet in my classroom with students prior to joining RuralNet.

$\square$ I allow my students to use the Internet during class to conduct research.

I require my students to use the Internet during class to conduct research.

$\square$ I have replaced traditional textbook materials with Internet materials.

$\square$ I supplement traditional textbook materials with Internet materials.

- Students are involved in collaborative learning experiences.

$\square$ More hands-on activities are being used in class.

$\square$ More project-based learning is being used in class.

My teaching practice has not changed because of participating in the RuralNet project. 


\section{Demographic Information}

Please check or complete the following questions about you.

1. Gender: $\square$ Male $\square$ Female

2. Age: $\square$ under 30 years old

$\square 30$ to 39 years old

$\square 40$ to 55 years old

$\square$ over 55 years old

3. I teach grade(s):

4. Number of years teaching

5. Are you willing to talk with the researcher about the RuralNet project and your use of the Internet as an instructional tool? $\square$ Yes $\square$ No

6. Are you willing to participate in classroom observations? $\quad \square$ Yes $\quad \square$ No

7. If you answered yes to question 5 or 6 please complete the following:

Name:

School:

School District:

E-mail address:

Convenient days and times to be reached by telephone

Day:

Time:

Day:

Time:

Telephone number to call: 
Appendix C

Interview Protocol 


\section{Introductory Script}

\section{The following will be read to participants prior to beginning the interview.}

Good morning (afternoon, evening). Thank you for agreeing to participate in this study.

This study is an attempt to gain insight into your perceptions of the West Virginia K-12 RuralNet Project and how it has affected your instructional practices. The information gathered through this study will be used to fulfill dissertation requirements, and for scholarly and professional publications.

I want to point out several things before we start, but please feel free to interrupt me if you have any questions.

- Your participation is entirely voluntary.

- You may refuse to respond to any question on the interview protocol.

- Your responses or lack thereof, will be kept confidential.

- I would like to audio tape this interview, but if you prefer not, you may exercise the right to refuse to be audio taped.

- The tapes and transcripts of interviews will not be labeled with your name.

- No attempt will be made to use demographic or descriptive information concerning your current school, position, job title, etc. to identify the tapes and transcripts.

- You may request a copy of the transcript of your interview.

- Participation in this study will not affect your status with the West Virginia K-12 RuralNet Project, West Virginia University or Marshall University.

- Interviews should take between 30 minutes and one hour to conduct.

Participants will be encouraged to ask questions during the presentation of this information and will be provided with a name, address, and telephone number of whom to contact in the event they have questions or concerns later. 


\section{Interview Protocol}

1. Demographics:

Please describe your educational background?

How many years of teaching experience do you have?

How many years have you been teaching at this school?

2. Could you walk me through a typical school day. (including mornings before students arrive and after students leave.)

3. Describe training or other experiences you've had related to using the Internet.

4. Share your perceptions of your RuralNet experience - positive and negative.

5. Describe the impact of your RuralNet experience.

Probes:

How did it impact lesson development?

How did it impact classroom preparation?

How did it impact management techniques?

How did it impact instructional delivery methods?

How did it impact student assessment?

6. From a student's perspective, how has their classroom experience changed due to your RuralNet participation?

7. If you were planning the next session of RuralNet, what would you keep and what would you change? Why?

8. Is there anything else you'd like to add? 


\section{Appendix D}

Observation Guide 


\section{Observation Guide}

This list is intended to provide prompts or reminders of things the observer should note while in the school or classroom. This list is only representative and is NOT all-inclusive.

\section{Physical Environment}
A. School
B. Classroom
- school location
- classroom layout
- number of students
- location of student/teacher
- building layout (open classroom, workstations wins, etc)
- classroom technology
- location of labs and special subject
- displays/student work classrooms
- color of room/temperature

\section{Social Environment}
A. Teacher-to-teacher interactions
C. Teacher-administration interactions
- verbal \& non-verbal
- verbal \& non-verbal
- formal \& informal
- formal \& informal

B. Teacher- student interactions

- verbal \& non-verbal

- formal \& informal

- during structured classroom activities

\section{III.Structured Activities}

- Teacher directed lessons

- Special events

- Independent (student directed) activities

\section{IV.Unplanned activities}

V. Nonoccurrences (what does not happen) 
Appendix E

RuralNet Participants 
Summer RuralNet Participants by Year and Instructional Level

\begin{tabular}{ccccc}
\hline & \multicolumn{4}{c}{ Instructional Level } \\
\cline { 2 - 4 } Year & Elementary & $\begin{array}{c}\text { Middle/Jr. } \\
\text { High } \\
6-9\end{array}$ & $\begin{array}{c}\text { High } \\
\text { School } \\
10-12\end{array}$ & $\begin{array}{c}\text { Year } \\
\text { Total }\end{array}$ \\
\hline 1995 & 16 & 6 & 20 & 42 \\
1996 & 213 & 94 & 113 & 420 \\
1997 & 178 & 117 & 109 & 404 \\
1998 & 102 & 65 & 38 & 205 \\
\hline $\begin{array}{c}\text { Level } \\
\text { Total }\end{array}$ & 509 & 282 & 280 & 1071 \\
\hline
\end{tabular}

RuralNet Course Completers for 1998-1999 Training Year

\begin{tabular}{ccccc}
\hline & \multicolumn{3}{c}{ Instructional Level } & \\
\cline { 2 - 4 } & Elementary & $\begin{array}{c}\text { Middle/Jr. } \\
\text { High } \\
\text { K-5 }\end{array}$ & $\begin{array}{c}\text { High } \\
\text { School }\end{array}$ & \\
& $6-9$ & $10-12$ & Total \\
\hline $\begin{array}{c}\text { Summer } \\
1998\end{array}$ & 102 & 65 & 38 & 205 \\
Fall 1998 & 20 & 11 & 10 & 41 \\
Spring & & & & 36 \\
1999 & 20 & 9 & 7 & 36 \\
\hline
\end{tabular}

